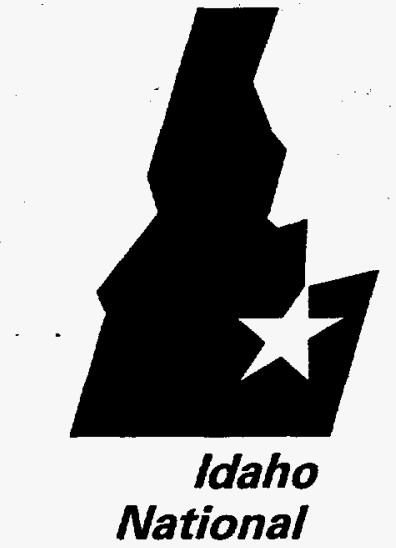

Engineering Laboratory
INEL-94/0177

December, 1994

RECEIVED

DEC 191996

SIMS Analysis:

OSTI

Evaluation

1994 Summary Report

G. S. Groenewold

A. D. Appelhans

J. C. Ingram

J. E. Delmore

D. A. Dahl

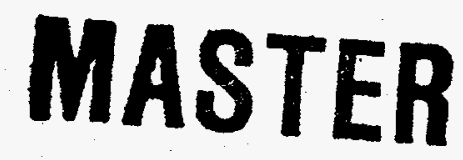

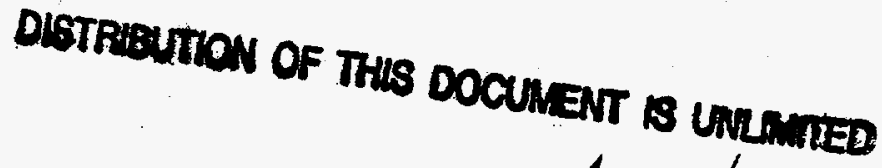

LOCKHEED MARTIN

lm 


\section{DISCLAIMER}

This report was prepared as an account of work sponsored by an agency of the United States Government. Neither the United States Government nor any agency thereof, nor any of their employees, makes any warranty, express or implied, or assumes any legal liability or responsibility for the accuracy, completeness, or usefulness of any information, apparatus, product, or process disclosed, or represents that its use would not infringe privately owned rights. Reference herein to any specific commercial product, process, or service by trade name, trademark, manufacturer, or otherwise does not necessarily constitute or imply its endorsement, recommendation, or favoring by the United States Government or any agency thereof. The views and opinions of authors expressed herein do not necessarily state or reffect those of the United States Government or any agency thereof. 


\section{DISCLAIMER}

Portions of this document may be illegible in electronic image products. Images are produced from the best available original document. 


\title{
SIMS Analysis: Development and Evaluation 1994 Summary Report
}

\author{
G. S. Groenewold \\ A. D. Appelhans \\ J. C. Ingram \\ J. E. Delmore \\ D. A. Dahl \\ Published December, 1994 \\ Idaho National Engineering Laboratory \\ Lockheed Idaho Technologies Corporation \\ Idaho Falls, Idaho 83415 \\ Prepared for the \\ U. S. Department of Energy \\ DOE Office of Technology Development \\ Under DOE Idaho Operations Office \\ Contract DE-AC07-94ID13223
}




\section{SIMS Analysis: Development and Evaluation 1994 Summary Report}

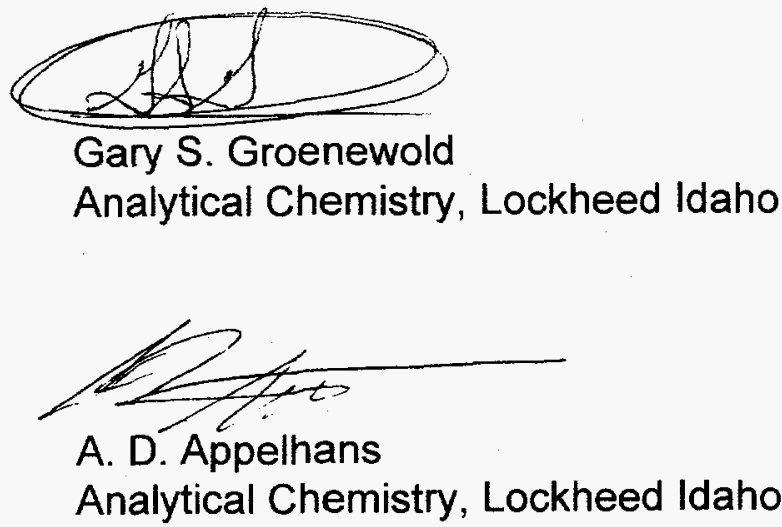

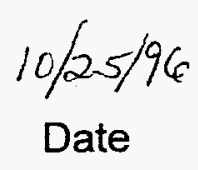

io/25/96

Date 


\begin{abstract}
Secondary ion mass spectrometry (SIMS) was evaluated for applicability to the characterization of "salt cake" and environmental samples. Salt cake is representative of waste found in radioactive waste storage tanks located at Hanford and at other DOE sites; it consists of nitrate, nitrite, hydroxide, and ferrocyanide salts, and the samples from the tanks are extremely radioactive. SIMS is an attractive technology for characterizing these samples because it has the capability for producing speciation information with little or no sample preparation, and it generates no additional waste. Experiments demonstrated that substantial speciation information could be readily generated using SIMS: metal clusters which include nitrate, nitrite, hydroxide, carbonate, cyanide, ferrocyanide and ferricyanide were observed. In addition, the mechanism of SIMS desorption of tributyl phosphate (TBP) was clearly identified, and minimum detection limit studies involving TBP were performed. Procurements leading to the construction of an ion trap SIMS instrument were initiated. Technology transfer of SIMS components to three instrument vendors was initiated. For FY95 , th SIMS evaluation program has been redirected toward identification of metal species on environmental samples.
\end{abstract}




\section{SUMMARY}

New secondary ion mass spectrometry (SIMS) technology is being evaluated for the identification and speciation of metals and low-volatile organic contaminants which are present in waste and environmental samples found at DOE sites. The new SIMS technology was developed at the Idaho National Engineering Laboratory (INEL), and has the advantages of being rapid (10 minutes or less), requiring no sample preparation, generating no laboratory waste, capable of analyzing low- or non-volatile organic contaminants on surfaces, and potentially transportable. In addition, SIMS has the capability for analyzing a variety of sample surfaces, including salts, rocks, soil and waste samples encountered at the INEL, Hanford, and other sites. If SIMS can be applied to DOE waste and environmental characterization and analyses activities, then the attributes of SIMS could result in a substantial savings of time and money. SIMS application requires demonstration of the technology for salient chemical characterizations, construction of prototype instrumentation leading to fieldable systems, and technology transfer of SIMS components to prospective manufacturers. These requirements comprise the objectives of the work described in this report.

The applications studies conducted in FY-94 have emphasized two broad areas. The first is the utilization of SIMS for the characterization of "salt cake" samples, which are similar to samples anticipated from radioactive waste storage tanks located at the Hanford reservation. The salt samples were generated from a variety of processes, including ferrocyanide precipitation, which removed cesium (Cs) and other radionuclides from nitric acid solutions. The resulting waste form is extremely radioactive, and contains many chemical species. The overall objective of the research is to come up with analytical methods which minimize the sample handling of the waste, provide good chemical speciation information, and generate little or no waste or their own. It should be emphasized that there are no rapid, inexpensive methods for the rapid characterization of highly radioactive salt cake samples: current procedure is to extrude a core sample, and then perform standard metals and ion chromatographic analyses. This approach provides highly accurate information, but it requires six to twelve months, generates additional mixed waste, and has an average cost of $\$ 700 \mathrm{~K}$ per core sample. Consequently, there is substantial interest in developing alternative characterization technologies.

The evaluation of SIMS for salt cake characterization involved the analysis of two different types of samples (nitrate/nitrite and ferrocyanide) which were synthetically generated at Pacific Northwest Laboratory. Significantly, nitrate, nitrite, hydroxide, and Group I metal complexes were readily observed in the analysis of the nitrate/nitrite samples. Ferrocyanide and nickel cyanide complexes were observed in the ferrocyanide samples. Initial evaluation of the ion abundances indicated that the technique could be refined to the point where quantitative information could be generated. We emphasize that no sample preparation was required for these analyses, and that no waste was generated. 
As part of the issue of evaluating SIMS for waste speciation, the mechanism of tributyl phosphate (TBP) desorption on envionmental mineral surfaces was investigated: this is the second broad area of chemical applications investigation conducted during FY-94. There is interest in the detection of TBP, because the compound was widely used as an extractant for uranium (U) and plutonium (Pu) in fuel reprocessing operations at DOE sites, and in many cases, TBP was disposed of with uranium and plutonium. In FY-93, it was established that SIMS was very sensitive for the detection of TBP on environmental mineral surfaces, and further that the SIM spectrum was variable depending on the chemical nature of the sample that it was adsorbed to. Hence the SIM spectrum represents a tool that can be used to elucidate information on the speciation of environmental and waste surfaces. A series of controlled experiments were conducted which clearly demonstrated the mechanism of TBP desorption, and showed that the TBP spectrum revealed the oxidation state of iron ( $\mathrm{Fe}$ ) existing on mineral surfaces. Because sensitivity is an important issue for any potential analytical screening technique, a series of experiments were conducted to assess the minimum detectable quantity of TBP on mineral surfaces.

Experiments to determine the minimum detection limit of TBP on soil samples were also conducted. The detection limit values were dependent on the soil studied, and ranged from 0.07 to 0.2 monolayers; this corresponds to $34-100$ $\mathrm{pg} / \mathrm{mm}^{2}$.

The SIMS Evaluation Program was designed to have instrumentation development proceeding parallel to the chemical analyses investigations. In FY93, it was determined that the best way to meet chemical characterization goals (for both waste and environmental characterization applications) was to implement SIMS technology on an ion trap mass spectrometer. The ion trap was been selected because it is smaller, more rugged, has reduced pumping requirements, and most importantly, is capable of greatly enhanced analytical selectivity because it is capable of operating in the mass spectrometry/mass spectrometry and high mass resolution modes. The ion trap also has the potential for improved sensitivity as a result of selected ion storage capability. Procurement of a commercial ion trap was initiated in FY-94, with the intention of modifying the instrument for SIMS evaluation. Delivery of the instrument is expected in the first quarter of FY-95.

In order for SIMS to effectively impact chemical characterization, commercial vendors will be required to supply and service SIMS technology. For this reason, transfer of SIMS technology has been an important aspect of the SIMS Evaluation Program. Technology transfer of SIMS components has been initiated with three instrument manufacturers. The manufacturers are interested in transfer of components, to be implemented as SIMS accessories to existing instrument designs. In this manner, the manufacturers are not required to develop new instruments from the ground up, which requires a lot of capital 
investment and time. Non-disclosure agreements have been signed with Teledyne, Charles Evans \& Associates, Inc., and Extrel. These firms are intested in ion source/ion gun technology, ion detection technology, and instrument control/data acquisition software.

Three educational collaborations were initiated under the SIMS Evaluation program in FY-94. A collaboration was started with Luke Hanley of the University of Illinois-Chicago, for the purpose of looking at detecting metal-EDTA complexes using laser desorption ion trap mass spectrometry. The INEL SIMS group began training an Idaho State University student, who is currently studying the desorption of tetrahexyl ammonium cations from steel targets. This subject is important to the SIMS development effort because the tetrahexyl ammonium cation is used for instrument calibration and performance assessment. $A$ collaboration was initiated with Andy Cramer of the Utah State Department of Civil and Environmental Engineering, for the purpose of detecting pentachlorophenol adsorbed to $\mathrm{MnO}_{2}$ oxidation catalysts.

The future direction of the SIMS evaluation program involves the construction and testing of the ion trap SIMS instrument, and technology transfer of SIMS components to instrument manufacturers. The direction of the chemical applications research has changed per the direction of DOE OTD in July, 1994. The new focus of the chemical applications studies will be the evaluation of SIMS for determination of speciation of $\mathrm{Hg}, \mathrm{Pb}, \mathrm{Cr}$ and other metals on environmental surfaces. The interest in speciation determination is motivated by the fact that environmental mobility and risk are profoundly affected by risk. For example, $\mathrm{Hg}$ as mercuric nitrate has a substantial environmental mobility compared to mercuric oxide. Remediation decisions are effected by the form of $\mathrm{Hg}$ in the environment, but at the present time, distinction between the $\mathrm{Hg}$ species in the environment is difficult. 


\section{Contents}

\begin{tabular}{|c|c|}
\hline Page & Section \\
\hline iii & Abstract \\
\hline iv & Summary \\
\hline$\underline{i x}$ & Figures \\
\hline $\bar{x}$ & Tables \\
\hline $\mathrm{xii}$ & Acronyms \\
\hline 1 & 1.0 Introduction \\
\hline 1 & \begin{tabular}{|l|} 
1.1. Program Background \\
\end{tabular} \\
\hline 2 & 1.2. Motivation for Selection of Analytes and Sample-Types \\
\hline 3 & 1.3. References \\
\hline 4 & 2.0 Analys is of Simulated Salt Cake Samples \\
\hline 4 & 2.1 Simulated Nitrate/Nitrite Salt Waste \\
\hline 4 & 2.1.1. Composition of Nitrate/Nitrite Salt Samples 1 and 2. \\
\hline 5 & 2.1.2. Cation SIMS Spectra, Simulated Salt Waste \\
\hline 9 & 2.1.3. Anion SIMS Spectra, Simulated Salt Waste \\
\hline 13 & 2.1.4. References \\
\hline 16 & 2.2. SIMS Spectra of 'Benchmark' Salts \\
\hline 16 & 2.2.1. $\mathrm{NaOH}$ \\
\hline 17 & 2.2.2. $\mathrm{NaNO}_{2}$ \\
\hline 19 & 2.2.3. $\mathrm{NaNO}_{3}$ \\
\hline 23 & 2.2.4. $\mathrm{Na}_{2} \mathrm{CO}_{3}$ \\
\hline 24 & 2.2.5. $\mathrm{NaHCO}_{3}$ \\
\hline 25 & 2.2.6. $\mathrm{Na}_{2} \mathrm{CrO}_{4}$ \\
\hline 26 & 2.2.7. $\mathrm{NaHSO}_{4}$ \\
\hline 28 & 2.2.8. $\mathrm{Na}_{2} \mathrm{HPO}_{4}$ \\
\hline 29 & 2.2.9. $\mathrm{NaHCO}_{2}$ \\
\hline 30 & 2.2.10. Conclusions: Analysis of Nitrate/Nitrite Salt Wastes \\
\hline 30 & 2.2.11. References \\
\hline 31 & 2.3 Simulated Ferrocyanide Salt Waste \\
\hline 31 & 2.3.1. Composition of Ferrocyanide Salt Samples 3 and 4 . \\
\hline 31 & 2.3.2. SIMS Spectra, Simulated Ferrocyanide Salt Waste \\
\hline 37 & 2.3.3. SIMS Spectra, Benchmark Ferrocyanide and Ferricyanide Salts. \\
\hline 40 & 2.3.4. Conclusions: Analysis of Ferrocyanide Salt Wastes \\
\hline 41 & 3.0 Mechanism of TBP Desorption from Surfaces \\
\hline 41 & 3.1 Introduction \\
\hline 42 & 3.2 Experimental \\
\hline 42 & 3.2.1. SIMS Instrumentation \\
\hline 43 & 3.2.2. Precision of SIMS data \\
\hline 44 & 3.2.3. $\mathrm{Cl}$ and $\mathrm{EI} \mathrm{MS}$ \\
\hline 44 & 3.2.4. SEM/EDS \\
\hline 44 & 3.2.5. Sample origin and handling and preparation \\
\hline 45 & 3.2.6. Chemicals \\
\hline 45 & 3.3 Results \\
\hline 45 & 3.3.1 SIMS Analysis of TBP on basalt, quartz, and iron oxides \\
\hline 47 & 3.3.2. SEM/EDS Analyses of Basalt \\
\hline
\end{tabular}




\section{Contents, continued}

\begin{tabular}{|c|c|}
\hline Page & Section \\
\hline 48 & 3.3.3. SIMS analysis of tributyl phosphite on basalt, quartz, and iron oxides \\
\hline 49 & 3.3.4. Gas-phase behavior of ionized TBP and tributyl phosphite \\
\hline 61 & 3.4 Discussion \\
\hline 61 & 3.4.1. Production of $\mathrm{m} / \mathrm{z} 137$ and related ions \\
\hline 61 & 3.4.2. Production of $\mathrm{m} / \mathrm{z} 153^{\circ}$ \\
\hline 62 & 3.4.3. Production of $\mathrm{m} / \mathrm{z} 99^{+}$and $155^{+}$ \\
\hline 62 & 3.4.4. Tributyl phosphite model for TBP reduction \\
\hline 63 & 3.4.5. Structure of $m / 2125^{+}, 217^{+}, 235^{+}$observed in the SIMS spectra of TBP \\
\hline 68 & 3.5 Conclusions: TBP Mechanism \\
\hline 68 & 3.6 References \\
\hline 70 & 4.0 Minimum Detectable Limit of TBP on Environmental Surfaces \\
\hline 70 & 4.1. Introduction \\
\hline 70 & 4.2. Experimental \\
\hline 71 & 4.3. Results and Discussion \\
\hline 72 & 4.4. Conclusions: Minimum Detectable Limit \\
\hline 73 & 5.0 Ion Trap SIMS Development \\
\hline 74 & 6.0 Technology Transfer \\
\hline 74 & 6.1. Teledyne \\
\hline 74 & 6.2. Charles Evans and Associates, Inc. \\
\hline 74 & 6.3. Extrel \\
\hline 75 & 7.0 University Collaborations \\
\hline 75 & 7.1. Idaho State University \\
\hline 75 & 7.2. Utah State University \\
\hline 75 & 7.3. University of Illinois-Chicago \\
\hline 75 & 7.4. University of Idaho \\
\hline 76 & 8.0 Future Directions \\
\hline
\end{tabular}




\section{Figures}

\begin{tabular}{|c|c|}
\hline Page & Figure \\
\hline 14 & Figure 1. Cation SIMS spectrum of simulated salt waste sample 1. \\
\hline 15 & Figure 2. Anion SIMS spectrum of simulated salt waste sample 1. \\
\hline 21 & Figure 3. Abundance ratio, $108^{+} / 92^{+}$versus nitrate/nitrite ratio (as added to sample). \\
\hline 22 & Figure 4. Relative Raman intensity versus nitrate/nitrite mole ratio. \\
\hline 35 & Figure 5. Cation SIMS spectrum of simulated ferrocyanide salt waste. \\
\hline 36 & Figure 6. Anion SIMS spectrum of simulated ferrocyanide salt waste. \\
\hline 39 & Figure 7. Ion abundance ratio of $\mathrm{m} / \mathrm{z} 134 / 108$ for $\mathrm{K}_{3} \mathrm{Fe}(\mathrm{CN})_{8}$ and $\mathrm{K}_{4} \mathrm{Fe}(\mathrm{CN})_{8}$. \\
\hline 40 & $\begin{array}{l}\text { Figure } 8 \text {. Reactions proposed for the formation of } \mathrm{m} / \mathrm{z} 134^{\circ} \text { and } 108^{\circ} \text { during the SIMS } \\
\text { analysis of potassium ferricyanide. }\end{array}$ \\
\hline 40 & $\begin{array}{l}\text { Figure } 9 . \text { Reactions proposed for the formation of } \mathrm{m} / \mathrm{z} 134^{\circ} \text { and } 108^{\circ} \text { during the SIMS } \\
\text { analysis of potassium ferrocyanide. }\end{array}$ \\
\hline 53 & Figure 10a. Cation SIMS spectrum of INEL basalt unexposed to TBP. \\
\hline 54 & Figure 10b. Cation SIMS spectrum of Elephant Mountain basalt exposed to TBP. \\
\hline 55 & Figure 10c. Cation SIMS spectrum of INEL basalt exposed to TBP. \\
\hline 56 & Figure 11a. Anion SIMS spectrum of INEL basalt unexposed to TBP. \\
\hline 57 & Figure 11b. Cation SIMS spectrum of Elephant Mountain basalt exposed to TBP. \\
\hline 58 & Figure 11c. Cation SIMS spectrum of INEL basalt exposed to TBP. \\
\hline 65 & $\begin{array}{l}\text { Figure 12. Mechanism proposed for the formation of } \mathrm{m} / \mathrm{z} 137^{+} \text {in the SIM spectrum of } \\
\text { TBP adsorbed to Fe(II)-bearing surfaces. }\end{array}$ \\
\hline 66 & $\begin{array}{l}\text { Figure 13. Proposed mechanism for surface hydride abstraction and subsequent } \\
\text { elimination of two } \mathrm{C}_{4} \mathrm{H}_{\mathrm{a}} \text { molecules, forming } \mathrm{m} / \mathrm{z}^{153^{+}} \text {. }\end{array}$ \\
\hline 67 & $\begin{array}{l}\text { Figure 14. Proposed mechanism for the surface protonation of TBP, and subsequent } \\
\text { elimination of three } \mathrm{C}_{4} \mathrm{H}_{8} \text { molecules. }\end{array}$ \\
\hline
\end{tabular}




\section{Tables}

\begin{tabular}{|c|c|}
\hline Page & Table \\
\hline 5 & Table 1. Composition of Simulated Salt Waste Samples 1 and 2. \\
\hline $6-7$ & $\begin{array}{l}\text { Table 2. Cations observed in the SIMS spectra collected using } \mathrm{ReO}_{4} \% \text { quad and } \\
\mathrm{Ga}+\mathrm{TOF} \text { instruments. Ion assignments. Accurate mass measurement, ppm error = } \\
\text { absolute value of calculated - measured mass. }\end{array}$ \\
\hline $11-12$ & $\begin{array}{l}\text { Table 3. Anions observed in the SIMS spectra collected using } \mathrm{ReO}_{4}{ }^{-} / q u a d \text { and } \\
\mathrm{Ga}^{+} / \mathrm{TOF} \text { instruments. Ion assignments. Accurate mass measurement, ppm error = } \\
\text { absolute value of calculated - measured mass. }\end{array}$ \\
\hline 17 & $\begin{array}{l}\text { Table 4. Salient cations and anions observed in the SIMS spectra of } \mathrm{NaOH} \text {. Spectra } \\
\text { were acquired using the ReO; quad SIMS instrument. }\end{array}$ \\
\hline 18 & $\begin{array}{l}\text { Table 5. Salient cations and anions observed in the SIMS spectra of } \mathrm{NaNO}_{2} \text {. Spectra } \\
\text { were acquired using the } \mathrm{ReO}_{4}^{\circ} \text { quad SIMS instrument. }\end{array}$ \\
\hline 20 & $\begin{array}{l}\text { Table 6. Salient cations and anions observed in the SIMS spectra of } \mathrm{NaNO}_{3} \text {. Spectra } \\
\text { were acquired using the ReO, quad SIMS instrument. }\end{array}$ \\
\hline 23 & $\begin{array}{l}\text { Table 7. Salient cations and anions observed in the SIMS spectra of } \mathrm{Na}_{2} \mathrm{CO}_{3} \text {. Spectra } \\
\text { were acquired using the } \mathrm{ReO}_{4}^{-} \text {quad SIMS instrument. }\end{array}$ \\
\hline 24 & $\begin{array}{l}\text { Table 8. Salient cations and anions observed in the SIMS spectra of } \mathrm{NaHCO}_{3} \text {. Spectra } \\
\text { were acquired using the } \mathrm{ReO}_{4}^{-} \text {quad SIMS instrument. }\end{array}$ \\
\hline $25-26$ & $\begin{array}{l}\text { Table 9. Salient cations and anions observed in the SIMS spectra of } \mathrm{Na}_{2} \mathrm{CrO}_{4} \text {. Spectra } \\
\text { were acquired using the } \mathrm{ReO}_{4}^{-} \text {quad SIMS instrument. }\end{array}$ \\
\hline 27 & $\begin{array}{l}\text { Table } 10 \text {. Salient cations and anions observed in the SIMS spectra of } \mathrm{NaHSO}_{4} \text {. } \\
\text { Spectra were acquired using the } \mathrm{ReO}_{4}^{-} \text {quad SIMS instrument. }\end{array}$ \\
\hline 28 & $\begin{array}{l}\text { Table 11. Salient cations and anions observed in the SIMS spectra of } \mathrm{Na}_{2} \mathrm{HPO}_{4} \text {. } \\
\text { Spectra were acquired using the } \mathrm{ReO}_{4}^{-} \text {quad SIMS instrument. }\end{array}$ \\
\hline 29 & $\begin{array}{l}\text { Table 12. Salient cations and anions observed in the SIMS spectra of } \mathrm{NaHCO}_{2} \text {. } \\
\text { Spectra were acquired using the } \mathrm{ReO}_{4}^{-} \text {quad SIMS instrument. }\end{array}$ \\
\hline 31 & $\begin{array}{l}\text { Table 13. Relative molar composition of ferrocyanide samples } 3 \text { and } 4 \text {, normalized to } \\
\mathrm{NaNO}_{3} \text {. }\end{array}$ \\
\hline 32 & $\begin{array}{l}\text { Table 14. Cation SIMS spectrum of simulated ferrocyanide waste salt, aquired using } \\
\mathrm{ReO}_{4}^{-} \text {quad SIMS instrument. }\end{array}$ \\
\hline 33 & $\begin{array}{l}\text { Table 15. Anion SIMS spectrum of simulated ferrocyanide waste salt, aquired using } \\
\mathrm{ReO}_{4}^{-} \text {quad SIMS instrument. }\end{array}$ \\
\hline 34 & $\begin{array}{l}\text { Table 16. Comparison of } \mathrm{Fe} \text { and Ni complex ions observed in simulated ferrocyanide } \\
\text { salt waste }\end{array}$ \\
\hline 37 & $\begin{array}{l}\text { Table 17. Salient cations in the SIMS spectrum of potassium ferricyanide }\left(\mathrm{K}_{3} \mathrm{Fe}(\mathrm{CN})_{6}\right) \\
\text { and potassium ferrocyanide }\left(\mathrm{K}_{4} \mathrm{Fe}(\mathrm{CN})_{6}\right) \text {. }\end{array}$ \\
\hline 38 & $\begin{array}{l}\text { Table 18. Salient anions in the SIMS spectrum of potassium ferricyanide }\left(\mathrm{K}_{3} \mathrm{Fe}(\mathrm{CN})_{6}\right) \\
\text { and potassium ferrocyanide }\left(\mathrm{K}_{4} \mathrm{Fe}(\mathrm{CN})_{6}\right) \text {. }\end{array}$ \\
\hline 51 & $\begin{array}{l}\text { Table 19. Typical relative abundances and relative standard deviations for salient ions } \\
\text { observed in the SIMS spectra of unexposed CFA basalt. }\end{array}$ \\
\hline
\end{tabular}




\section{Tables, continued}

\begin{tabular}{|c|l|}
\hline Page & Table \\
\hline 52 & $\begin{array}{l}\text { Table 20. Abundances of cations (relative to } \mathrm{m} / 2 \mathrm{99}^{+} \text {) observed in representative SIMS } \\
\text { spectra of TBP and tributyl phosphite on mineral surfaces. }\end{array}$ \\
\hline 59 & Table 21. Methane Cl mass spectra of TBP, tributyl phosphite \\
\hline 60 & Table 22. El mass spectra of TBP, tributyl phosphite. \\
\hline 71 & $\begin{array}{l}\text { Table 23. Minimum detectable limit determinations, for detection of TBP on soil using } \\
\text { the ReO }\end{array}$ \\
\hline
\end{tabular}




\section{ACRONYMS and SYMBOLS}

\begin{tabular}{|c|c|}
\hline $\begin{array}{c}\text { Acronym or } \\
\text { Symbol }\end{array}$ & Definition \\
\hline $\mathrm{A}$ & aluminum \\
\hline $\mathrm{Ba}$ & barium \\
\hline $\mathrm{C}$ & carbon \\
\hline $\mathrm{Ca}$ & calcium \\
\hline CFA & Central Facilities Area (located at the INEL) \\
\hline $\mathrm{CH}_{4}$ & methane \\
\hline $\mathrm{CHA}$ & cyclohexyl amine \\
\hline $\mathrm{CH}_{2} \mathrm{Cl}_{2}$ & methylene chloride \\
\hline $\mathrm{C}_{4} \mathrm{H}_{8}$ & butene \\
\hline $\mathrm{Cl}$ & chemical ionization \\
\hline $\mathrm{Cl}$ & chlorine \\
\hline $\mathrm{CN}^{-}$ & cyanide \\
\hline $\mathrm{CO}_{2}$ & carbon dioxide \\
\hline $\mathrm{CO}_{3}^{-2}$ & carbonate \\
\hline $\mathrm{Cr}$ & chromium \\
\hline $\mathrm{CrO}_{4}^{-2}$ & chromate \\
\hline Cs & cesium \\
\hline $\mathrm{DOE}$ & \begin{tabular}{|l} 
Department of Energy \\
\end{tabular} \\
\hline EDS & energy dispersive $\mathrm{x}$-ray spectroscopy \\
\hline EDTA & \begin{tabular}{|l} 
ethylene diamine tetraacetic acid \\
\end{tabular} \\
\hline EI & \begin{tabular}{|l} 
electron ionization \\
\end{tabular} \\
\hline $\mathrm{F}$ & fluorine \\
\hline $\mathrm{Fe}$ & iron \\
\hline $\mathrm{Fe}(\mathrm{CN})_{8}^{-3}$ & ferricyanide \\
\hline $\mathrm{Fe}(\mathrm{CN})_{8}^{-4}$ & ferrocyanide \\
\hline $\mathrm{FeO}$ & ferrous oxide \\
\hline $\mathrm{Fe}_{2} \mathrm{O}_{3}$ & ferric oxide \\
\hline$F Y$ & fiscal year \\
\hline Ga & gallium \\
\hline GC & gas chromatography \\
\hline GC/MS & gas chromatography/ mass spectrometry \\
\hline $\mathrm{H}$ & hydrogen \\
\hline $\mathrm{H}$ & hydride \\
\hline $\mathrm{HCO}_{2}^{-}$ & formate \\
\hline $\mathrm{HCO}_{3}^{-}$ & bicarbonate \\
\hline $\mathrm{HO}, \mathrm{OH}^{-}$ & hydroxide \\
\hline
\end{tabular}




\section{ACRONYMS and SYMBOLS, continued}

\begin{tabular}{|c|c|}
\hline $\begin{array}{l}\text { Acronym or } \\
\text { Symbol }\end{array}$ & Definition \\
\hline $\mathrm{HSO}_{4}^{-}$ & bisulfate \\
\hline INEL & Idaho National Engineering Laboratory \\
\hline ITMS & ion trap mass spectrometer \\
\hline K & potassium \\
\hline $\mathrm{K}_{3} \mathrm{Fe}(\mathrm{CN})_{8}$ & potassium ferricyanide \\
\hline $\mathrm{K}_{4} \mathrm{Fe}(\mathrm{CN})_{6}$ & potassium ferrocyanide \\
\hline $\mathrm{keV}$ & \begin{tabular}{|l|} 
kiloelectron volt \\
\end{tabular} \\
\hline$m / z$ & mass to charge ratio \\
\hline $\mathrm{MDL}$ & minimum detectable limit \\
\hline $\mathrm{Mg}$ & magnesium \\
\hline $\mathrm{mm}$ & millimeter \\
\hline MS & mass spectrometry \\
\hline MS/MS & mass spectrometry/mass spectrometry \\
\hline $\mathrm{N}$ & nitrogen \\
\hline $\mathrm{Na}$ & sodium \\
\hline $\mathrm{ng}$ & nanograms \\
\hline $\mathrm{Ni}$ & nickel \\
\hline NJ & New Jersey \\
\hline $\mathrm{NO}_{2}^{\circ}$ & nitrite \\
\hline $\mathrm{NO}_{3}^{\circ}$ & nitrate \\
\hline 0 & oxygen \\
\hline $\mathrm{P}$ & phosphorus \\
\hline $\mathrm{Pb}$ & lead \\
\hline $\mathrm{pg}$ & picogram \\
\hline $\mathrm{pH}$ & $-\log$ of hydrogen ion concentration, a measure of acidity \\
\hline PHIRHOZ & $\begin{array}{l}\text { a software routine for converting EDS data to elemental } \\
\text { compositions of surfaces }\end{array}$ \\
\hline PNL & Pacific Northwest Laboratory \\
\hline $\mathrm{ppm}$ & part per million \\
\hline $\mathrm{Pu}$ & plutonium \\
\hline r.a. & relative abundance \\
\hline $\operatorname{Re}$ & rhenium \\
\hline $\mathrm{ReO}_{4}^{-}$ & perrhenate \\
\hline isd & relative standard deviation \\
\hline RWMC & Radioactive Waste Management Complex \\
\hline $\mathrm{s}$ & sulfur \\
\hline SDA & subsurface disposal area \\
\hline
\end{tabular}


ACRONYMS and SYMBOLS, continued

\begin{tabular}{|c|l|}
\hline $\begin{array}{c}\text { Acronym or } \\
\text { Symbol }\end{array}$ & Definition \\
\hline SEM & scanning electron microscopy \\
\hline $\mathrm{Si}$ & silicon \\
\hline $\mathrm{SIMS}_{\mathrm{SO}}^{-2}$ & secondary ion mass spectrometry \\
\hline $\mathrm{TBP}$ & sulfate \\
\hline $\mathrm{Ti}$ & tributyl phosphate \\
\hline $\mathrm{TOF}$ & titanium \\
\hline$U$ & time-of-flight \\
\hline $\mathrm{u}$ & uranium \\
\hline Ug & one mass unit, based on ${ }^{12} \mathrm{C}$ \\
\hline USU & microgram \\
\hline ZAF & Utah State University \\
\hline & Z\#, absorption, fluorescence correction for EDS data \\
\hline
\end{tabular}




\title{
SIMS Analysis: Development and Evaluation 1994 Summary Report
}

\author{
G. S. Groenewold, J. C. Ingram, A. D. Appelhans, J. E. Delmore, D. A. Dahl \\ Idaho National Engineering Laboratory
}

\subsection{INTRODUCTION}

The purpose of the title program is to develop secondary ion mass spectrometry (SIMS) instrumentation and methodology capable of detecting the presence of trace quantities of metals and other low volatile analytes, and also identifying the chemical species of these contaminants. An ideal analytical technology would be transportable, have good sensitivity and selectivity, require no sample preparation, generate no waste, and have a moderate cost. SIMS is a technology which has undergone improvement at the Idaho National Engineering Laboratory (INEL); consequently, SIMS possesses many of these desirable attributes. Thus the majority of this report will focus on application of SIMS to salt cake and environmental sample characterization, development of an ion trap SIMS instrument, and technology transfer.

\subsection{Program Background}

The SIMS Analysis Program was initiated in April of 1992, and was initially focused on the detection of low-volatile and non-volatile organic contaminants which have been used as chelating or complexing agents for radionuclides. The program began by looking at tributyl phosphate, and ethylene diamine tetraacetic acid (EDTA) and other chelating agents. This research was conducted using a laboratory-based quadrupole SIMS instrument, and demonstrated that TBP could be very sensitively detected on a variety of mineral surfaces. Furthermore, the SIM spectrum of TBP was observed to change, depending on the chemical nature of the mineral surface. This observation suggested that TBP could be used as a probe molecule for assessing surface chemistry. Later, the mechanism of TBP desorption from mineral surfaces was elucidated, and this study is included in this report. SIMS signatures of EDTA, and metals including $\mathrm{Pb}$ could also be obtained. In the case of EDTA, however, the detection limits achievable were only on the order of 1 part-per-thousand, and hence it was concluded that SIMS was not the optimal technique for EDTA assessment.

In December of 1993, the SIMS Analysis Program was reoriented toward the characterization of "salt cake". There exists a need for analytical methods which can give inorganic species information with minimal sample handling and no waste generation, because salt cake originates (primarily) from extremely radioactive waste tanks on the Hanford reservation. A collaboration was initiated 
with the Laser Ablation Mass Spectrometry program at Pacific Northwest Laboratory (PNL), and simulated salt cake samples were generated and sent to INEL for SIMS analysis. All of the major chemical species that were added to the simulated salt cake were detected in the INEL SIMS analysis, with the exception of EDTA. These species included nitrates, nitrites, cyanides, carbonates, hydroxides, peroxides, and metal-anion complexes of $\mathrm{Fe}, \mathrm{Ni}, \mathrm{Na}, \mathrm{K}$, and $\mathrm{Ca}$. The data compared favorably with a more sophisticated and expensive SIMS instrument at Charles Evans \& Associates, Inc. The INEL instrument, which is equipped with a novel perrhenate $\left(\mathrm{ReO}_{4}\right)$ primary ion gun, gave abundant molecular secondary ions from the salt cake samples. The Evans instrument produced excellent mass and spatially resolved spectra using a $\mathrm{Ga}^{+}$ primary ion gun, but was not as sensitive to higher mass molecular species.

The SIMS analysis program has also worked toward the development of transportable instrumentation, which has improved sensitivity and selectivity. To this end, a decision was made in FY-93 to develop an ion trap SIMS instrument, because ion trap technology shows promise in meeting these requirments. A commercial ion trap mass spectrometer was ordered in FY-94. At the date of this writing, the spectrometer has not yet been received.

Technology transfer activities were initiated in FY-93, which began to come to fruition in FY-94. Teledyne, Charles Evans \& Associates, Inc., and Extrel are instrument manufacturers that have expressed an interest in SIMS components, and non-disclosure agreements were signed with all three firms. Later, instrument control and data acquisition software, which was developed to control INEL SIMS instrumentation, was licensed to Extrel for their internal use and evaluation. Additional detail describing the interest of the manufacturers is provided within this report.

\subsection{Motivation for Selection of Analytes and Sample-Types}

The analysis of samples from radioactive waste storage tanks is a chemical characterization problem which is particularly problematic, costly, timeconsuming and hazardous. Chemical species information is needed for accurate thermodynamic modeling of the tanks, which in turn is needed for risk assessment. The cataloging and characterization of the tanks has been extensive', but little is known about the chemical species present in the tank holdings. The reason for the lack of chemical knowledge is that the tank contents are extremely radioactive, a fact which greatly increases the hazard of working with samples from the tanks. The radioactivity also induces radiolytic and thermal chemical reactions ${ }^{2}$, which means that even if detailed knowledge of what went into the tanks were available, it would be impossible to predict the current composition.

The study of tri-n-butyl phosphate (TBP) was initiated because this compound was used as an extractant and solvent modifier in the purification of uranium (U) 
and plutonium $(\mathrm{Pu})$. It had originally been thought that TBP could be used as a bellwether for the presence of the transuranic nuclides in the environment, but there was little information on the presence of TBP at DOE waste disposal sites. Riley and Zachara state that the "absence of data on alkyl phosphates... was due to several factors, including (1) the site-specific nature of the constituents, (2) the lack of regulation, and (3) limitations of the analytical measurement technique..$^{13}$ These authors further explain that since the alkyl phosphates are unregulated, "they are not routinely measured as part of environmental compliance programs, and that analytical sampling and measurement methodologies may be inadequate to accurately measure, monitor, or even detect these constituents in the environment." As a result, the presence of TBP "may be far more common than is suggested by the monitoring and characterization data from the 91 waste sites." These considerations motivated research toward applying SIMS to the detection of TBP, and culminated with the elucidation of the mechanism of TBP desorption, and the determination of the minimum detectable quantity of TBP on soils: these advances are described in this report.

It is noteworthy that non-typical sample types exist at DOE waste disposal sites, which are not readily amenable to conventional analytical methodologies (i.e... extraction, concentration, and analysis). Sample types which can be difficult to extract, but nevertheless need analysis include rocks (e.g., basalt), concrete, asphalt, wood, and selected plastics, in addition to the afore mentioned salt cake samples.

\subsection{References}

${ }^{1}$ Husa, E. I.; Raymond, R. E.; Welty, R. K.; Griffith, S. M.; Hanlon, B. M.; Rios, T. T.; Vermeulen, N. J.; "Hanford Site Waste Storage Tank Information Notebook", DOE report WHC-EP-0625, July, 1993.

${ }^{2}$ Adanov, V. M., Andreev, V. I., Belyaev, B. N., Markov, G. S., Polyakov, M. S., Ritari, A. E., Shil'nikov, A. Yu., "Identification of decomposition products of extraction systems based on tri-n-butyl phosphate in aliphatic hydrocarbons", Kerntechnik, 1990, 55, 133-137.

${ }^{3}$ Riley, R. G., Zachara, J. M., "Nature of Chemical Contaminants on DOE Lands and Identification of Representative Contaminant Mixtures for Basic Subsurface Science Research", Draft Report, Pacific Northwest Laboratory, Richland, WA, 99352, June 1991. 


\subsection{ANALYSIS OF SIMULATED SALT CAKE}

Pacific Northwest Laboratory (PNL) personnel generated four simulated salt cake samples for the purpose of evaluating the possibility of using SIMS for characterization. The way in which SIMS was envisioned to fit into the overall analytical scheme was that salt cake particulate was to be generated in the tanks, transported pneumatically out of the tanks, and finally collected on filter paper. Hazards associated with high levels of radioactivity would be mitigated by the fact that the total quantity of salt cake particulate was to be kept small.

During the course of this study, the simulated salt cake samples were analyzed using quadrupole SIMS instrument (Idaho National Engineering Laboratory), and also time-of-flight (TOF) SIMS instrument (Charles Evans \& Associates, Inc.). The TOF SIMS instrument benefits the present analyses in that it is capable of high resolution accurate mass measurement, and high spatial resolution as a result of the secondary ion mass spectrometer optics and a microfocusing $\mathrm{Ga}^{+}$ gun. The quadrupole SIMS instrument benefits the analyses by virtue of the $\mathrm{ReO}_{4}$ p primary ion gun, which may be more efficient at sputtering larger, molecular secondary ions as a result of the massive, molecular nature of the primary particle. The present study provides an opportunity to gain insight into the latter supposition.

\subsection{Simulated Nitrate/Nitrite Salt Waste}

2.1.1. Composition of Nitrate/Nitrite Salt Samples 1 and 2. The simulated nitrate/nitrite salt samples are very complex solid materials which were generated by dissolving salts into water, mixing thoroughly, and then allowing the water to evaporate. The samples consist primarily of sodium nitrite, sodium nitrate, and a sodium aluminate-sodium hydroxide hydrate; these three components account for about $65 \%$ of the mass of salts added. The composition of two samples (1 and 2), described in terms of mass of salts added, is given in Table 1. Note that sample 1 is identical to sample 2 in all components except $\mathrm{NaNO}_{3}$ : an additional $37.78 \mathrm{~g}$ of $\mathrm{NaNO}_{3}$ was added to sample 2. The purpose of adding additional $\mathrm{NaNO}_{3}$ was to determine if small differences in the quantitative composition could be identified using the SIMS spectrum. 


\begin{tabular}{|l|r|r|}
\hline \multicolumn{3}{|l|}{ Table 1. Composition of Simulated Salt Waste Samples 1 and 2. } \\
\hline & mass added (grams) \\
\hline Component & Sample 1 & Sample 2 \\
\hline $\mathrm{Na} \mathrm{EDTA}$ & 77.95 & 77.95 \\
\hline $\mathrm{NaCl}$ & 30.75 & 30.75 \\
\hline $\mathrm{Na}_{3} \mathrm{PO}_{4}-12\left(\mathrm{H}_{2} \mathrm{O}\right)$ & 68.04 & 68.04 \\
\hline $\mathrm{NaAlO}_{2}-0.21 \mathrm{NaOH}-1.33 \mathrm{H}_{2} \mathrm{O}$ & 235.75 & 235.75 \\
\hline $\mathrm{NaNO}_{2}$ & 272.55 & 272.55 \\
\hline $\mathrm{NaNO}_{3}$ & 186.98 & 224.76 \\
\hline $\mathrm{Na}_{2} \mathrm{CO}_{3}$ & 42.42 & 42.42 \\
\hline $\mathrm{NaF}$ & 4.20 & 4.20 \\
\hline $\mathrm{NaOH}$ & 98.00 & 98.00 \\
\hline $\mathrm{Cr}\left(\mathrm{NO}_{3}\right)_{3}-9\left(\mathrm{H}_{2} \mathrm{O}\right)$ & 42.06 & 42.06 \\
\hline $\mathrm{Fe}\left(\mathrm{NO}_{3}\right)_{3}-9(\mathrm{H} 2 \mathrm{O})$ & 2.99 & 2.99 \\
\hline $\mathrm{Ni}\left(\mathrm{NO}_{3}\right)_{2}-6\left(\mathrm{H}_{2} \mathrm{O}\right)$ & 0.62 & 0.62 \\
\hline $\mathrm{Na} \mathrm{SO}_{4}$ & 4.55 & 4.55 \\
\hline $\mathrm{CaCl}$ & 0.93 & 0.93 \\
\hline $\mathrm{KCl}$ & 10.89 & 10.89 \\
\hline $\mathrm{Sum}$ & 1078.68 & 1116.46 \\
\hline
\end{tabular}

\subsubsection{Cation SIMS Spectra, Simulated Salt Waste}

The cation spectrum of sample 1 (Table 2 and Figure 1) is representative of the cation spectra that were acquired for both samples (using either instrument). Most ion assignments were based on accurate mass measurements, which were made using the $\mathrm{Ga}^{+}$TOF-SIMS (the quadrupole instrument is not capable of making the accurate mass measurements). Not all ions that were observed in the spectrum from the $\mathrm{ReO}_{4}$; quad SIMS were observed in the $\mathrm{Ga}^{+}$TOF-SIMS spectrum, and hence no accurate mass measurement could be made. For these ions (which are identified by having no 'ppm error' listed in Table 2), ion assignments were made by comparing with the SIMS spectra of the simulated waste with that of 'standard' salts (see below). 
Table 2 (continued on page 7). Cations observed in the SIMS spectra of simulated nitrate/nitrite waste, collected using $\mathrm{ReO}_{4} /$ quad and $\mathrm{Ga}^{+} / \mathrm{TOF}$ instruments.

\begin{tabular}{|c|c|c|c|c|}
\hline $\begin{array}{l}\text { Cation } \\
\text { Mass }^{\prime}\end{array}$ & \begin{tabular}{|r|} 
R.A." $\mathrm{ReO}_{4}$ \\
/quadrupole \\
SIMS \\
\end{tabular} & $\begin{array}{l}\text { R.A." } \\
\text { Ga }^{+} / \text {TOF } \\
\text { SIMS }\end{array}$ & Cation Assignment & $\begin{array}{l}\text { ppm error of } \\
\text { accurate mass } \\
\text { measurement }\end{array}$ \\
\hline 15 & $0.17 \%$ & $0.24 \%$ & $\mathrm{CH}_{3}{ }^{+}$ & 20 \\
\hline 23 & $100 . \%$ & $100 . \%$ & $\mathrm{Na}^{+}$ & 4 \\
\hline 27 & $1.3 \%$ & $1.6 \%$ & $\mathrm{Al}^{+}$ & 4 \\
\hline 27 & & $0.51 \%$ & $\mathrm{C}_{2} \mathrm{H}_{3}{ }^{+}$ & \\
\hline 29 & $0.53 \%$ & $0.31 \%$ & $\mathrm{C}_{2} \mathrm{H}_{5}^{+}$ & 21 \\
\hline 39 & $5.4 \%$ & $0.35 \%$ & $\mathrm{~K}^{+}$ & 5 \\
\hline 39 & & $0.23 \%$ & $\mathrm{C}_{3} \mathrm{H}_{3}{ }^{+}$ & 13 \\
\hline 41 & $0.87 \%$ & $0.30 \%$ & $\mathrm{C}_{3} \mathrm{H}_{5}^{+}$ & 5 \\
\hline 43 & $0.22 \%$ & $0.19 \%$ & $\mathrm{C}_{3} \mathrm{H}_{7}^{+}$ & 12 \\
\hline 43 & & $0.04 \%$ & $\mathrm{C}_{2} \mathrm{H}_{3} \mathrm{O}^{+}$ & 12 \\
\hline 46 & $2.0 \%$ & $0.33 \%$ & $\mathrm{Na}_{2}^{+}$ & 0 \\
\hline 47 & $2.6 \%$ & $0.16 \%$ & $\mathrm{HNa}_{2}^{+}$ & 9 \\
\hline 53 & $0.44 \%$ & $0.06 \%$ & $\mathrm{CH}_{2} \mathrm{ONa}^{+}$ & 11 \\
\hline 53 & & $0.04 \%$ & $\mathrm{C}_{4} \mathrm{H}_{5}^{+}$ & 8 \\
\hline 55 & $0.17 \%$ & $0.09 \%$ & $\mathrm{C}_{4} \mathrm{H}_{7}^{+}$ & \\
\hline 57 & $0.15 \%$ & $0.07 \%$ & $\mathrm{C}_{4} \mathrm{H}_{9}{ }^{+}$ & 12 \\
\hline 62 & $2.4 \%$ & $0.22 \%$ & $\mathrm{Na}_{2} \mathrm{O}^{+}$ & 2 \\
\hline 63 & $9.6 \%$ & $0.42 \%$ & $\mathrm{Na}_{2} \mathrm{OH}^{+}$ & 16 \\
\hline 72 & $0.47 \%$ & $0.00 \%$ & $\mathrm{Na}_{2} \mathrm{CN}^{+}$ & \\
\hline 77 & $0.10 \%$ & $0.29 \%$ & $\mathrm{CH}_{3} \mathrm{ONa}_{2}{ }^{+}$ & \\
\hline 78 & $0.57 \%$ & $0.00 \%$ & $\mathrm{Na}_{2} \mathrm{O}_{2}^{+}$ & \\
\hline 79 & $0.81 \%$ & $0.00 \%$ & $\mathrm{Na}_{2} \mathrm{O}_{2} \mathrm{H}^{+}$ & \\
\hline 81 & $0.35 \%$ & $0.00 \%$ & $(\mathrm{NaOH})_{2} \mathrm{H}^{+}$ & \\
\hline 83 & $0.17 \%$ & $0.00 \%$ & $\mathrm{NaHAlO}_{2}{ }^{+}$ & \\
\hline 85 & $1.5 \%$ & $0.03 \%$ & $\mathrm{Na}_{3} \mathrm{O}^{+}$ & 0 \\
\hline 91 & $0.35 \%$ & $0.00 \%$ & $\mathrm{Na}_{2} \mathrm{HCO}_{2}{ }^{+}$ & \\
\hline 92 & $0.54 \%$ & $0.00 \%$ & $\mathrm{Na}_{2} \mathrm{NO}_{2}^{+}$ & \\
\hline 101 & $0.34 \%$ & $0.00 \%$ & $\mathrm{Na}_{3} \mathrm{O}_{2}{ }^{+}$ & \\
\hline 103 & $0.54 \%$ & $0.00 \%$ & $(\mathrm{NaOH})_{2} \mathrm{Na}^{+}$ & \\
\hline 105 & $0.50 \%$ & $0.00 \%$ & $\mathrm{Na}_{2} \mathrm{AlO}_{2}{ }^{+}$ & \\
\hline 108 & $0.23 \%$ & $0.00 \%$ & $\mathrm{Na}_{2} \mathrm{NO}_{3}{ }^{+}$ & \\
\hline \multicolumn{5}{|c|}{$\begin{array}{l}\text { lons cited twice were observed as a single peak in the } \mathrm{ReO}_{4} \text { /quad SIMS } \\
\text { experiments, but were multiplets in the } \mathrm{Ga}^{+} / \mathrm{TOF} \text { SIMS experiments. } \\
\text { ii } \mathrm{R} \text {. A. is relative abundance = ion abundance/base peak abundance } \\
\text { expressed as a percentage. } \\
\text { iii Measurements made using } \mathrm{Ga}^{+} / \mathrm{TOF} \text { SIMS instrument. PPM error = } \\
\text { accurate mass calculated for composition - measured mass (absolute value) }\end{array}$} \\
\hline
\end{tabular}


Table 2, (continued from page 6). Cations observed in the SIMS spectra of simulated nitrate/nitrite waste, collected using $\mathrm{ReO}_{4}{ }^{-} /$quad and $\mathrm{Ga}^{+} / \mathrm{TOF}$ instruments.

\begin{tabular}{|c|c|c|c|c|}
\hline $\begin{array}{l}\text { Cation } \\
\text { Mass }^{i}\end{array}$ & \begin{tabular}{|r|}
$R^{R . A .}{ }^{\text {it }} \mathrm{ReO}_{4}$ \\
/quadrupole \\
SIMS \\
\end{tabular} & $\begin{array}{l}\text { R.A." } \\
\text { Ga+/TOF } \\
\text { SIMS } \\
\end{array}$ & Cation Assignment & $\begin{array}{l}\text { ppm error of } \\
\text { accurate mass } \\
\text { measurement }\end{array}$ \\
\hline 113 & $0.23 \%$ & $0.00^{\circ}$ & $\mathrm{Na}_{3} \mathrm{CO}_{2}{ }^{+}$ & 5 \\
\hline 125 & $0.27 \%$ & 0.00 & $\left(\mathrm{Na}_{2} \mathrm{O}\right)_{2} \mathrm{H}^{+}$ & \\
\hline 129 & $2.7 \%$ & $0.08^{\circ}$ & $\mathrm{Na}_{3} \mathrm{CO}_{3}{ }^{+}$ & 1 \\
\hline 143 & $0.10 \%$ & $0.00^{\circ}$ & $\mathrm{Na}_{2} \mathrm{HSO}_{4}^{+}$ & \\
\hline 145 & $0.59 \%$ & $0.02^{c}$ & $\mathrm{Na}_{3} \mathrm{CO}_{4}{ }^{+}$ & $3 \varepsilon$ \\
\hline 147 & $0.22 \%$ & 0.00 & $\left(\mathrm{Na}_{2} \mathrm{O}\right) \mathrm{Na}^{+}$ & \\
\hline 165 & $0.22 \%$ & $0.00^{\circ}$ & $\mathrm{Na}_{3} \mathrm{HPO}_{4}$, or $\mathrm{Na}_{3} \mathrm{SO}_{4}^{+}$ & \\
\hline 169 & $0.29 \%$ & $0.00^{\circ}$ & $\mathrm{Na}_{3} \mathrm{CO}_{3}(\mathrm{NaOH})^{+}$ & \\
\hline 187 & $0.18 \%$ & $0.00^{\circ}$ & $\mathrm{Na}_{4} \mathrm{PO}_{4}^{+}$ & \\
\hline \multicolumn{5}{|c|}{$\begin{array}{l}\text { Ions cited twice were observed as a single peak in the } \mathrm{ReO}_{4} / \text { quad SIMS } \\
\text { experiments, but were multiplets in the } \mathrm{Ga}^{+} / \mathrm{TOF} \text { SIMS experiments. } \\
\text { ii } \mathrm{R} \text {. A. is relative abundance = ion abundance/base peak abundance } \\
\text { expressed as a percentage. } \\
\text { iii Measurements made using } \mathrm{Ga}^{+} / \mathrm{TOF} \text { SIMS instrument. PPM error = } \\
\text { accurate mass calculated for composition - measured mass (absolute value) }\end{array}$} \\
\hline
\end{tabular}

The cation spectra permit several general conclusions. $\mathrm{Na}^{+}$is by far the most abundant ion, and other major ions in the spectrum are interpreted in terms of oxides, hydroxides, phosphates, and carbonates of sodium. In addition, interesting ions at $m / z 46$ and 47 are attributed to $\mathrm{Na}_{2}{ }^{+}$and $\mathrm{Na}_{2} \mathrm{H}^{+}$: the former ion is a radical species, and the latter perhaps a hydride-bound dimer of $\mathrm{Na}^{+}$. The small ion at $m / z 72^{+}$is most likely $\mathrm{Na}_{2} \mathrm{CN}^{*}$, where the $\mathrm{CN}$ moiety is thought to originate from EDTA. $M / z 72^{+}$has been observed in the SIMS spectra of sodium EDTA salts in our laboratory. There is no other evidence in these spectra for the presence of EDTA. $M / z 72^{+}$is an equivocal signature for EDTA because it will also be observed in the SIMS spectra of samples containing $\mathrm{Na}^{+}$and $\mathrm{CN}$.

Lower abundance ions at $m / z 78^{+}, 79^{\circ}$, and $101^{\circ}$, observed only in the $\mathrm{ReO}_{4}$ spectrum, are attributed to peroxy species $\mathrm{NaOONa}^{+}, \mathrm{NaOONaH}^{+}$, and $\mathrm{NaOONa}_{2}^{+}$. These ions may indicate the presence of peroxides on the surface of the salt samples. An alternative explanation is that they are induced by the use of the $\mathrm{ReO}_{4}$; primary ion beam. Perhaps significantly, these ions are not observed in the SIMS spectra collected using the $\mathrm{Ga}^{+}$TOF SIMS instrument.

In light of the large quantities of sodium nitrite and sodium nitrate added to the salt mixture (Table 1), it was surprising that only low abundance nitrate and nitrite-bearing ions were observed in the cation $\mathrm{ReO}_{4}^{-} \mathrm{SIMS}_{\text {spectrum, and that }}$ no nitrate- / nitrite-bearing cations were observed in the $\mathrm{Ga}^{+}$TOF SIMS experiment. The cations attributed to nitrite/nitrate are $m / z 92^{+}\left(\mathrm{Na}_{2} \mathrm{NO}_{2}{ }^{+}\right)$, and 
$108^{+}\left(\mathrm{Na}_{2} \mathrm{NO}_{3}{ }^{+}\right)_{;}$the origin of these ions cannot be ascribed unequivocally to the presence of condensed-phase species (see below).

A large ion at $m / z 129^{+}$corresponds to the trisodium carbonate cation. It is of interest that carbonate was not added to the salt mixture, and hence we presume that the origin of the carbonate is adsorption of atmospheric $\mathrm{CO}_{2}$ into the basic salt sample. We observe the same effect in the SIMS spectrum of other Group I hydroxides. Low abundance ions at $\mathrm{m} / \mathrm{z} 169^{+}$and $145^{\circ}$ are also thought to be derived from adsorbed $\mathrm{CO}_{2}$.

lons containing potassium, calcium, and aluminum can also be observed: $K^{*}$ is observed at $\mathrm{m} / \mathrm{z} 39$, and part of the very low abundance ion at $\mathrm{m} / \mathrm{z} 40^{+}$(not included in Table 2) is attributable to $\mathrm{Ca}^{+}$. Aluminum is observed at $\mathrm{m} / \mathrm{z} 27^{+}$, and may be present in the ions at $m / 283^{+}$and $105^{\circ}$, although this has not been confirmed. Despite the fact that smaller quantities of $\mathrm{Cr}, \mathrm{Ni}$ and $\mathrm{Fe}$-bearing salts were put into the samples, no ions were observed which contained these metals.

Hydrocarbons, and oxygenated hydrocarbons are likely responsible for ions observed at $\mathrm{m} / 215^{*}, 27^{+}, 29^{+}, 39^{*}, 41^{*}, 43^{*}, 53^{+}, 55^{*}, 57^{*}$, and $77^{+}$. These are likely the result of atmospheric contaminants which become adsorbed to the salt surfaces; this behavior has been observed previously in the SIMS analysis of mineral samples.'

Sample 1 was analyzed ten times using the $\mathrm{ReO}_{4}$ quad SIMS, and the spectra collected from seven of those analyses were very similar from both a qualitative and quantitative perspective. As a result those seven analyses were used to generate relative standard deviations (rsd) for each mass. For the cations, rsd values were in the 20 to $40 \%$ range at lower mass, and steadily increased to the $60-80 \%$ range for masses $>100 \mathrm{u}$. The average rsd for cations at $\mathrm{m} / \mathrm{z} 10-200$ was $50 \%$. In the case of the anions, the average of the rsd value was $55 \%$, and was relatively independent of mass.

Having established the precision of the measurements, the spectra collected for sample 1 were compared with those collected for sample 2. No substantial difference could be discerned, and hence we conclude that we are unable to distinguish between salt samples that have moderate differences in nitrate content.

On three occasions, the spectra of sample 1 that were acquired were substantially different from the spectra described above. In the first instance, the spectra of samples 1 and 2 appeared very rich in formate-bearing ions, which were observed at $m / z 45^{\circ}\left(\mathrm{HCO}_{2}\right), 91^{+}\left(\mathrm{Na}_{2} \mathrm{HCO}_{2}{ }^{+}\right)$, and $113^{-}\left(\mathrm{Na}\left(\mathrm{HCO}_{2}\right)_{2}\right)$. We hypothesize that formic acid, present as a laboratory atmospheric contaminant, was adsorbed onto the surface of the salt sample, and was observed in the SIMS spectrum as the above-mentioned ions. We have no other evidence for this hypothesis, but the observation of these ions on sample 1 and sample 2, on 
the same day (but on no other days) is consistent with the atmospheric contamination scenario.

In the second instance where a substantially different SIMS spectrum was recorded, peaks corresponding to $\mathrm{NO}_{2}{ }^{-}$and $\mathrm{NO}_{3}{ }^{-}$were the most abundant ions in the anion spectrum. This behavior is reminiscent of the SIMS spectra of $\mathrm{NaNO}_{2}$ and $\mathrm{NaNO}_{3}$ (see below). We believe that the best explanation for this spectrum is the random selection of salt subsample which was very high in nitrate and or nitrite. Since in nearly all analyses, no sample preparation was performed for the $\mathrm{ReO}_{4}$ quad SIMS analyses, this explanation is certainly within the realm of plausibility. These types of observations underscore the value in being able to perform ion imaging (a capability of the $\mathrm{Ga}^{+} \mathrm{TOF}$ SIMS); in this experiment, however, the data was collected using the broad beam $\mathrm{ReO}_{4}^{-}$quad SIMS.

The third spectral aberration occurred when the sample was prepared by dissolving it in water, applying the solution to a target, and then allowing the water to evaporate. In this case, abundant ions were observed in the anion spectrum at $m / z 183^{\circ}, 80^{\circ}$, and $64^{\circ}$ : these have been previously observed in other samples and have been ascribed to the presence of alkyl benzene sulfonate ions, which are derived from soap. Hence these ions are explainable in terms of soap contamination of the water or glassware used.

Based on the data presented for Sample 1, it is likely that the ReO primary ion is generating molecular secondary species with greater efficiency than is the $\mathrm{Ga}^{+}$ primary. This conclusion is consistent with earlier work performed in our laboratory (INEL). ${ }^{2}$ Nearly all of the ion species in Table 2 are greater in the spectrum from the ReO, quad SIMS instrument, when normalized to $\mathrm{Na}^{*}$. In the present comparison, this conclusion cannot be made unequivocally, because the ion optics on the front end of the Ga* TOF SIMS are more tolerant of high energy secondary ions, and hence would transmit more secondary $\mathrm{Na}^{+}$than would the quadrupole. This factor may be somewhat offset, however, by decreased quadrupole sensitivity for higher mass ions, relative to the TOF instrument. While the excellent secondary ion transmission of the TOF is sufficient to permit enough counts for accurate mass measurement of ions like $\mathrm{m} / \mathrm{z}^{129^{+}}$, the dramatic relative abundance difference $\left(2.7 \%\right.$ for the $\mathrm{ReO}_{4}{ }^{-}$quad SIMS vs. $0.08 \%$ for the $\mathrm{Ga}^{+}$TOF SIMS) leads to the conclusion that massive, polyatomic particles are advantageous for sputtering polyatomic secondary ions.

\subsubsection{Anion SIMS Spectra, Simulated Salt Waste}

A representative anion spectrum is dominated by oxygen species, specifically $O$; $\mathrm{OH}^{\circ}, \mathrm{O}_{2}$, and $\mathrm{HO}_{2}$. Low abundance ions corresponding to $\mathrm{Cl}^{-}$and $\mathrm{F}$ were observed, as were $\mathrm{NO}_{2}{ }_{2}, \mathrm{NO}_{3}, \mathrm{CO}_{2} ; \mathrm{CO}_{3}, \mathrm{PO}_{2}$, and $\mathrm{PO}_{3}^{-}$. The low abundance of nitrite, nitrate carbonate, and phosphate were surprising in view of the large quantities of these materials that were added. The low abundance $\mathrm{m} / \mathrm{z} 97$ and $119^{\circ}$ observed in the $\mathrm{ReO}_{4}{ }^{-}$quad SIMS analyses may be indicative of sulfate 
$\left(\mathrm{HSO}_{4}{ }^{-}\right.$and $\left.\mathrm{NaSO}_{4}\right)$, but we were unable to confirm these assignments using the $\mathrm{Ga}^{+}$TOF SIMS. The origin of the $\mathrm{CN}^{-}(m / z 26)$ is not known, but EDTA is a possibility; we note again that no cyanide-bearing salts were added to this sample.

Few metal-bearing anions were observed, other than those containing $\mathrm{Na}^{+}$. Aluminum-bearing anions were observed at $m / z 43^{\circ}, 59$, and perhaps 119 . No ions could be unequivocally ascribed to $\mathrm{Cr}, \mathrm{Fe}$ or $\mathrm{Ni}$. We suspect that part of the abundance observed at $\mathrm{m} / \mathrm{z} 100^{\circ}$, and $84^{+}$in the ReO, quad SIMS spectrum may be due to $\mathrm{CrO}_{3}{ }^{-}$and $\mathrm{CrO}_{2}$, (see spectra of $\mathrm{Na}_{2} \mathrm{CrO}_{4}$, below), but we cannot confirm these assignments using the $\mathrm{Ga}^{+}$TOF SIMS data.

The anion SIMS spectrum revealed a substantial number of organic species. $\mathrm{C}_{n}$, highly unsaturated hydrocarbon anions, and oxygen-bearing anions were observed. We believe that the best interpretation for these ions is the presence of organic acids or hydrocarbons adsorbed to the surface of the salt samples. Furthermore, the most abundant compound of this type would appear to be formic acid, which we believe is represented by $m / z 45^{\circ}$ and $113^{\circ}$. Since static SIMS is a surface analysis technique, these species derived from surfaceadsorbed contaminants constitute a substantial fraction of the anion spectrum, even though they are probably not present in the bulk sample. 


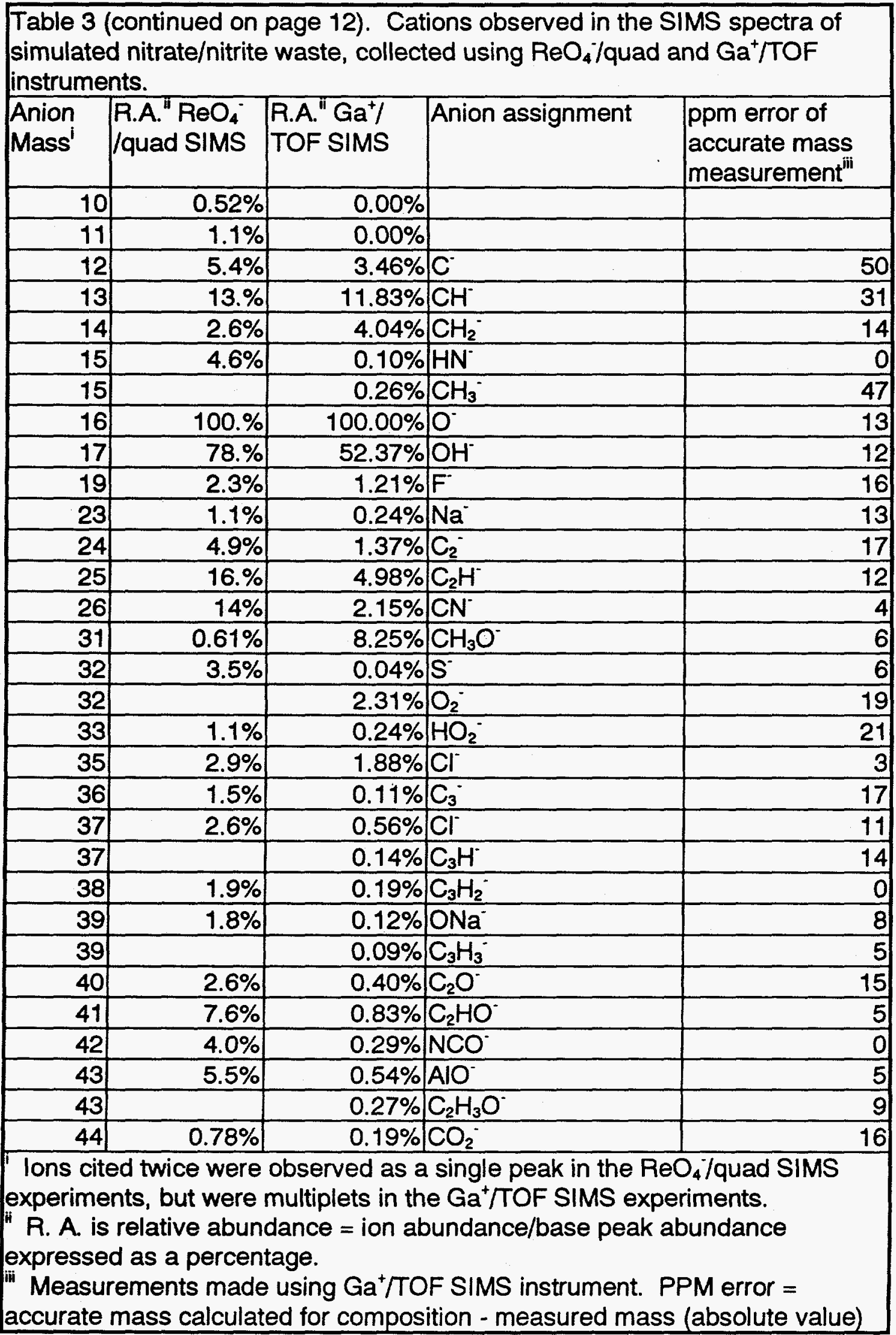




\begin{tabular}{|c|c|c|c|c|}
\hline $\begin{array}{l}\text { Table 31 } \\
\text { simulate }\end{array}$ & $\begin{array}{l}\text { (continued fron } \\
\text { d nitrate/nitrite }\end{array}$ & $\begin{array}{l}m \text { page 11). } \\
\text { waste, using }\end{array}$ & $\begin{array}{l}\text { Cations observed in } \\
\mathrm{ReO}_{4} / \text { /quad and } \mathrm{Ga}\end{array}$ & $\begin{array}{l}\text { SIMS spectra of } \\
\text { OF instruments. }\end{array}$ \\
\hline \begin{tabular}{|l|} 
Anion \\
Mass
\end{tabular} & $\begin{array}{l}\text { R.A." } \mathrm{ReO}_{4}{ }^{\circ} \\
\text { /quad SIMS }\end{array}$ & $\begin{array}{l}\text { R.A." } \mathrm{Ga}^{+} \text {I } \\
\text { TOF SIMS }\end{array}$ & Anion assignment & $\begin{array}{l}\text { ppm error of } \\
\text { accurate mass } \\
\text { measurement }\end{array}$ \\
\hline 45 & $6.3 \%$ & $1.50 \%$ & $6 \mathrm{HCO}_{2}^{-}$ & 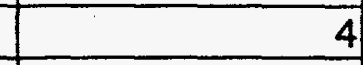 \\
\hline 46 & $8.8 \%$ & $1.31 \%$ & $6 \mathrm{NO}_{2}^{-}$ & 0 \\
\hline 48 & $1.6 \%$ & $0.05 \%$ & $6 \mathrm{C}_{4}^{*}$ & 10 \\
\hline 49 & $3.0 \%$ & $0.16 \%$ & 6. $\mathrm{C}_{4} \mathrm{H}^{-}$ & 10 \\
\hline 59 & $4.8 \%$ & $0.30 \%$ & $\mathrm{AlO}_{2}$ & 2 \\
\hline 59 & & $0.27 \%$ & $\mathrm{C}_{2} \mathrm{H}_{3} \mathrm{O}_{2}$ & 5 \\
\hline 60 & $1.6 \%$ & $0.47 \%$ & $\mathrm{CO}_{3}^{-}$ & 5 \\
\hline 62 & $4.3 \%$ & $0.60 \%$ & $\mathrm{NO}_{3}^{-}$ & 3 \\
\hline 63 & $1.3 \%$ & $0.11 \%$ & $\mathrm{PO}_{2}^{\circ}$ & 3 \\
\hline 71 & $2.1 \%$ & $0.22 \%$ & $\mathrm{C}_{3} \mathrm{H}_{3} \mathrm{O}_{2}^{-}$ & 6 \\
\hline 75 & $1.0 \%$ & $0.44 \%$ & $\mathrm{C}_{2} \mathrm{H}_{3} \mathrm{O}_{3}$ & 3 \\
\hline 77 & $2.2 \%$ & $0.07 \%$ & $\mathrm{HNONa}_{2}$ & 29 \\
\hline 77 & & $0.03 \%$ & $\mathrm{C}_{6} \mathrm{H}_{5}$ & 39 \\
\hline 79 & $2.9 \%$ & $0.05 \%$ & $\mathrm{PO}_{3}$ & 15 \\
\hline 84 & $2.2 \%$ & & & \\
\hline 85 & $1.7 \%$ & $0.02 \%$ & 6. $\mathrm{C}_{4} \mathrm{H}_{5} \mathrm{O}_{2}^{-}$ & 4 \\
\hline 86 & $1.8 \%$ & & & \\
\hline 87 & $1.3 \%$ & & & \\
\hline 95 & $1.1 \%$ & & $\mathrm{PO}_{4}^{-}$ & \\
\hline 97 & $0.96 \%$ & & $\mathrm{HSO}_{4}^{\circ}$ & \\
\hline 99 & $1.2 \%$ & & & \\
\hline 100 & $2.6 \%$ & $0.03 \%$ & $\mathrm{C}_{3} \mathrm{H}_{2} \mathrm{NO}_{3}$ & \\
\hline 101 & $3.3 \%$ & $0.11 \%$ & $\mathrm{C}_{5} \mathrm{H}_{9} \mathrm{O}_{2}$ & 11 \\
\hline 102 & $1.2 \%$ & & & \\
\hline 113 & $1.0 \%$ & & $\mathrm{Na}\left(\mathrm{HCO}_{2}\right)_{2}^{-}$ & \\
\hline 115 & $1.2 \%$ & & & \\
\hline 119 & $1.7 \%$ & $0.02 \%$ & $\mathrm{Al}_{2} \mathrm{O}_{4} \mathrm{H}^{-}$, or $\mathrm{NaSO}_{4}^{-}$ & \\
\hline 121 & $1.4 \%$ & $0.04 \%$ & $\mathrm{C}_{7} \mathrm{H}_{5} \mathrm{O}_{2}^{-}$ & \\
\hline 127 & $0.96 \%$ & $0.02 \%$ & $\mathrm{C}_{7} \mathrm{H}_{11} \mathrm{O}_{2}$ & 19 \\
\hline 129 & $0.61 \%$ & $0.06 \%$ & $\mathrm{C}_{7} \mathrm{H}_{13} \mathrm{O}_{2}^{-}$ & 8 \\
\hline 143 & $0.78 \%$ & $0.06 \%$ & $\mathrm{C}_{8} \mathrm{H}_{15} \mathrm{O}_{2}^{-}$ & 6 \\
\hline 157 & $0.61 \%$ & $0.03 \%$ & $\mathrm{C}_{9} \mathrm{H}_{17} \mathrm{O}_{2}$ & 1 \\
\hline $\begin{array}{l}\text { lons cite } \\
\text { experime } \\
\text { ii } R \text {. A. is } \\
\text { expresse } \\
\text { iii Measur } \\
\text { accurate }\end{array}$ & $\begin{array}{l}\text { ed twice were } \\
\text { nts, but were r } \\
\text { relative abunc } \\
\text { d as a percent } \\
\text { rements made } \\
\text { mass calculate }\end{array}$ & $\begin{array}{l}\text { observed as a } \\
\text { multiplets in th } \\
\text { dance = ion at } \\
\text { tage. } \\
\text { using } \mathrm{Ga}^{+} / \mathrm{TO} \\
\text { ed for compos }\end{array}$ & $\begin{array}{l}\text { a single peak in the } \\
\text { he Ga'/TOF SIMS ex } \\
\text { bundance/base peal } \\
\text { OF SIMS instrument. } \\
\text { sition - measured ma }\end{array}$ & $\begin{array}{l}\text { i }{ }^{4} \text { quad SIMS } \\
\text { iments. } \\
\text { undance } \\
\text { M error = } \\
\text { (absolute value) }\end{array}$ \\
\hline
\end{tabular}




\subsubsection{References}

1 "Static SIMS Analysis Of Tributyl Phosphate On Mineral Surfaces: Effect Of Fe(II)", Groenewold, G. S., Ingram, J. C., Delmore, J. E., Appelhans, A. D., J. Am. Soc. Mass Spectrom., in press.

${ }^{2 n}$ Comparison of Polyatomic and Atomic Primary Beams for Secondary lon Mass Spectrometry of Organics", Appelhans, A. D.; Delmore, J. E.; Anal. Chem., $1989,61,1087-1093$. 


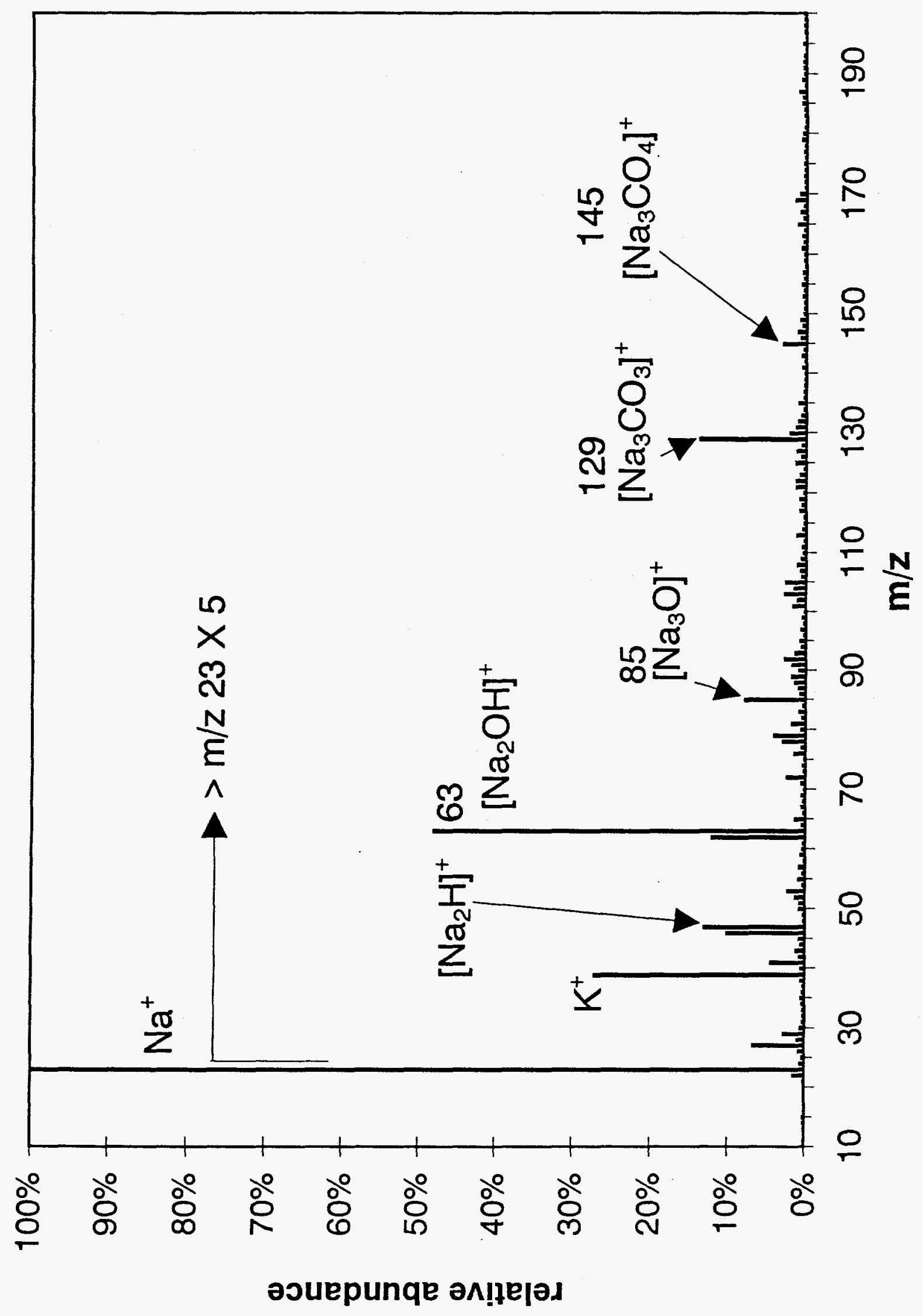




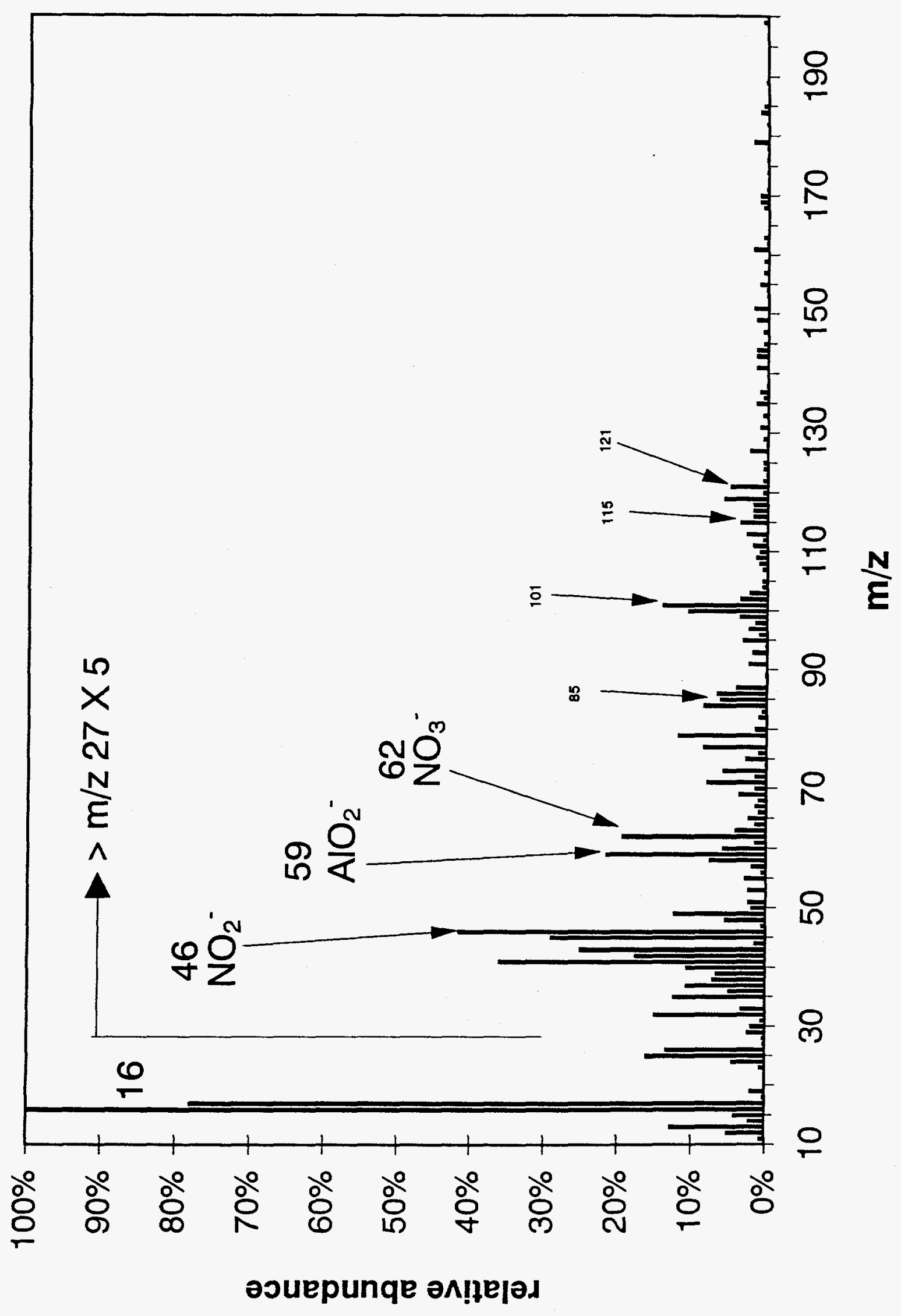




\subsection{SIMS Spectra of 'Benchmark' Salts}

Several salt compounds were analyzed in order to clarify ion assignments, and to develop some feel for the relationship between secondary ions observed and species that might be present in the samples. These spectra were acquired using the $\mathrm{ReO}_{4}$ quad SIMS instrument. We emphasize that the purpose of these analyses was not to exhaustively study the SIMS behavior of each salt, but rather to identify the most abundant ions that would be expected.

2.2.1. $\mathrm{NaOH}$. The cation spectrum (Table 4) contains the expected $\mathrm{Na}^{+}$base peak, but also has abundant ions at $m / z 63^{+}, 85^{+}, 103^{+}$, and $129^{+}$. The fact that many of these ions were prominent in the SIMS spectra of the simulated salt sample is indicative that the latter has substantial $\mathrm{NaOH}$ character. As in the case of the simulated salt samples, the $\mathrm{NaOH}$ pellet clearly contained substantial carbonate at or near the surface.

The abundance of $m / 262^{+}\left(\mathrm{Na}_{2} \mathrm{O}^{+}\right)$is substantially lower in the spectrum of the $\mathrm{NaOH}$ pellet, compared with the simulated salt. While the mechanism of formation of $\mathrm{Na}_{2} \mathrm{O}^{+}$is an open question, it appears that the appearance of an abundant $62^{+}$is related to the presence of nitrate in the sample. This is consistent with subsequent nitrate experiments described in later sections.

The anion SIMS spectrum (Table 4) is dominated by $\mathrm{O}^{\circ}$ and $\mathrm{OH}^{\circ}$, however in the present spectra, $m / z 17$ is substantially more abundant than is $m / z 16$. This is consistent with the prevalence of $\mathrm{OH}^{-}$, and points to a substantial difference between the simulated salt sample and an alkali hydroxide. The anion SIMS spectrum of $\mathrm{NaOH}$ also contains substantial ions which probably correspond to the conjugate bases of organic acids. These compounds were observed in the SIMS spectra of some of the simulated salt samples that were analyzed using the $\mathrm{Ga}^{+}$TOF SIMS: elemental compositions were confirmed using accurate mass measurements. These compounds are not significant components of the $\mathrm{NaOH}$ sample, and consequently we hypothesize that they are deposited from the atmosphere. The extremely basic nature of the surface facilitates adsorption and ion formation, but we cannot determine which of these processes is more important based on the present data.

Another significant ion in the anion spectrum is $m / z 26$, which is ascribed to $C N$. Unlike the simulated salt sample, there is no EDTA present in the $\mathrm{NaOH}$ pellet, and thus $\mathrm{CN}^{\prime}$ must have another (as yet unidentified) origin in the present sample. It is possible that the ion bombardment process is responsible for the observation of $\mathrm{m} / \mathrm{z} 26$, and as a result, this ion may be an unreliable indicator for $\mathrm{CN}^{-}$in the sample. 


\begin{tabular}{|c|c|c|c|c|c|}
\hline \begin{tabular}{|l|} 
Cation \\
mass
\end{tabular} & $\begin{array}{l}\text { Cation } \\
\text { R.A.' }\end{array}$ & Cation Assignment & \begin{tabular}{|l|} 
Anion \\
mass
\end{tabular} & $\begin{array}{l}\text { Anion } \\
\text { R.A. }\end{array}$ & $\begin{array}{l}\text { Anion } \\
\text { Assignment }\end{array}$ \\
\hline 23 & $100 . \%$ & $\mathrm{Na}^{+}$ & 16 & $51 . \%$ & $0^{\circ}$ \\
\hline 41 & $1.3 \%$ & $\mathrm{NaOH}_{2}^{+}$ & 17 & $100 . \%$ & $\mathrm{OH}$ \\
\hline 46 & $4.1 \%$ & $\mathrm{Na}_{2}^{+}$ & 24 & $9.7 \%$ & $\mathrm{C}_{2}^{-}$ \\
\hline 62 & $4.8 \%$ & $\mathrm{Na}_{2} \mathrm{O}^{+}$ & 25 & $29 . \%$ & $\mathrm{C}_{2} \mathrm{H}^{-}$ \\
\hline 63 & $31 . \%$ & $\mathrm{Na}_{2} \mathrm{OH}^{+}$ & 26 & $18 . \%$ & $\mathrm{CN}^{-}$ \\
\hline 85 & $13 . \%$ & $\mathrm{Na}_{3} \mathrm{O}^{+}$ & 41 & $24 . \%$ & \\
\hline 101 & $2.0 \%$ & $\mathrm{Na}_{3} \mathrm{O}_{2}^{+}$ & 43 & $12 . \%$ & \\
\hline 102 & $1.7 \%$ & $\mathrm{Na}_{3} \mathrm{O}_{2} \mathrm{H}^{+}$ & 45 & $17 . \%$ & $\mathrm{HCO}_{2}$ \\
\hline 103 & $8.0 \%$ & $(\mathrm{NaOH})_{2} \mathrm{Na}^{+}$ & 59 & $29 . \%$ & $\mathrm{CH}_{3} \mathrm{CO}_{2}$ \\
\hline 125 & $1.4 \%$ & $\left(\mathrm{Na}_{2} \mathrm{O}\right)_{2} \mathrm{H}^{+}$ & 73 & $6.9 \%$ & $\mathrm{C}_{2} \mathrm{H}_{5} \mathrm{CO}_{2}^{-}$ \\
\hline 127 & $1.2 \%$ & & 85 & $11 . \%$ & \\
\hline 129 & $14 . \%$ & $\mathrm{Na}_{3} \mathrm{CO}_{3}{ }^{+}$ & 87 & $12 . \%$ & $\mathrm{C}_{3} \mathrm{H}_{7} \mathrm{CO}_{2}^{-}$ \\
\hline 143 & $1.6 \%$ & $(\mathrm{NaOH})_{3} \mathrm{Na}^{+}$ & 93 & $15 . \%$ & \\
\hline 145 & $1.9 \%$ & $\mathrm{Na}_{3} \mathrm{CO}_{4}^{+}$ & 97 & $6.9 \%$ & \\
\hline 147 & $0.74 \%$ & $(\mathrm{Na2O})_{2} \mathrm{Na}^{+}$ & 99 & $8.3 \%$ & \\
\hline 159 & $0.96 \%$ & & 101 & $8.3 \%$ & $\mathrm{C}_{4} \mathrm{H}_{9} \mathrm{CO}_{2}^{-}$ \\
\hline 165 & $1.0 \%$ & $(\mathrm{NaOH})_{2}\left(\mathrm{Na}_{2} \mathrm{O}\right) \mathrm{Na}^{+}$ & & & \\
\hline
\end{tabular}

2.2.2. NaNO. The cation SIMS spectrum of sodium nitrite (Table 5) bears some similarity to that of the $\mathrm{NaOH}$ pellet, and to the simulated salt sample: the most abundant peaks are ascribed to $\mathrm{Na}^{+}, \mathrm{Na}_{2} \mathrm{O}^{+}, \mathrm{Na}_{2} \mathrm{OH}^{+}$, and $\mathrm{Na}_{3} \mathrm{O}^{+}$. In addition, the spectrum of sodium nitrite displays a fairly substantial $\mathrm{Na}_{3} \mathrm{CO}_{3}{ }^{+}$ion, which indicates absorption of $\mathrm{CO}_{2}$. The present spectrum is distinguished from that of $\mathrm{NaOH}$ by the fact that $\mathrm{Na}_{2} \mathrm{O}^{+}$is nearly as abundant as $\mathrm{Na}_{2} \mathrm{OH}^{+}$, and also by the presence of an abundant ion at $m / z 92^{+}$, which certainly corresponds to $\mathrm{Na}_{2} \mathrm{NO}_{2}^{+}$.

$\mathrm{O}$ corresponds to the base peak in the anion spectrum of $\mathrm{NaNO}_{2}$ (instead of $\mathrm{OH}$ as in the $\mathrm{NaOH}$ spectrum). This spectrum contained none of the ions ascribed to the organic acids (with the exception of formate), which may indicate that they 
are either not being adsorbed, or not being ionized by the more neutral $\mathrm{NaNO}_{2}$ surface (again compared to $\mathrm{NaOH}$ ). A prominent $\mathrm{NO}_{2}$, was observed at $\mathrm{m} / z 46$, as well as a lower abundance $\mathrm{NO}_{3}^{-}(62)$. This latter ion serves to confuse distinction between nitrite and nitrate. It is not known whether this ion is derived from a nitrate impurity on the surface, or is an artifact from the ion bombardment process. Another ion which is potentially diagnostic for nitrite is observed at $\mathrm{m} / \mathrm{z}$ 115, which corresponds to $\mathrm{Na}\left(\mathrm{NO}_{2}\right)_{2}$.

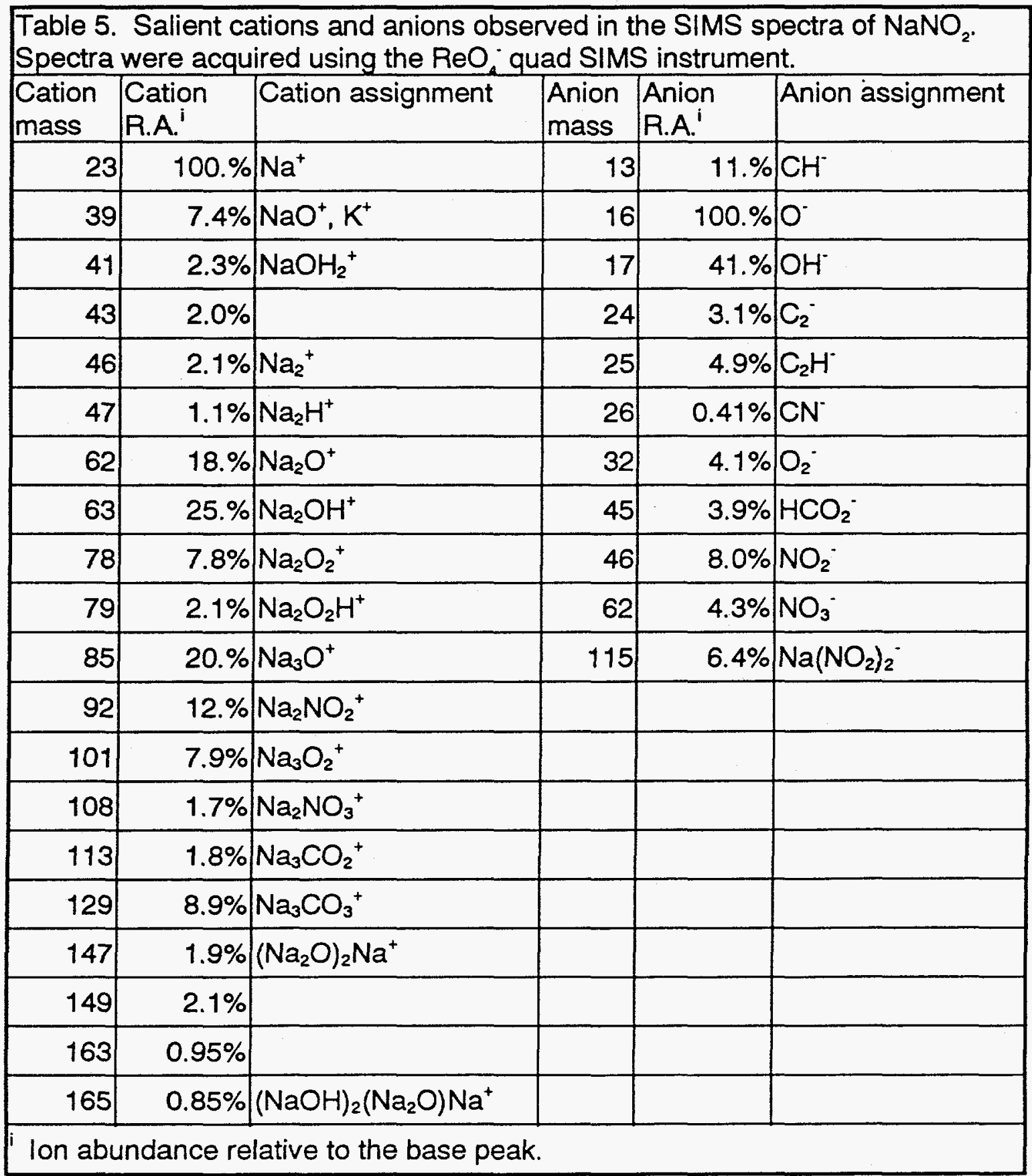


2.2.3. NaNO . The cation SIMS spectrum of sodium nitrate (Table 6) is qualitatively similar to that of $\mathrm{NaNO}_{2}$. The most significant difference between the spectra of the two compounds is in the abundance of $\mathrm{m} / \mathrm{z} 108^{+}\left(\mathrm{Na}_{2} \mathrm{NO}_{3}{ }^{+}\right)$, which is much more abundant in the spectrum of the nitrate than in the nitrite. The nitrate spectrum also contained an abundant $m / z 92^{+}\left(\mathrm{Na}_{2} \mathrm{NO}_{2}{ }^{+}\right)$, and thus this ion is equivocal for distinguishing between nitrite and nitrate. Several other ions are more abundant in the spectrum of the nitrate, in particular $\mathrm{Na}_{2} \mathrm{O}^{+}$, $\mathrm{Na}_{2} \mathrm{O}_{2}{ }^{*}$. Sodium nitrate does not display the tendency to adsorb and /or ionize carbonate (as do the simulated salt sample, $\mathrm{NaOH}$, and $\mathrm{NaNO}_{2}$ ). We speculate that $\mathrm{NO}_{3}$ is too weak a base to promote the adsorption of $\mathrm{CO}_{2}$.

$\mathrm{NO}_{3}{ }^{-}$is the base peak in the anion spectrum of $\mathrm{NaNO}_{3}$, and a substantial $\mathrm{NO}_{2}{ }^{-}$ $(25 \%)$ is also observed. This observation indicates clearly that the presence of $\mathrm{NO}_{2}{ }^{-}$cannot be used alone for identification of nitrite Abundant ions at $m / 2131$ and 147 correspond to $\mathrm{Na}\left(\mathrm{NO}_{3}\right)_{2}$ and $\mathrm{Na}\left(\mathrm{NO}_{2}\right)\left(\mathrm{NO}_{3}\right)^{-}$, and these ions were not observed in the spectra of sodium nitrite. Three lower abundance anions are observed at $m / z 85,101$, and 117: these ions have not been unequivocally identified, but may represent hyperoxidized sodium nitrate/nitrite species.

Because nitrate/nitrite determination is an important aspect of salt characterization, a series of sodium nitrate/sodium nitrite mixtures were analyzed. The goal of this study was to evaluate whether $m / z 108^{+}, 92^{+}, 62$; 115,131 , and/or 147 could be used to quantitate nitrate/nitrite ratios. A plot of the $108^{+} / 92^{+}$cation abundance ratio versus nitrate/nitrite mole fraction (Figure 3 ) shows that $108^{+}$is nearly twice as abundant as $92^{+}$for pure sodium nitrate, but then decreases to $0.6-0.4$ in the spectra of the mixed salts, and finally drops to about 0.1 in the spectrum of pure nitrite. This non-linear behavior was also observed for $m / z 62,131^{*}$, and $147^{*}$.

Raman spectra were collected for these same samples to determine whether the non-linear behavior was due to the SIMS event or to some other chemical phenomenon. When the intensity of $\mathrm{NO}_{3}^{-}$peaks at $185 \mathrm{~cm}^{-1}$ and $725 \mathrm{~cm}^{-1}$ were plotted versus nitrate/nitrite mole fraction, remarkably similar non-linear behavior was observed (Figure 4). In contrast, the nitrite peaks at $120 \mathrm{~cm}^{-1}$ and $829 \mathrm{~cm}^{-1}$ were relatively invariant relative to the nitrate/nitrite mole fraction. The good correlation observed between the SIMS $108^{+} / 92^{+}$ratio and the Raman nitrate abundances indicates that the spectral behavior shown in Figure 3 is probably the result of nitrate/nitrite chemistry, and not an artifact of the bombardment process. On the basis of these data, we conclude that the surface of the mixed salts have similar nitrate/nitrite ratios, irrespective of the fraction of nitrate/nitrite originally added. 


\begin{tabular}{|c|c|c|c|c|c|}
\hline $\begin{array}{l}\text { Cation } \\
\text { mass }\end{array}$ & $\begin{array}{l}\text { Cation } \\
\text { R.A. }^{i}\end{array}$ & Cation assignment & $\begin{array}{l}\text { Anion } \\
\text { mass }\end{array}$ & $\begin{array}{l}\text { Anion } \\
\text { R.A. }\end{array}$ & Anion assignment \\
\hline 23 & $100 \%$ & $\mathrm{Na}^{+}$ & 13 & $7.5 \%$ & $6 \mathrm{CH}^{-}$ \\
\hline 27 & $2.5 \%$ & $\mathrm{C}_{2} \mathrm{H}_{3}^{+}$ & 16 & $68 . \%$ & $60^{\circ}$ \\
\hline 29 & $2.0 \%$ & $\mathrm{C}_{2} \mathrm{H}_{5}^{+}, \mathrm{HN}_{2}^{+}$ & 17 & $28 . \%$ & $6 \mathrm{OH}^{-}$ \\
\hline 39 & $4.5 \%$ & $\mathrm{NaO}^{+}, \mathrm{K}^{+}, \mathrm{C}_{3} \mathrm{H}_{3}^{+}$ & 25 & $4.5 \%$ & $6 \mathrm{C}_{2} \mathrm{H}^{-}$ \\
\hline 41 & $5.2 \%$ & $\mathrm{NaOH}_{2}{ }^{+}, \mathrm{C}_{3} \mathrm{H}_{5}{ }^{+}$ & 26 & $5.9 \%$ & $\mathrm{CN}^{-}$ \\
\hline 43 & $3.0 \%$ & $\mathrm{C}_{3} \mathrm{H}_{7}^{+}$ & 32 & $10 . \%$ & $\mathrm{O}_{2}^{-}$ \\
\hline 53 & $1.1 \%$ & $\mathrm{C}_{4} \mathrm{H}_{5}^{+}$ & 46 & $25 . \%$ & $\mathrm{NO}_{2}^{-}$ \\
\hline 55 & $2.5 \%$ & $\mathrm{C}_{4} \mathrm{H}_{7}^{+}$ & 62 & $100 . \%$ & $\mathrm{NO}_{3}^{-}$ \\
\hline 57 & $2.3 \%$ & $\mathrm{C}_{4} \mathrm{H}_{9}^{+}$ & 85 & $5.2 \%$ & $\mathrm{NaONO}_{2}^{-}$ \\
\hline 62 & $56 . \%$ & $\mathrm{Na}_{2} \mathrm{O}^{+}$ & 101 & $6.6 \%$ & $\mathrm{NaONO}_{3}{ }^{-}$ \\
\hline 63 & $19 . \%$ & $\mathrm{Na}_{2} \mathrm{OH}^{+}$ & 115 & $7.8 \%$ & $\mathrm{Na}\left(\mathrm{NO}_{2}\right)_{2}$ \\
\hline 78 & $26 . \%$ & $\mathrm{Na}_{2} \mathrm{O}_{2}^{+}$ & 117 & $4.5 \%$ & $\mathrm{NaO}_{2} \mathrm{NO}_{3}^{-}$ \\
\hline 85 & $30 . \%$ & $\mathrm{Na}_{3} \mathrm{O}^{+}$ & 131 & $26 . \%$ & $6 \mathrm{Na}\left(\mathrm{NO}_{2}\right)\left(\mathrm{NO}_{3}\right)^{\circ}$ \\
\hline 92 & $20 . \%$ & $\mathrm{Na}_{2} \mathrm{NO}_{2}{ }^{+}$ & 147 & $55 . \%$ & $\mathrm{Na}\left(\mathrm{NO}_{3}\right)_{2}$ \\
\hline 101 & $19 . \%$ & $\mathrm{Na}_{3} \mathrm{O}_{2}^{+}$ & & & \\
\hline 108 & 35. $\%$ & $\mathrm{Na}_{2} \mathrm{NO}_{3}{ }^{+}$ & & & \\
\hline 147 & $3.7 \%$ & $\left(\mathrm{Na}_{2} \mathrm{O}\right)_{2} \mathrm{Na}^{+}$ & & & \\
\hline 163 & $1.5 \%$ & & & & \\
\hline 165 & $2.1 \%$ & $(\mathrm{NaOH})_{2}\left(\mathrm{Na}_{2} \mathrm{O}\right) \mathrm{Na}^{+}$ & & & \\
\hline
\end{tabular}




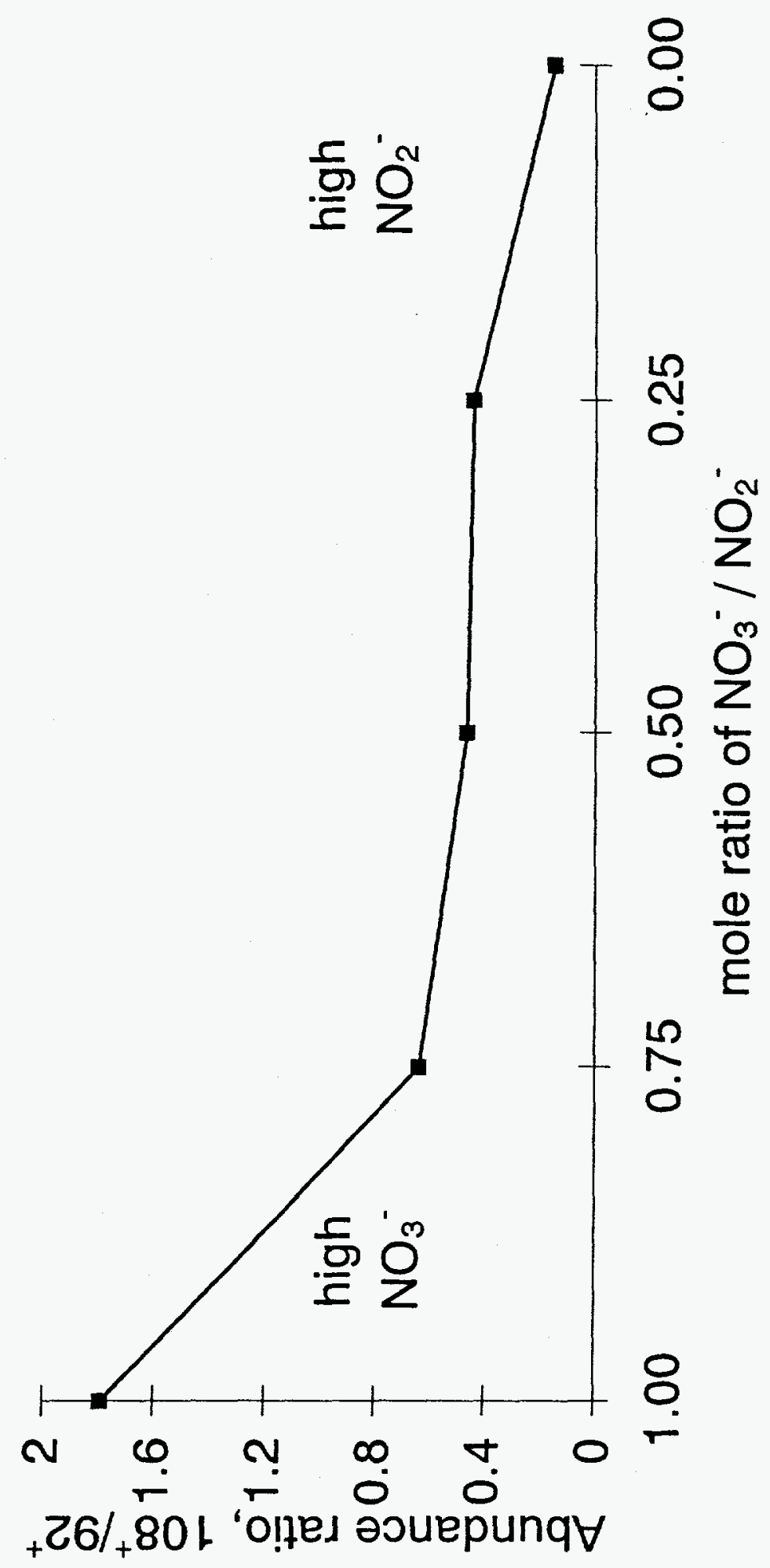

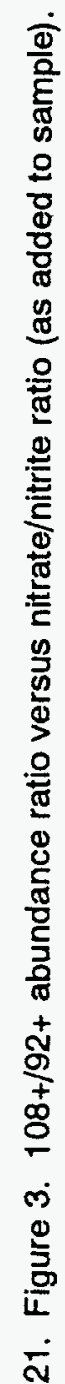




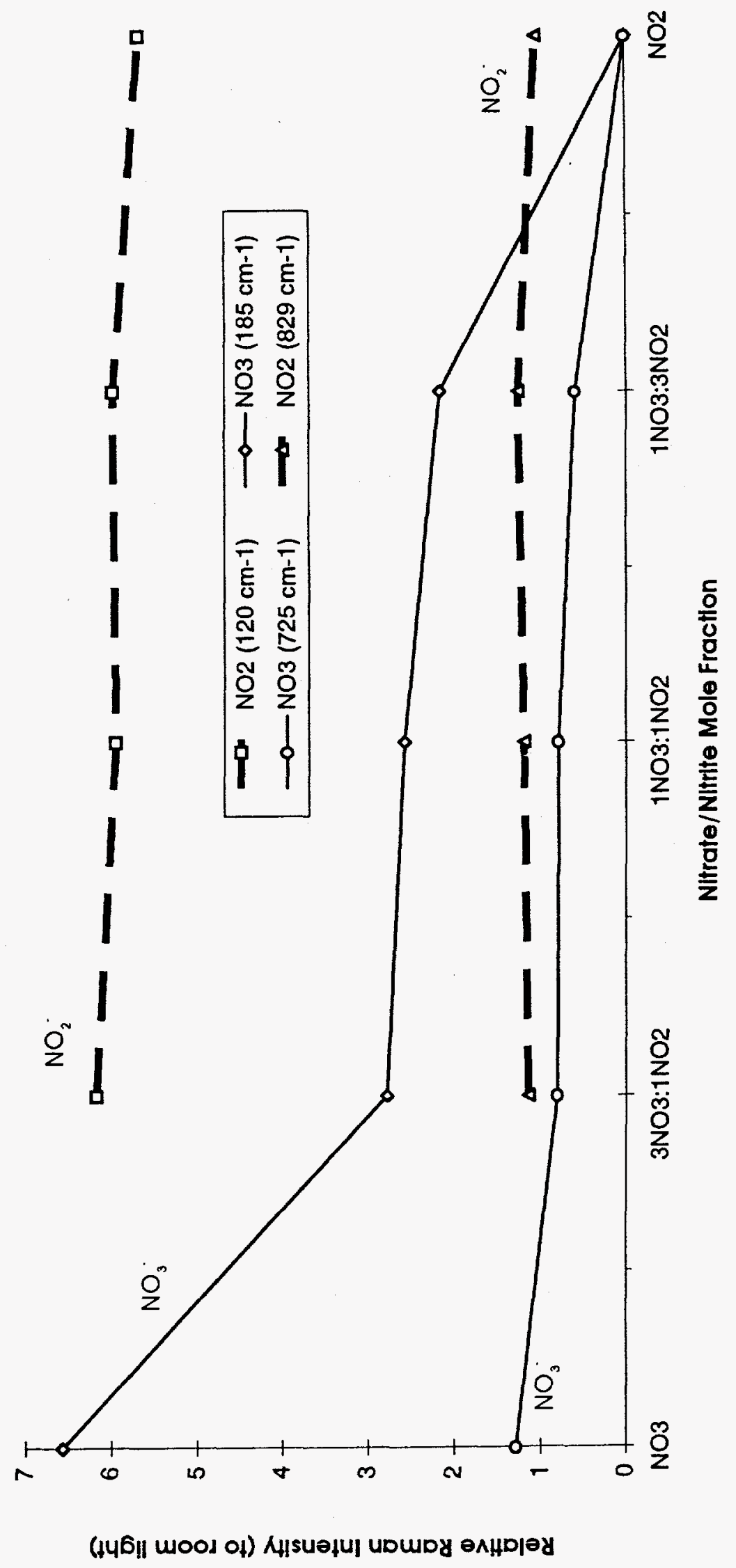

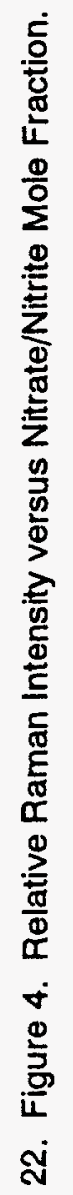


2.2.4. $\mathrm{Na}_{2} \mathrm{CO}_{2}$. The cation SIMS spectrum of sodium carbonate (Table 7) is qualitatively very similar to that recorded for $\mathrm{NaOH}$ in that the most abundant ions correspond to $\mathrm{Na}^{+}, \mathrm{Na}_{2} \mathrm{O}^{+}, \mathrm{Na}_{2} \mathrm{OH}^{+}, \mathrm{Na}_{3} \mathrm{O}^{+}$, and $\mathrm{Na}_{3} \mathrm{CO}_{3}{ }^{+}$. Unsurprisingly, the abundance of $\mathrm{Na}_{3} \mathrm{CO}_{3}{ }^{+}$is about three times greater in the present analysis than in the case of $\mathrm{NaOH}$. The anion spectrum contains little information relative to the carbonate moiety, with the exception of low abundance ions corresponding to $\mathrm{HCO}_{3}{ }^{\circ}$ and $\mathrm{CO}_{3}{ }^{\circ}$ at $\mathrm{m} / 261^{\circ}$ and $60^{\circ} . \mathrm{PO}_{3}{ }^{\circ}$ and $\mathrm{PO}_{2}{ }^{\circ}$ are present as the result of atmospheric phosphate contamination in our lab atmosphere (INEL).

\begin{tabular}{|c|c|c|c|c|c|}
\hline $\begin{array}{l}\text { Cation } \\
\text { mass }\end{array}$ & $\begin{array}{l}\text { Gation } \\
\text { r.a. }\end{array}$ & Cation assignment & \begin{tabular}{|l|} 
Anion \\
mass
\end{tabular} & $\begin{array}{l}\text { Anion } \\
\text { r.a. }\end{array}$ & Anion assignment \\
\hline 23 & $100 . \%$ & $\mathrm{Na}^{+}$ & 13 & $9.1 \%$ & $6 \mathrm{CH}^{\circ}$ \\
\hline 46 & $2.4 \%$ & $\mathrm{Na}_{2}{ }^{+}$ & 16 & $100 . \%$ & 60 \\
\hline 47 & $1.1 \%$ & $\mathrm{Na}_{2} \mathrm{H}^{+}$ & 17 & $62 . \%$ & $6 \mathrm{OH}^{-}$ \\
\hline 62 & $9.8 \%$ & $\mathrm{Na}_{2} \mathrm{O}^{+}$ & 19 & $1.9 \%$ & 6 \\
\hline 63 & $17 . \%$ & $\mathrm{Na}_{2} \mathrm{OH}^{+}$ & 24 & $3.0 \%$ & $6 \mathrm{C}_{2}^{-}$ \\
\hline 78 & $2.3 \%$ & $\mathrm{Na}_{2} \mathrm{O}_{2}^{+}$ & 25 & $5.5 \%$ & $\mathrm{C}_{2} \mathrm{H}^{-}$ \\
\hline 85 & $10 . \%$ & $\mathrm{Na}_{3} \mathrm{O}^{+}$ & 26 & $1.6 \%$ & $\mathrm{CN}$ \\
\hline 101 & $1.5 \%$ & $\mathrm{Na}_{3} \mathrm{O}_{2}^{+}$ & 32 & $3.6 \%$ & $\mathrm{O}_{2}^{\circ}$ \\
\hline 102 & $1.0 \%$ & $\mathrm{Na}_{3} \mathrm{O}_{2} \mathrm{H}^{+}$ & 35 & $3.0 \%$ & $\mathrm{Cl}$ \\
\hline 103 & $1.4 \%$ & $(\mathrm{NaOH})_{2} \mathrm{Na}^{+}$ & 37 & $1.0 \%$ & $\mathrm{Cl}$ \\
\hline 125 & $1.2 \%$ & $\left(\mathrm{Na}_{2} \mathrm{O}\right)_{2} \mathrm{H}^{+}$ & 45 & $2.5 \%$ & $\mathrm{HCO}_{2}$ \\
\hline 129 & $38 . \%$ & $\mathrm{Na}_{3} \mathrm{CO}_{3}^{+}$ & 46 & $2.6 \%$ & $\mathrm{NO}_{2}^{-}$ \\
\hline 165 & $0.40 \%$ & $(\mathrm{NaOH})_{2}\left(\mathrm{Na}_{2} \mathrm{O}\right) \mathrm{Na}^{+}$ & 60 & $1.9 \%$ & $\mathrm{CO}_{3}^{\circ}$ \\
\hline 187 & $0.98 \%$ & $\left(\mathrm{Na}_{2} \mathrm{O}\right)_{3} \mathrm{H}^{+}$ & 61 & $1.2 \%$ & $\mathrm{HCO}_{3}{ }^{-}$ \\
\hline \multirow[t]{3}{*}{191} & $0.57 \%$ & $\left(\mathrm{Na}_{3} \mathrm{CO}_{3}\right)\left(\mathrm{Na}_{2} \mathrm{O}\right)^{+}$ & 62 & $2.6 \%$ & $\mathrm{NO}_{3}{ }^{-}$ \\
\hline & & & 63 & $2.6 \%$ & $\mathrm{PO}_{2}^{-}$ \\
\hline & & & 79 & $6.7 \%$ & $\mathrm{PO}_{3}$ \\
\hline
\end{tabular}


2.2.5. NaHCO. The cation and anion SIMS spectra of sodium bicarbonate (Table 8 ) is very similar to those of sodium carbonate (as well as other sodium salts). The biggest difference between the spectra of the two compounds lies in the abundance of $\mathrm{Na}_{2} \mathrm{OH}^{+}\left(\mathrm{m} / \mathrm{z} 63^{+}\right)$relative to $\mathrm{Na}_{2} \mathrm{O}^{+}\left(\mathrm{m} / \mathrm{z} 62^{+}\right)$. Unsurprisingly, the bicarbonate spectrum has more of the $\mathrm{H}$-bearing ion. A second difference is the appearance of $m / z 189^{\circ}$ in the bicarbonate spectrum, which we have attributed to $\left(\mathrm{NaCO}_{3}\right)_{2} \mathrm{Na}$, although it is unclear why this ion should appear in the bicarbonate spectrum but not in the spectrum of sodium carbonate.

\begin{tabular}{|c|c|c|c|c|c|}
\hline $\begin{array}{l}\text { Cation } \\
\text { mass }\end{array}$ & $\begin{array}{l}\text { Cation } \\
\text { R.A. }\end{array}$ & Cation assignments & \begin{tabular}{|l|} 
Anion \\
mass
\end{tabular} & $\begin{array}{l}\text { Anion } \\
\text { R.A. }\end{array}$ & Anion assignments \\
\hline 23 & $100 . \%$ & $\mathrm{Na}^{+}$ & 13 & $11 . \%$ & $\mathrm{CH}^{-}$ \\
\hline 27 & $1.3 \%$ & $\mathrm{C}_{2} \mathrm{H}_{3}^{+}$ & 16 & $100 . \%$ & $0^{-}$ \\
\hline 29 & $1.1 \%$ & $\mathrm{CHO}^{+}$ & 17 & $68 . \%$ & $\mathrm{OH}^{\circ}$ \\
\hline 39 & $5.4 \%$ & $\mathrm{~K}^{+}, \mathrm{NaO}^{+}$ & 19 & $1.5 \%$ & $F^{-}$ \\
\hline 41 & $1.9 \%$ & $\mathrm{NaOH}_{2}{ }^{+}, \mathrm{C}_{3} \mathrm{H}_{5}{ }^{+}$ & 24 & $3.5 \%$ & $\mathrm{C}_{2}^{-}$ \\
\hline 46 & $2.4 \%$ & $\mathrm{Na}_{2}^{+}$ & 25 & $10 . \%$ & $\mathrm{C}_{2} \mathrm{H}^{-}$ \\
\hline 47 & $1.4 \%$ & $\mathrm{Na}_{2} \mathrm{H}^{+}$ & 32 & $3.8 \%$ & $\mathrm{O}_{2}^{-}$ \\
\hline 62 & $13 . \%$ & $\mathrm{Na}_{2} \mathrm{O}^{+}$ & 35 & $9.8 \%$ & $\mathrm{Cl}^{-}$ \\
\hline 63 & $63 . \%$ & $\mathrm{Na}_{2} \mathrm{OH}^{+}$ & 37 & $3.3 \%$ & $\mathrm{Cl}^{-}$ \\
\hline 78 & $2.9 \%$ & $\mathrm{Na}_{2} \mathrm{O}_{2}{ }^{+}$ & 45 & $13 . \%$ & $\mathrm{HCO}_{2}^{-}$ \\
\hline 79 & $1.7 \%$ & $\mathrm{Na}_{2} \mathrm{O}_{2} \mathrm{H}^{+}$ & 60 & $6.8 \%$ & $\mathrm{CO}_{3}^{\circ}$ \\
\hline 85 & $7.1 \%$ & $\mathrm{Na}_{3} \mathrm{O}^{+}$ & 61 & $2.6 \%$ & $\mathrm{HCO}_{3}^{-}$ \\
\hline 101 & $2.7 \%$ & $\mathrm{Na}_{3} \mathrm{O}_{2}{ }^{+}$ & 63 & $4.5 \%$ & $\mathrm{PO}_{2}^{-}$ \\
\hline 102 & $3.1 \%$ & $\mathrm{Na}_{3} \mathrm{O}_{2} \mathrm{H}^{+}$ & 79 & $15 . \%$ & $\mathrm{PO}_{3}^{-}$ \\
\hline 103 & $6.3 \%$ & $(\mathrm{NaOH})_{2} \mathrm{Na}^{+}$ & 123 & $2.6 \%$ & \\
\hline 125 & $1.4 \%$ & $\left(\mathrm{Na}_{2} \mathrm{O}\right)_{2} \mathrm{H}^{+}$ & 163 & $1.8 \%$ & \\
\hline 129 & $69 . \%$ & $\mathrm{Na}_{3} \mathrm{CO}_{3}{ }^{+}$ & 189 & $4.0 \%$ & $\left(\mathrm{CO}_{3}\right)_{2} \mathrm{Na}_{3}^{-}$ \\
\hline 145 & $1.9 \%$ & $\mathrm{Na}_{3} \mathrm{CO}_{4}^{+}$ & & & \\
\hline 169 & $0.89 \%$ & $(\mathrm{NaOH})_{2}\left(\mathrm{Na}_{2} \mathrm{O}\right) \mathrm{Na}^{+}$ & & & \\
\hline 187 & $0.71 \%$ & $\left(\mathrm{Na}_{2} \mathrm{O}\right)_{3} \mathrm{H}^{+}$ & & & \\
\hline 191 & $0.46 \%$ & $\left(\mathrm{Na}_{3} \mathrm{CO}_{3}\right)\left(\mathrm{Na}_{2} \mathrm{O}\right)^{+}$ & & & \\
\hline
\end{tabular}


2.2.6. $\mathrm{Na}$ CrO. The cation SIMS spectra of sodium chromate (Table 9) contains several higher mass ions which may be indicative of different chromium oxide species, and/or oxidation states existing on the salt surface. These are best interpreted in terms of natiated chromium oxide species, in which $\mathrm{Cr}$ would be in the $V I\left(m / z 185^{+}\right), I V\left(m / z 169^{+}\right)$, and $V\left(m / z 146^{+}\right)$states. $C r^{+}$is also observed. In the anion spectrum, the base peak corresponds to $\mathrm{CrO}_{3}{ }^{\circ}(\mathrm{Cr}(\mathrm{V})$ ). $M / Z 101^{+}$is interpreted in terms of $\mathrm{HCrO}_{3}^{-}$(IV), because the abundance of this ion is greater than what would be expected from the ${ }^{53} \mathrm{Cr}$ isotope of $\mathrm{CrO}_{3}$. Lower abundance anions at $\mathrm{m} / \mathrm{z} 84,116$ and 117 are most easily interpreted in terms of $\mathrm{CrO}_{2}^{-}(\mathrm{III}), \mathrm{CrO}_{4}^{-} \mathrm{N}$, peroxy structure) and $\mathrm{HCrO}_{4}^{-}(\mathrm{VI})$. Higher mass ions at $m / z 168,184^{\circ}, 200^{\circ}$, and $223^{\circ}$ suggest assignments containing two $\mathrm{Cr}$. If this interpretation is correct, then $\mathrm{m} / \mathrm{z} 168^{\circ}$ would correspond to $\mathrm{Cr}_{2} \mathrm{O}_{4}^{\circ}$ (III and IV), $184^{\circ}$ to $\mathrm{Cr}_{2} \mathrm{O}_{5}^{-}$(IV and V), $200^{\circ}$ to $\mathrm{Cr}_{2} \mathrm{O}_{6}^{-}\left(\mathrm{V}\right.$ and $\mathrm{VI}$ ), and 223 to $\mathrm{NaCr}_{2} \mathrm{O}_{8}^{-}(\mathrm{N}$ ).

\begin{tabular}{|c|c|c|c|c|c|}
\hline $\begin{array}{l}\text { Cation } \\
\text { mass }\end{array}$ & $\begin{array}{l}\text { Cation } \\
\text { R.A. }{ }^{i} \\
\end{array}$ & Cation assignment & $\begin{array}{l}\text { Anion } \\
\text { mass }\end{array}$ & $\begin{array}{l}\text { Anion } \\
\text { R.A. }\end{array}$ & Anion assignment \\
\hline 23 & $100 . \%$ & $\mathrm{Na}^{+}$ & 16 & $75 . \%$ & $0^{\circ}$ \\
\hline 27 & $2.2 \%$ & $\mathrm{C}_{2} \mathrm{H}_{3}^{+}$ & 17 & $50 . \%$ & $\mathrm{OH}^{-}$ \\
\hline 29 & $1.9 \%$ & $\mathrm{CHO}^{+}$ & 19 & $10 . \%$ & $F$ \\
\hline 39 & $12 . \%$ & $\mathrm{~K}^{+}, \mathrm{NaO}^{+}$ & 25 & $9.2 \%$ & $\mathrm{C}_{2} \mathrm{H}^{-}$ \\
\hline 41) & $2.6 \%$ & $\mathrm{C}_{3} \mathrm{H}_{5}^{+}$ & 26 & $3.4 \%$ & $\mathrm{CN}^{-}$ \\
\hline 43 & $0.76 \%$ & $\mathrm{C}_{3} \mathrm{H}_{7}^{+}$ & 32 & $7.1 \%$ & $\mathrm{O}_{2}^{\circ}$ \\
\hline 46 & $0.69 \%$ & $\mathrm{Na}_{2}{ }^{+}$ & 35 & $12 . \%$ & $\mathrm{Cl}^{-}$ \\
\hline 47 & $0.36 \%$ & $\mathrm{Na}_{2} \mathrm{H}^{+}$ & 37 & $5.1 \%$ & $\mathrm{Cl}^{-}$ \\
\hline 52 & $2.4 \%$ & $\mathrm{Cr}^{+}$ & 62 & $6.6 \%$ & $\mathrm{NO}_{3}^{-}(?)$ \\
\hline 53 & $0.93 \%$ & & 63 & $13 . \%$ & $\mathrm{PO}_{2}^{-}$ \\
\hline 62 & $1.8 \%$ & $\mathrm{Na}_{2} \mathrm{O}^{+}$ & 79 & $46 . \%$ & $\mathrm{PO}_{3}{ }^{-}$ \\
\hline 63 & $3.6 \%$ & $\mathrm{Na}_{2} \mathrm{OH}^{+}$ & 84 & $13 . \%$ & $\mathrm{CrO}_{2}^{\circ}$ \\
\hline 69 & $0.66 \%$ & & 85 & $4.2 \%$ & isotope \\
\hline 78 & $1.0 \%$ & $\mathrm{Na}_{2} \mathrm{O}_{2}^{+}$ & 98 & $7.3 \%$ & isotope \\
\hline 99 & $0.48 \%$ & $\mathrm{H}_{4} \mathrm{PO}_{4}^{+}$ & 99 & $5.1 \%$ & isotope \\
\hline 125 & $1.0 \%$ & unassigned & 100 & $100 . \%$ & $\mathrm{CrO}_{3}^{-}$ \\
\hline 146 & $1.0 \%$ & $\mathrm{Na}_{2} \mathrm{CrO}_{3}{ }^{+}$ & 101 & $24 . \%$ & $\mathrm{HCrO}_{3}$, isotope \\
\hline
\end{tabular}


Table 9 (continued from page 25). Salient cations and anions observed in the spectra of $\mathrm{Na}_{2} \mathrm{CrO}_{4}$. Spectra were acquired using the $\mathrm{ReO}_{4}{ }^{\circ}$ quad SIMS.

\begin{tabular}{|c|c|c|c|c|c|}
\hline $\begin{array}{l}\text { Cation } \\
\text { mass } \\
\end{array}$ & $\begin{array}{l}\text { Cation } \\
\text { R.A. }\end{array}$ & Cation assignment & \begin{tabular}{|l|} 
Anion \\
mass \\
\end{tabular} & \begin{tabular}{|l|} 
Anion \\
R.A. $^{\prime}$ \\
\end{tabular} & Anion assignment \\
\hline 169 & $1.1 \%$ & $\mathrm{Na}_{3} \mathrm{CrO}_{3}^{+}$ & 102 & $5.3 . \%$ & isotope \\
\hline \multirow[t]{17}{*}{185} & $1.7 \%$ & $\mathrm{Na}_{3} \mathrm{CrO}_{4}{ }^{+}$, or $\mathrm{HCr}_{2} \mathrm{O}_{5}{ }^{+}$ & 103 & $2.2 \%$ & isotope \\
\hline & & & 116 & $10 . \%$ & $\mathrm{CrO}_{4}^{-}$ \\
\hline & & & 117 & $8.3 \%$ & isotope \\
\hline & & & 137 & $2.0 \%$ & \\
\hline & & & 139 & $3.1 \%$ & \\
\hline & & & 168 & $5.3 \%$ & $\mathrm{Cr}_{2} \mathrm{O}_{4}^{-}$ \\
\hline & & & 169 & $2.0 \%$ & isotope \\
\hline & & & 170 & $1.4 \%$ & isotope \\
\hline & & & 182 & $1.5 \%$ & isotope \\
\hline & & & 183 & $1.7 \%$ & isotope \\
\hline & & & 184 & $14 . \%$ & $\mathrm{Cr}_{2} \mathrm{O}_{5}^{-}$ \\
\hline & & & 185 & $4.8 \%$ & isotope \\
\hline & & & 186 & $1.7 \%$ & isotope \\
\hline & & & 200 & $3.9 \%$ & $\mathrm{Cr}_{2} \mathrm{O}_{8}^{-}$ \\
\hline & & & 201 & $1.53 \%$ & isotope \\
\hline & & & 202 & $1.53 \%$ & isotope \\
\hline & & & 223 & $2.04 \%$ & $\mathrm{NaCr}_{2} \mathrm{O}_{6}^{-}$ \\
\hline
\end{tabular}

2.2.7. NaHSO. The cation SIMS spectra of sodium bisulfate (Table 10) contains a number of ions which result from surface hydrocarbon contamination; nevertheless, the salient ions derived from the sodium bisulfate are observed and correspond to $\mathrm{Na}^{+}, \mathrm{Na}_{2} \mathrm{HSO}_{4}^{+}\left(\mathrm{m} / 2143^{+}\right)$, and $\mathrm{Na}_{3} \mathrm{SO}_{4}^{+}\left(\mathrm{m} / \mathrm{z} 165^{+}\right)$. An abundant ion at $\mathrm{m} / 297\left(\mathrm{HSO}_{4}\right)$ was the most significant in the anion spectrum. Surprisingly, the natiated form of this ion $\left(\mathrm{NaSO}_{4}\right)$ was observed only at very low abundance. 


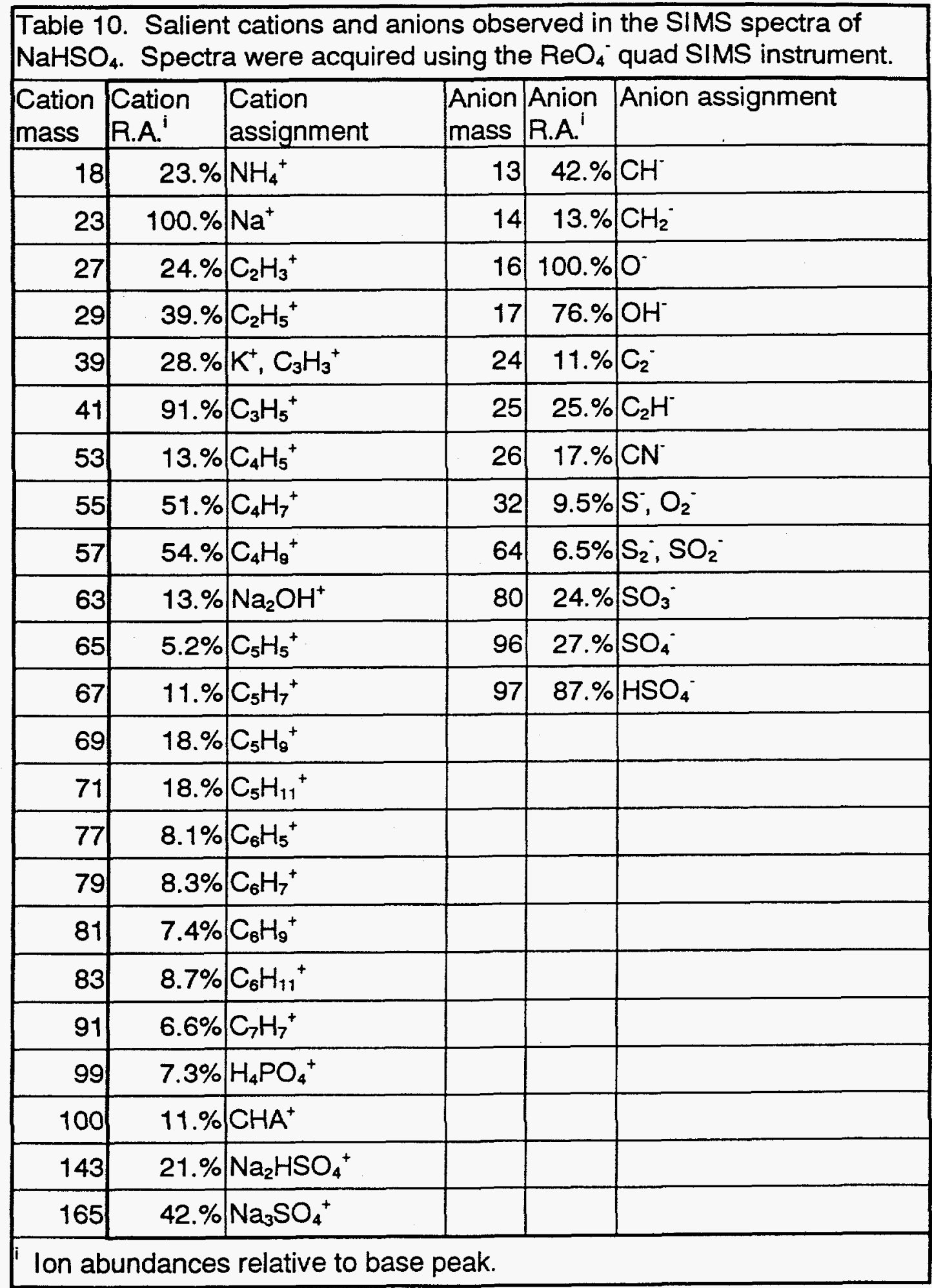


2.2.8. $\mathrm{Na}_{2} \mathrm{HPO}_{\text {. }}$. The cation SIMS spectra of disodium phosphate (Table 11) contains the expected peaks corresponding to $\mathrm{Na}^{+}$and $\mathrm{Na}_{2} \mathrm{OH}^{+}$, as well as some hydrocarbon surface contamination. Ions which are more structurally significant are $\mathrm{m} / \mathrm{z} 187^{+}$and $165^{\circ}$, which contain the intact phosphate moiety. The most abundant ions in the anion spectrum correspond to $\mathrm{PO}_{3}{ }^{-}(\mathrm{m} / \mathrm{z} 79)$ and $\mathrm{PO}_{2}{ }_{2}(\mathrm{~m} / \mathrm{z}$ 63). These ions are typical of phosphate and phosphonate compounds.' The disodium forms of these ions are also observed in the cation spectrum at $\mathrm{m} / \mathrm{z}$ $109^{+}$and $125^{+}$.

\begin{tabular}{|c|c|c|c|c|c|}
\hline \begin{tabular}{|l|} 
Cation \\
mass
\end{tabular} & $\begin{array}{l}\text { Cation } \\
\text { R.A. }\end{array}$ & $\begin{array}{l}\text { Cation } \\
\text { assignments }\end{array}$ & \begin{tabular}{|l|} 
Anion \\
mass
\end{tabular} & $\begin{array}{l}\text { Anion } \\
\text { R.A. }\end{array}$ & Anion assignments \\
\hline 23 & $100 . \%$ & $\mathrm{Na}^{+}$ & 13 & $10 . \%$ & $\mathrm{CH}^{-}$ \\
\hline 27 & $3.5 \%$ & $\mathrm{C}_{2} \mathrm{H}_{3}^{+}$ & 16 & $25 . \%$ & $0^{-}$ \\
\hline 29 & $5.1 \%$ & $\mathrm{C}_{2} \mathrm{H}_{5}^{+}$ & 17 & $24 . \%$ & $\mathrm{OH}^{-}$ \\
\hline 39 & $4.7 \%$ & $\mathrm{~K}^{+}, \mathrm{C}_{3} \mathrm{H}_{3}^{+}$ & 25 & $30 . \%$ & $\mathrm{C}_{2} \mathrm{H}^{-}$ \\
\hline 41 & $7.9 \%$ & $\mathrm{C}_{3} \mathrm{H}_{5}^{+}$ & 26 & $15 . \%$ & $\mathrm{CN}^{-}$ \\
\hline 43 & $6.6 \%$ & $\mathrm{C}_{3} \mathrm{H}_{7}^{+}$ & 35 & $6.5 \%$ & $\mathrm{Cl}^{-}$ \\
\hline 53 & $2.2 \%$ & $\mathrm{C}_{4} \mathrm{H}_{5}^{+}$ & 37 & $5.2 \%$ & $\mathrm{Cl}^{\circ}$ \\
\hline 55 & $5.4 \%$ & $\mathrm{C}_{4} \mathrm{H}_{7}^{+}$ & 41 & $15 . \%$ & \\
\hline 57 & $4.5 \%$ & $\mathrm{C}_{4} \mathrm{H}_{8}^{+}$ & 42 & $9.8 \%$ & \\
\hline 58 & $3.6 \%$ & $\mathrm{C}_{3} \mathrm{H}_{8} \mathrm{~N}^{+}$ & 43 & $9.1 \%$ & \\
\hline 62 & $2.6 \%$ & $\mathrm{Na}_{2} \mathrm{O}^{+}$ & 45 & $6.5 \%$ & \\
\hline 63 & $21 . \%$ & $\mathrm{Na}_{2} \mathrm{OH}^{+}$ & 49 & $5.1 \%$ & \\
\hline 109 & $2.6 \%$ & $\mathrm{Na}_{2} \mathrm{PO}_{2}^{+}$ & 63 & $46 . \%$ & $\mathrm{PO}_{2}^{-}$ \\
\hline 125 & $2.9 \%$ & $\mathrm{Na}_{2} \mathrm{PO}_{3}^{+}$ & 79 & $100 . \%$ & $\mathrm{PO}_{3}{ }^{-}$ \\
\hline 165 & $3.1 \%$ & $\mathrm{Na}_{3} \mathrm{HPO}_{4}^{+}$ & 80 & $9.3 \%$ & $\mathrm{PO}_{3} \mathrm{H}^{-}$ \\
\hline 187 & $2.4 \%$ & $\mathrm{Na}_{4} \mathrm{PO}_{4}^{+}$ & & & \\
\hline
\end{tabular}


2.2.9. NaHCO. The cation SIMS spectra of sodium formate (Table 12) has very abundant ions corresponding to $\mathrm{Na}^{+}, \mathrm{Na}_{2} \mathrm{OH}^{+}, \mathrm{Na}_{3} \mathrm{O}^{+}$, and $\mathrm{Na}_{3} \mathrm{CO}_{3}{ }^{+}$; in this respect, it is very similar to many of the other sodium salts that we have analyzed. In addition, a significant $\mathrm{m} / \mathrm{z} 91^{+}$is observed, which corresponds to $\mathrm{Na}_{2} \mathrm{HCO}_{2}{ }^{*}$. There is abundant evidence for formate in the anion spectrum: the base peak is $\mathrm{HCO}_{2}^{\circ}$, and $\mathrm{m} / 2113^{\circ}$ and $85^{\circ}$ also contain formate.

\begin{tabular}{|c|c|c|c|c|c|}
\hline $\begin{array}{l}\text { Cation } \\
\text { mass }\end{array}$ & $\begin{array}{l}\text { Cation } \\
\text { R.A. }\end{array}$ & Cation assignment & \begin{tabular}{|l|} 
Anion \\
mass
\end{tabular} & $\begin{array}{l}\text { Anion } \\
\text { R.A. }\end{array}$ & Anion assignment \\
\hline 23 & $100 . \%$ & $\mathrm{Na}^{+}$ & 13 & \begin{tabular}{l|l}
3 & $16 . \%$ \\
\end{tabular} & $\mathrm{CH}^{-}$ \\
\hline 27 & $3.4 \%$ & $\mathrm{C}_{2} \mathrm{H}_{3}^{+}$ & 16 & \begin{tabular}{l|l}
6 & $45 . \%$ \\
\end{tabular} & $0^{\circ}$ \\
\hline 29 & $4.7 \%$ & $\mathrm{CHO}^{+}$or $\mathrm{C}_{2} \mathrm{H}_{5}{ }^{+}$ & 17 & \begin{tabular}{l|l|}
7 & $51 . \%$ \\
\end{tabular} & $\mathrm{OH}^{\circ}$ \\
\hline 39 & $3.3 \%$ & $\mathrm{C}_{3} \mathrm{H}_{3}^{+}$ & 25 & \begin{tabular}{|l|l|}
5 & $67 . \%$ \\
\end{tabular} & $\mathrm{C}_{2} \mathrm{H}^{-}$ \\
\hline 41 & $7.0 \%$ & $\mathrm{C}_{3} \mathrm{H}_{5}^{+}$ & 41 & \begin{tabular}{l|l|}
1 & $21 . \%$ \\
\end{tabular} & $\mathrm{HC}_{2} \mathrm{O}^{-}$ \\
\hline 43 & $4.1 \%$ & $\mathrm{C}_{2} \mathrm{H}_{3} \mathrm{O}^{+}$or $\mathrm{C}_{3} \mathrm{H}_{7}^{+}$ & 45 & $5100 \%$ & $\mathrm{HCO}_{2}^{-}$ \\
\hline 46 & $3.1 \%$ & $\mathrm{Na}_{2}^{+}$ & 55 & \begin{tabular}{|l|l|}
5 & $14 . \%$ \\
\end{tabular} & $\mathrm{H}_{3} \mathrm{C}_{3} \mathrm{O}^{-}$ \\
\hline 47 & $8.1 \%$ & $\mathrm{Na}_{2} \mathrm{H}^{+}$ & 69 & $\begin{array}{ll}9 & 17 . \% \\
\end{array}$ & $\mathrm{H}_{5} \mathrm{C}_{4} \mathrm{O}^{\circ}$ \\
\hline 55 & $5.3 \%$ & $\mathrm{C}_{4} \mathrm{H}_{7}^{+}$ & 71 & \begin{tabular}{l|l|}
$10 . \%$ \\
\end{tabular} & \\
\hline 57 & $2.6 \%$ & $\mathrm{C}_{3} \mathrm{H}_{5} \mathrm{O}^{+}$ & 85 & \begin{tabular}{|l|l|}
5 & $12 . \%$ \\
\end{tabular} & $\mathrm{Na}(\mathrm{OH})\left(\mathrm{HCO}_{2}\right)^{-}$ \\
\hline 62 & $3.1 \%$ & $\mathrm{Na}_{2} \mathrm{O}^{+}$ & 113 & \begin{tabular}{|l|l|}
3 & $37 . \%$ \\
\end{tabular} & $\mathrm{Na}\left(\mathrm{HCO}_{2}\right)_{2}^{-}$ \\
\hline 63 & $55 . \%$ & $\mathrm{Na}_{2} \mathrm{OH}^{+}$ & & & \\
\hline 85 & $6 . \%$ & $\mathrm{Na}_{3} \mathrm{O}^{+}$ & & & \\
\hline 91 & $10 . \%$ & $\mathrm{Na}_{2} \mathrm{HCO}_{2}^{+}$ & & & \\
\hline 103 & $4.1 \%$ & $(\mathrm{NaOH})_{2} \mathrm{Na}^{+}$ & & & \\
\hline 113 & $2.3 \%$ & $\mathrm{Na}_{3} \mathrm{CO}_{2}^{+}$ & & & \\
\hline 129 & $13 . \%$ & $\mathrm{Na}_{3} \mathrm{CO}_{3}{ }^{+}$ & & & \\
\hline \multicolumn{6}{|c|}{ Ion abundances relative to base peak. } \\
\hline
\end{tabular}




\subsubsection{Conclusions: Analysis of Nitrate/Nitrite Salt Wastes}

The use of SIMS for gaining a quantitative description of speciation in complex salt samples is beyond the capability of SIMS at the present time, as demonstrated by the fact that sample 1 was indistinguishable from sample 2. Nevertheless, the studies presented herein show that the SIMS spectra do permit generalizations which appear to be accurate in the context of salt species actually added to the simulated salt sample. Specifically:

- The SIMS spectra of many of the sodium salts are dominated by $\mathrm{Na} / \mathrm{O}$ bearing ions, presumably due to their stability and facile formation during ion bombardment;

- $\mathrm{OH}^{-}$appears to be a gross indicator of the hydroxide content;

- $\mathrm{Na}_{2} \mathrm{NO}_{3}{ }^{+} / \mathrm{Na}_{2} \mathrm{NO}_{2}{ }^{+}$has potential for nitrate/nitrite distinction;

- organic acids (especially formic) are readily observed using SIMS, but may not represent the sample bulk;

- peroxide species are observed using SIMS;

- aluminum oxide species are observed in the anion spectra;

In addition, it appears that there is an advantage in using a molecular primary ion as opposed to an atomic, as evidenced by greater relative abundances in the higher mass, molecular secondary ions in the spectra collected using the $\mathrm{ReO}_{4}{ }^{-}$ quad SIMS instrument. Furthermore, many significant species cannot be unequivocally identified without high resolution, accurate mass measurement capability (such as is available on the TOF SIMS instrument). A good example of this capability is the identification of the aluminum oxide anions, which were indistinguishable from isobaric ions in the spectra collected using the quad SIMS.

\subsubsection{References}

1 "Detection of Alkyl Methylphosphonic Acids on Leaf Surfaces by Static Secondary Ion Mass Spectrometry", Ingram, J. C., Groenewold, G. S., Appelhans, A. D., Delmore, J. E., Dahl, D. A., Anal. Chem., in press. 


\subsection{Simulated Ferrocyanide Salt Waste}

2.3.1. Composition of Ferrocyanide Salt Samples 3 and 4. The simulated ferrocyanide salt samples were less complex than the nitrate/nitrite samples in terms of the number of components added. The samples consist primarily of sodium nitrate, with a significant quantity of nitrite and sodium nickel ferrocyanide, and a minor quantity of sulfate. The composition of two samples ( 3 and 4), described in terms of the relative number of moles added, is given in Table 13. Note that sample 3 is identical to sample 4, except for the fact that sample 4 contains $10 \%$ additional sodium nickel ferrocyanide. The purpose of adding additional sodium nickel ferrocyanide was to determine if small differences in the quantitative composition could be identified using the SIMS spectrum.

\begin{tabular}{|c|c|c|}
\hline Component & Sample 3 & Sample 4 \\
\hline $\mathrm{NaNO}_{3}$ & 1.000 & 1.000 \\
\hline $\mathrm{NaNO}_{2}$ & 0.100 & 0.100 \\
\hline $\mathrm{Na}_{3} \mathrm{NO}_{3} \mathrm{SO}_{4}-\mathrm{H}_{2} \mathrm{O}$ & 0.010 & 0.010 \\
\hline $\mathrm{Na}_{2} \mathrm{NiFe}(\mathrm{CN})_{6}$ & 0.220 & 0.242 \\
\hline
\end{tabular}

\subsubsection{SIMS Spectra, Simulated Ferrocyanide Salt Waste}

The cation SIMS spectrum (Table 14, Figure 5) of sample 3 contains a very abundant $\mathrm{Na}^{+}$, and other ions indicative of sodium salts, namely $\mathrm{Na}_{2} \mathrm{O}^{+}, \mathrm{Na}_{2} \mathrm{OH}^{+}$, $\mathrm{Na}_{2} \mathrm{O}_{2}{ }^{+}, \mathrm{Na}_{3} \mathrm{O}^{+}, \mathrm{Na}_{3} \mathrm{O}_{2}{ }^{+}$and $\mathrm{Na}_{3} \mathrm{CO}_{3}{ }^{+}$. Sodium nitrate and nitrite-bearing ions were observed at $\mathrm{m} / \mathrm{z} 92^{+}$and $108^{+}$. The abundance ratio $108^{+} / 92^{+}$was measured at 0.8 , which is consistent with a mixed nitrate/nitrite sample (see Figure 3 ). Cyanide was observable in the form of an abundant $\mathrm{Na}_{2} \mathrm{CN}$, and a less abundant $\mathrm{Na}_{3}(\mathrm{CN})_{2}{ }^{+}$. A low abundance ion at $\mathrm{m} / 256^{+}$is attributed to $\mathrm{Fe}^{+}$, and ions at $\mathrm{m} / \mathrm{z} 156^{*} / 158^{+}$are best interpreted in terms of Ni(SO $)^{*}$. Significant ions observed at $\mathrm{m} / z 187^{*}, 165^{*}$, and $125^{+}$indicate the presence of phosphate (as do $m / z 79^{\circ}$ and 63$)$; this is surprising in that no phosphate was reported to have been added to the simulated salt sample. The appearance of $\mathrm{m} / z 133^{+}$is also surprising, because it is normally attributable to $\mathrm{Cs}^{*}$, but no $\mathrm{Cs}^{+}$was reported to have been added. 


\begin{tabular}{|c|c|c|}
\hline \begin{tabular}{|l|c} 
Cation Mass & \\
\end{tabular} & Cation r.a.' & Cation Assignment \\
\hline 23 & $100 . \%$ & $\mathrm{Na}^{+}$ \\
\hline 27 & $0.73 \%$ & $\mathrm{C}_{2} \mathrm{H}_{3}{ }^{+}$ \\
\hline 29 & $0.60 \%$ & $6 \mathrm{CHO}^{+}, \mathrm{C}_{2} \mathrm{H}_{5}^{+}$ \\
\hline 39 & $0.59 \%$ & $6 \mathrm{C}_{3} \mathrm{H}_{3}{ }^{+}, \mathrm{K}^{+}$ \\
\hline 41 & $0.63 \%$ & $\mathrm{C}_{2} \mathrm{OH}^{+}, \mathrm{C}_{3} \mathrm{H}_{5}^{+}$ \\
\hline 46 & $0.64 \%$ & $\mathrm{Na}_{2}{ }^{+}$ \\
\hline 56 & $0.35 \%$ & $6 \mathrm{Fe}^{+}$ \\
\hline 62 & $4.9 \%$ & $\mathrm{Na}_{2} \mathrm{O}^{+}$ \\
\hline 63 & $3.2 \%$ & $\mathrm{Na}_{2} \mathrm{OH}^{+}$ \\
\hline 72 & $7.8 \%$ & $\mathrm{Na}_{2} \mathrm{CN}^{+}$ \\
\hline 78 & $2.0 \%$ & $\mathrm{Na}_{2} \mathrm{O}_{2}^{+}$ \\
\hline 85 & $3.4 \%$ & $\mathrm{Na}_{3} \mathrm{O}^{+}$ \\
\hline 88 & $0.70 \%$ & \\
\hline 92 & $1.6 \%$ & $\mathrm{Na}_{2} \mathrm{NO}_{2}{ }^{+}$ \\
\hline 101 & $1.7 \%$ & $\mathrm{Na}_{3} \mathrm{O}_{2}^{+}$ \\
\hline 108 & $1.1 \%$ & $\mathrm{Na}_{2} \mathrm{NO}_{3}{ }^{+}$ \\
\hline 121 & $0.47 \%$ & $\mathrm{Na}_{3}(\mathrm{CN})_{2}^{+}$ \\
\hline 125 & $0.56 \%$ & $\mathrm{Na}_{2} \mathrm{PO}_{3}{ }^{+}$ \\
\hline 129 & $0.92 \%$ & $\mathrm{Na}_{3} \mathrm{CO}_{3}{ }^{+}$ \\
\hline 133 & $0.48 \%$ & $\mathrm{Cs}^{+}$ \\
\hline 147 & $0.42 \%$ & \\
\hline 149 & $0.50 \%$ & $\mathrm{C}_{8} \mathrm{H}_{5} \mathrm{O}_{4}^{+}$ \\
\hline 156 & $0.63 \%$ & $\mathrm{NiSO}_{4}^{+}$ \\
\hline 158 & $0.27 \%$ & $\mathrm{NiSO}_{4}{ }^{+}$ \\
\hline 165 & $0.59 \%$ & $\mathrm{Na}_{3} \mathrm{SO}_{4}{ }^{+}$or $\mathrm{Na}_{3} \mathrm{HPO}_{4}{ }^{+}$ \\
\hline 187 & $0.39 \%$ & $\mathrm{Na}_{4} \mathrm{PO}_{4}^{+}$ \\
\hline
\end{tabular}


The most abundant ion in the anion spectrum is $\mathrm{CN}$, and relatively abundant $\mathrm{Na}$, $\mathrm{Fe}$ and $\mathrm{Ni}$ cyanide complexes are also readily observable at $\mathrm{m} / \mathrm{z} 75,108,110$, $112,134^{\circ}, 136^{\circ}$, and $138^{\circ}$ (Table 15, Figure 6). For $\mathrm{Fe}$ and $\mathrm{Ni}$, the appearance of two complexes is interpreted in terms of two gas-phase oxidation states. For ease of comparison, these ions and their abundances were extracted into Table 16.

\begin{tabular}{|c|c|c|}
\hline $\begin{array}{l}\text { Table 15. An } \\
\text { waste salt, ac }\end{array}$ & $\begin{array}{l}\text { hion SIMS sp } \\
\text { quired using }\end{array}$ & $\begin{array}{l}\text { ectrum of simulatec } \\
\mathrm{ReO}_{4} \text { quad SIMS ir }\end{array}$ \\
\hline Anion mass & Anion r.a.' & Anion assignment \\
\hline 16 & $23 . \%$ & $10^{\circ}$ \\
\hline 17 & $8.9 \%$ & $\mathrm{OH}^{-}$ \\
\hline 19 & $1.2 \%$ & $F^{-}$ \\
\hline 24 & $1.9 \%$ & $\mathrm{C}_{2}^{-}$ \\
\hline 25 & $3.8 \%$ & $\mathrm{C}_{2} \mathrm{H}^{-}$ \\
\hline 26 & $100 . \%$ & $\mathrm{CN}^{-}$ \\
\hline 30 & $1.2 \%$ & $\mathrm{~N}_{2} \mathrm{H}_{2}$ \\
\hline 32 & $1.9 \%$ & $\mathrm{O}_{2}$ \\
\hline 42 & $4.6 \%$ & $\mathrm{CNO}^{\circ}$ \\
\hline 46 & $4.7 \%$ & $\sqrt[\mathrm{NO}_{2}]{-}$ \\
\hline 62 & $3.7 \%$ & $\mathrm{NO}_{3}$ \\
\hline 63 & $1.5 \%$ & $\mathrm{PO}_{2}^{-}$ \\
\hline 64 & $1.2 \%$ & \\
\hline 75 & $1.5 \%$ & $\mathrm{Na}(\mathrm{CN})_{2}$ \\
\hline 79 & $3.1 \%$ & $\mathrm{PO}_{3}$ \\
\hline 90 & $1.8 \%$ & \\
\hline 108 & $2.6 \%$ & $\mathrm{Fe}(\mathrm{CN})_{2}$ \\
\hline 110 & $14 . \%$ & $\mathrm{Ni}(\mathrm{CN})_{2}$ \\
\hline 112 & $6.6 \%$ & $\mathrm{Ni}(\mathrm{CN})_{2}$ \\
\hline 114 & $1.5 \%$ & \\
\hline 115 & $1.4 \%$ & $\mathrm{Na}\left(\mathrm{NO}_{2}\right)_{2}^{-}$ \\
\hline 124 & $1.7 \%$ & \\
\hline 126 & $1.4 \%$ & \\
\hline 134 & $6.9 \%$ & $\mathrm{Fe}(\mathrm{CN})_{3}$ \\
\hline 136 & $3.4 \%$ & $\mathrm{Ni}(\mathrm{CN})_{3}$ \\
\hline 138 & $2.4 \%$ & $\mathrm{Ni}(\mathrm{CN})_{3}$ \\
\hline 150 & $1.5 \%$ & \\
\hline
\end{tabular}




\begin{tabular}{|c|c|c|c|}
\hline$m / z$ & ion assignment & metal and state & relative abundance \\
\hline $108^{\circ}$ & $\mathrm{Fe}(\mathrm{CN})_{2}$ & $\mathrm{Fe}(I)$ & $2.6 \%$ \\
\hline $134^{\circ}$ & $\mathrm{Fe}(\mathrm{CN})_{3}$ & $\mathrm{Fe}(I I)$ & $6.9 \%$ \\
\hline $110 / 112$ & $\mathrm{Ni}(\mathrm{CN})_{2}$ & $\mathrm{Ni}(\mathrm{I})$ & $20 \%$ \\
\hline $136 / 138$ & $\mathrm{Ni}(\mathrm{CN})_{3}$ & $\mathrm{Ni}(11)$ & $5.8 \%^{\prime}$ \\
\hline
\end{tabular}

The comparison presented in Table 16 permits several conclusions: 1) the $\mathrm{Ni}$ cyanide complexes are observed more readily than $\mathrm{Fe}$ (note that the sample contained equimolar quantities of $\mathrm{Fe}$ and $\mathrm{Ni}$ ). We find this surprising in light of the solution phase formation constants, which would indicate that $\mathrm{Fe}(\mathrm{CN})_{8}^{-3}>$ $\mathrm{Fe}(\mathrm{CN})_{8}^{-}>\mathrm{Ni}(\mathrm{CN})_{4}^{-2}$. 2) The observation of the metal (II) cyanide anion is preferred in the case of $\mathrm{Fe}$, while the metal (I) cyanide anion is preferred for $\mathrm{Ni}$. 3) Both metals are reduced from the II state to the I state, albeit to different extents. The reduction may be occurring in the salt mixture, or during the SIMS bombardment; recall that both metals started in the II state $\left(\mathrm{Na}_{2} \mathrm{NiFe}(\mathrm{CN})_{6}\right)$.

The SIMS spectra of sample 4 were extremely similar to those of sample 3, with the exception of ions at $m / z 115,131^{\circ}$ and 147 , which were significantly more abundant in sample 4. These ions correspond to $\mathrm{Na}\left(\mathrm{NO}_{2}\right)_{2}, \mathrm{Na}\left(\mathrm{NO}_{2}\right)\left(\mathrm{NO}_{3}\right)^{\circ}$, and $\mathrm{Na}\left(\mathrm{NO}_{3}\right)_{2}$, and are also observed in samples that are high in nitrate. Since there are no significant differences in the nitrate concentration between samples 3 and 4 , we hypothesize that the observation is due to sample inhomogeneity, which might result from incomplete sample mixing, or salt separation upon drying. 


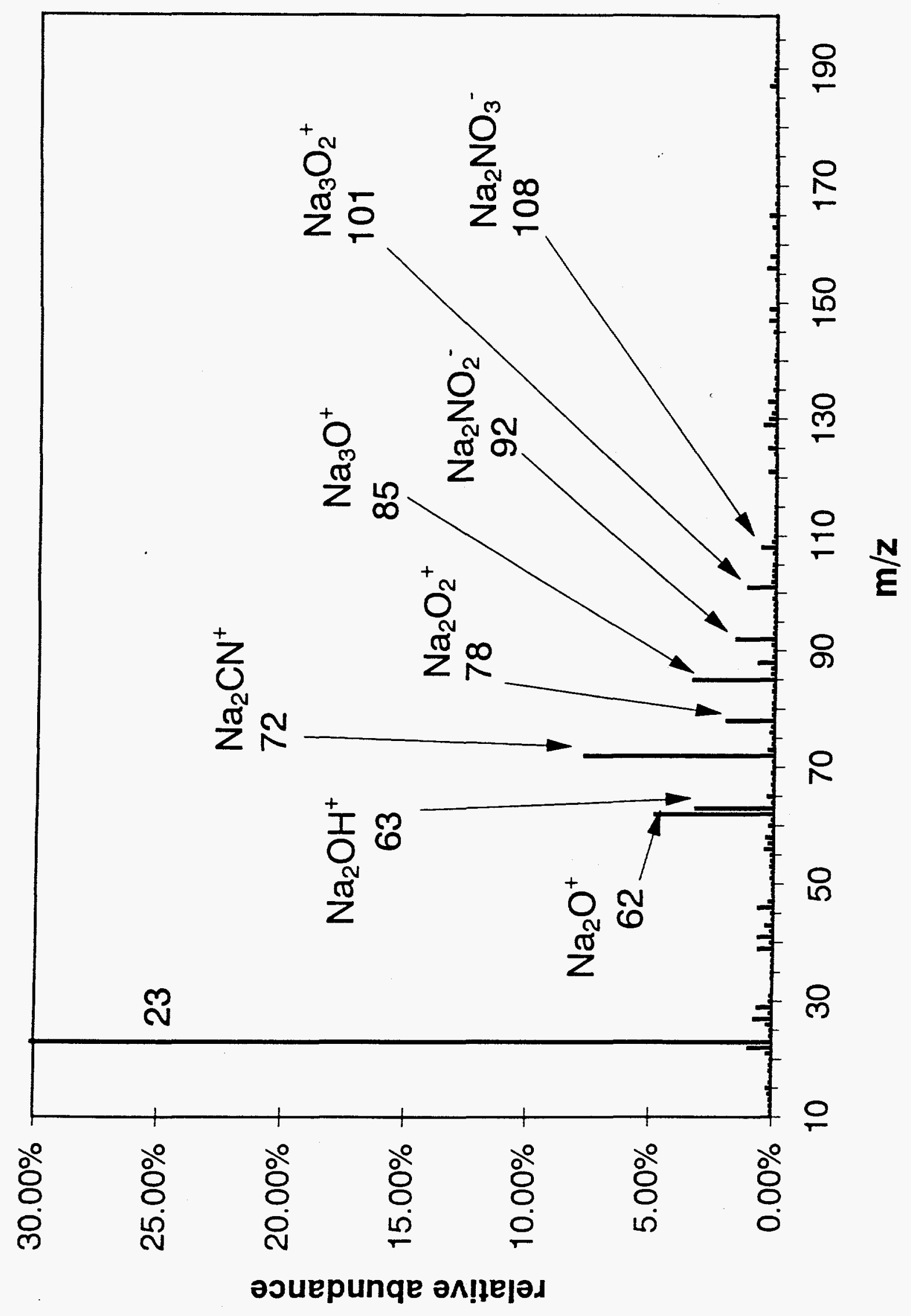




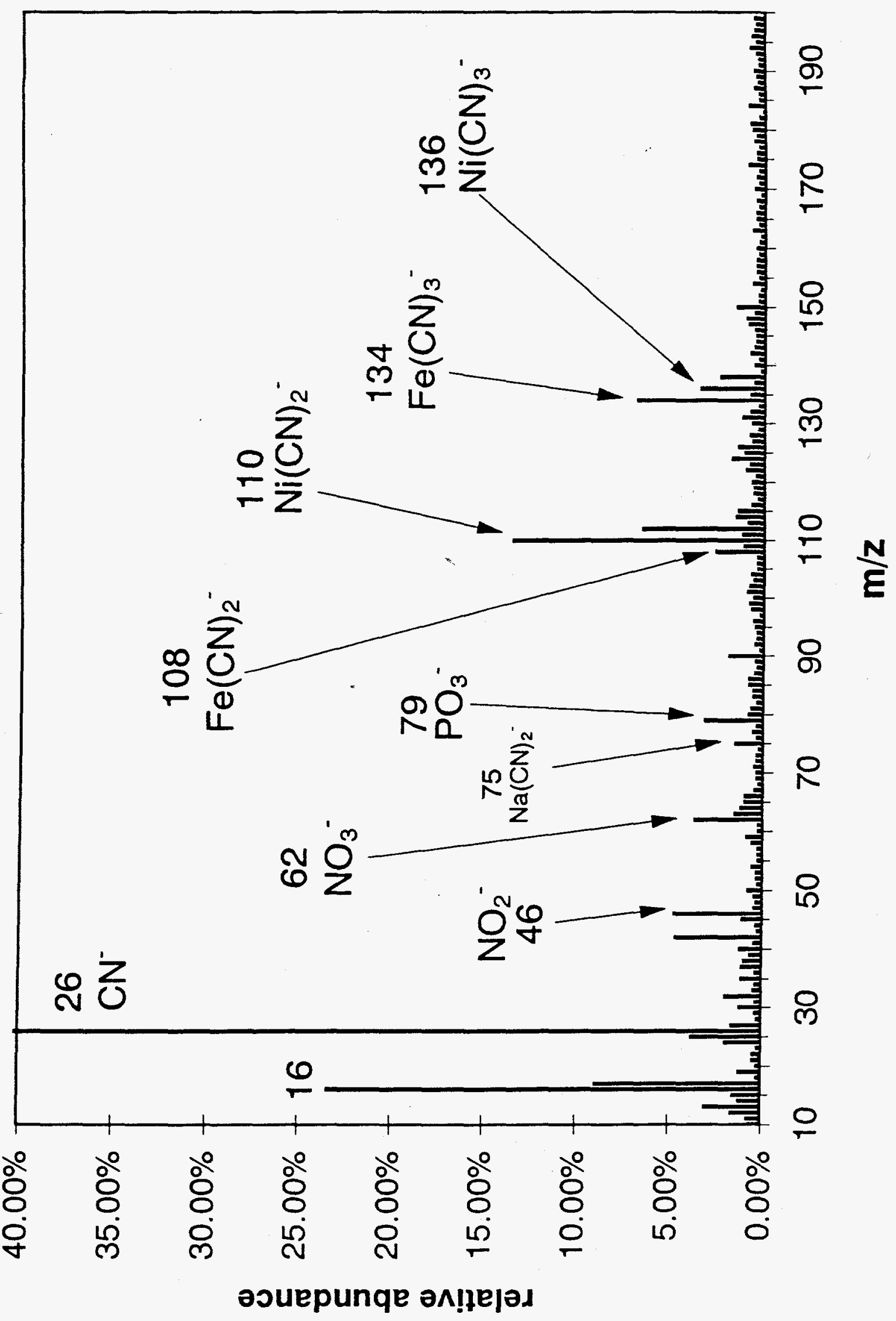


2.3.3. SIMS Spectra, Benchmark Ferrocyanide and Ferricyanide Salts. An important issue in assessing the stability of the salt waste is the ability to distinguish between ferrocyanide and ferricyanide species. For this reason, potassium ferrocyanide $\left(\mathrm{K}_{4} \mathrm{Fe}(\mathrm{CN})_{2}\right)$ and potassium ferricyanide $\left(\mathrm{K}_{3} \mathrm{Fe}(\mathrm{CN})_{\alpha}\right)$ were analyzed. Crystals of these salts were attached to a stainless steel target, and no other sample manipulation was performed prior to analysis.

The cation spectra of both salts were qualitatively and quantitatively the same (within experimental error). The only abundant ions corresponded to $\mathrm{K}^{+}, \mathrm{K}_{2}(\mathrm{CN})^{+}$, and a much smaller $\mathrm{K}_{3}(\mathrm{CN})_{2}{ }^{*}$ ion (Table 17).

\begin{tabular}{|c|c|c|}
\hline Cation mass & $\mathrm{K}_{3} \mathrm{Fe}(\mathrm{CN})_{6}^{i}$ & $\mathrm{~K}_{4} \mathrm{Fe}(\mathrm{CN})_{8}{ }^{i}$ assignments \\
\hline 39 & $100 . \%$ & $100 . \% \mid \mathrm{K}^{+}$ \\
\hline 41 & $8.5 \%$ & $11 . \%{ }^{41} \mathrm{~K}^{+}$ \\
\hline 55 & $0.77 \%$ & $1.7 \% \mathrm{C}_{4} \mathrm{H}_{7}^{+}$ \\
\hline 56 & $1.0 \%$ & $1.1 \% / \mathrm{Fe}^{+}$ \\
\hline 57 & $0.89 \%$ & $2.2 \% \mathrm{C}_{4} \mathrm{H}_{8}^{+}$ \\
\hline 104 & $7.9 \%$ & $11 . \% / \mathrm{K}_{2} \mathrm{CN}^{+}$ \\
\hline 106 & $1.2 \%$ & $1.9 \%{ }^{41} \mathrm{~K}^{39} \mathrm{KCN}^{+}$ \\
\hline 169 & $0.20 \%$ & $0.29 \% \mid \mathrm{K}_{3}(\mathrm{CN})_{2}{ }^{+}$ \\
\hline
\end{tabular}

The anion spectra of $\mathrm{K}_{3} \mathrm{Fe}(\mathrm{CN})_{6}$ and $\mathrm{K}_{4} \mathrm{Fe}(\mathrm{CN})_{8}$ were also very similar (Table 18). The most significant difference observed was in the abundance of $\mathrm{m} / \mathrm{z} 90^{\circ}$ which was more abundant in the ferricyanide spectrum: unfortunately, the identity of this ion has not yet been unequivocally established. 


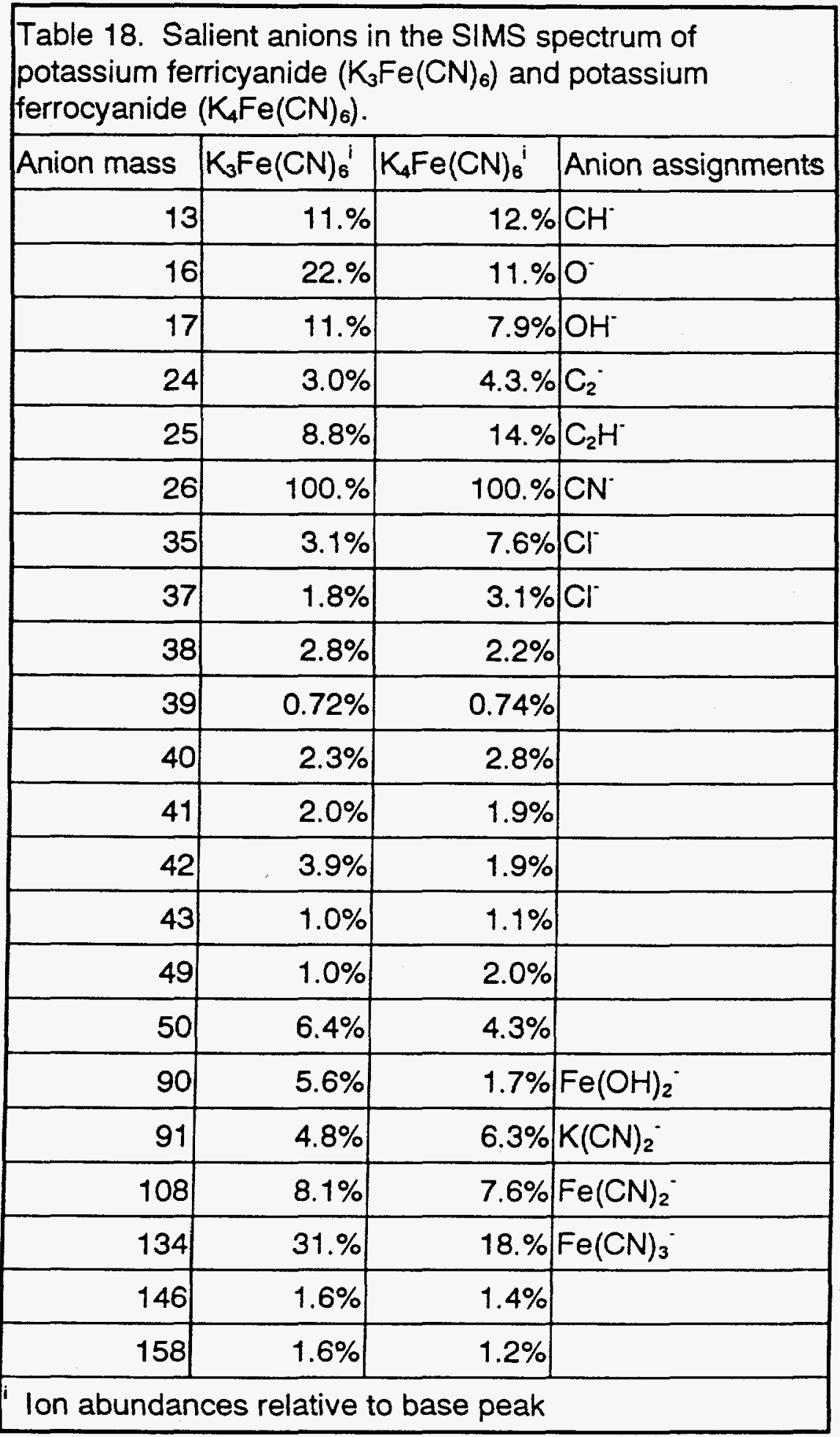

Because there appeared to be subtle differences in the abundances of $m / 2134^{\circ}$ and 108, the samples were irradiated for prolonged periods of time, in order to ablate the top one or two monolayers. We felt that this might augment spectral differences between the two salts, which might otherwise be obscured by 
surface contaminants. We adopted the ion abundance ratio of $134 / 108$ as a figure of merit for these experiments (Figure 7). In the case of the ferricyanide, the ratio slowly increases from about 3.5 to slightly greater than 4 . Given the uncertainty in our measurements, this increase is probably not significant. The $134 / 108$ ratio for the ferrocyanide, on the other hand, underwent a decrease from approximately 2.5 to about 1 after prolonged irradiation.

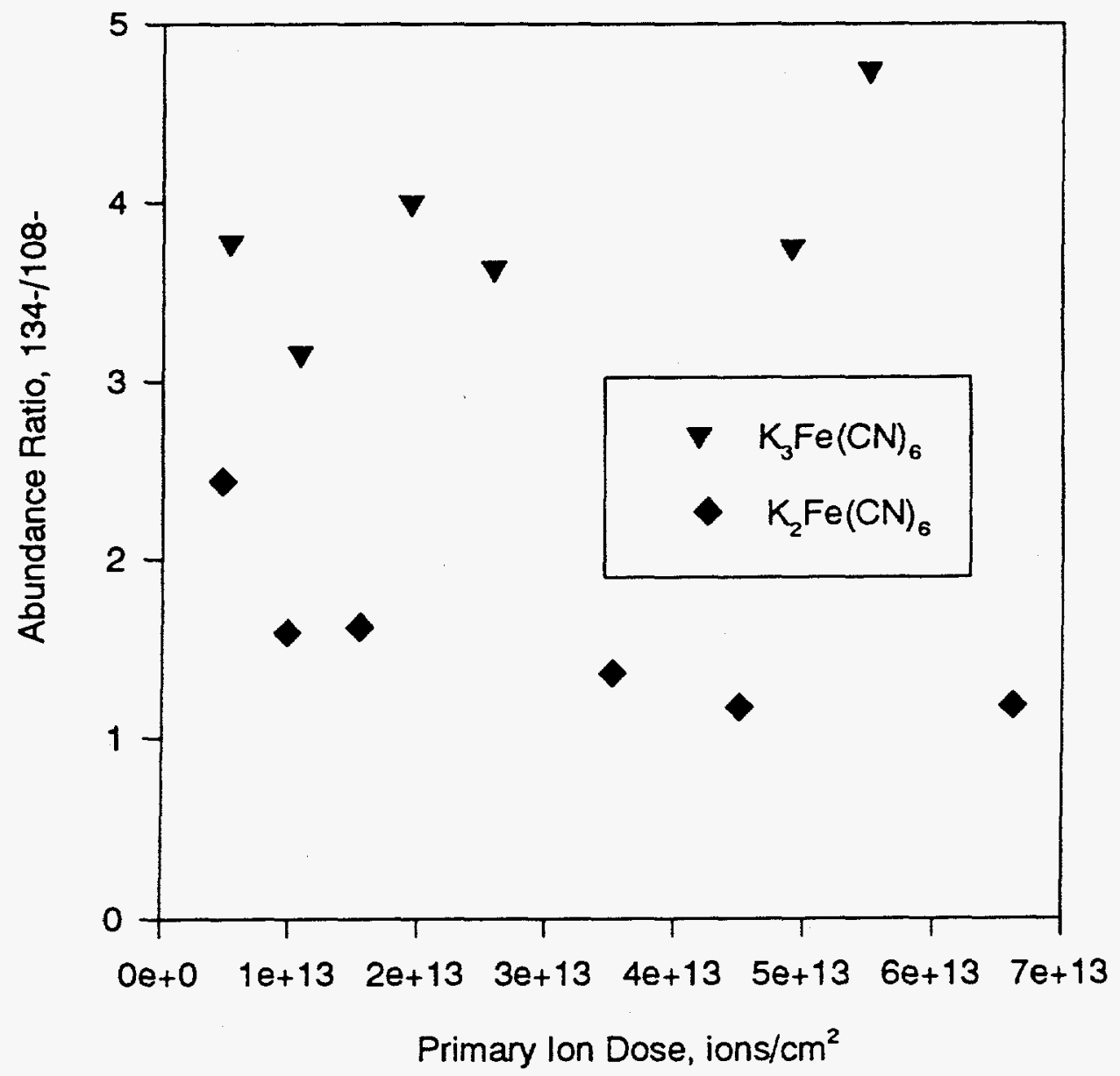

Figure 7. Ion abundance ratio of $m / 2134 / 108$ for $\mathrm{K}_{3} \mathrm{Fe}(\mathrm{CN})_{8}$ and $\mathrm{K}_{4} \mathrm{Fe}(\mathrm{CN})_{6}$.

Thus ferricyanide is somewhat more proficient at forming $m / z 134^{\circ}\left(\mathrm{Fe}(\mathrm{CN})_{3}\right.$ ) than is the ferrocyanide We speculate that the reason for the observation of enhanced $m / 2134$ in the case of the ferrocyanide after a limited dose is that the outermost layers of this salt are exposed to atmospheric oxygen, which may oxidize the $\mathrm{Fe}$ (II) to $\mathrm{Fe}(\mathrm{III})$. When the oxidized ferrocyanide is irradiated with a 
dose of about $10^{13}$ ions $/ \mathrm{cm}^{2}$ (near the 'static SIMS limit'), then a more limited propensity for the formation of $\mathrm{m} / \mathrm{z} 134$ is observed.

The production of $\mathrm{m} / \mathrm{z} 134^{\circ}$ and $108^{\circ}$ during SIMS bombardment of ferricyanide requires one and two electron reductions of $\mathrm{Fe}$ (III) (Figure 8 ). Presumably $\mathrm{m} / \mathrm{z}$ $134^{\circ}$ is more abundant because it is easier to achieve a one $e^{-}$reduction than a two e reduction required for the formation of $\mathrm{m} / \mathrm{z} 108$. There is no evidence for a reducing agent in the SIMS spectrum; it is possible that the ReO; primary ion might serve as an electron source, although we do not have a good hypothesis at this time.

$\mathrm{K}_{3} \mathrm{Fe}(\mathrm{CN})_{6}+e^{-} \longrightarrow \mathrm{Fe}(\mathrm{CN})_{3}^{-}+3 \mathrm{CN}^{-}+3 \mathrm{~K}^{+}$
$\mathrm{K}_{3} \mathrm{Fe}(\mathrm{CN})_{6}+2 \mathrm{e}^{-} \longrightarrow \mathrm{Fe}(\mathrm{CN})_{2}^{-}+4 \mathrm{CN}^{-}+3 \mathrm{~K}^{+}$

Figure 8 . Reactions proposed for the formation of $\mathrm{m} / \mathrm{z} 134$ and $108^{\circ}$ during the SIMS analysis of potassium ferricyanide.

The production of $\mathrm{m} / \mathrm{z} 134^{\circ}\left(\mathrm{Fe}(\mathrm{CN})_{3}\right)$ in the SIMS spectrum of ferrocyanide can be written as a neutral reaction (Figure 9). Yet, as primary ion bombardment proceeds, the formation of this ion becomes less prevalent compared to the formation of $\mathrm{m} / \mathrm{z}^{108}\left(\mathrm{Fe}(\mathrm{CN})_{2}\right)$, which again requires a one e reduction.

$\mathrm{K}_{4} \mathrm{Fe}(\mathrm{CN})_{6} \longrightarrow \mathrm{Fe}(\mathrm{CN})_{3}^{-}+3 \mathrm{CN}^{-}+4 \mathrm{~K}^{+}$
$\mathrm{K}_{4} \mathrm{Fe}(\mathrm{CN})_{6}+e^{-} \longrightarrow \mathrm{Fe}(\mathrm{CN})_{2}^{-}+4 \mathrm{CN}^{-}+4 \mathrm{~K}^{+}$

Figure 9 . Reactions proposed for the formation of $\mathrm{m} / \mathrm{z}^{134^{\circ}}$ and $108^{\circ}$ during the SIMS analysis of potassium ferrocyanide.

These results offer some hope of being able to distinguish between the two iron cyanide species. It might be possible to enhance spectral differences if the $\mathrm{ReO}_{4}$ primary ion gun could be used to probe salt surface subsequent to surface ablation using a high amperage (microamps) primary ion gun (e.g., $\mathrm{Cs}^{+}$) capable of ablating many monolayers.

\subsubsection{Conclusions: Analysis of Ferrocyanide Salt Wastes.}

The ReO, quadrupole SIMS instrumentation displays many of the species that are thought to be present in the simulated salt waste, including nitrate, cyanide, and ions at $m / z 134$ and $108^{\circ}$ which are representative of ferrocyanide. We note that these latter ions are also indicative of ferricyanide, but at the present time understanding has not been developed which would permit distinction between the two closely related species ferricyanide and ferrocyanide. Experiments to distinguish between the two species offer the hope that the $\mathrm{m} / \mathrm{z}^{134 / 108}$ abundance ratio is sensitive to the $\mathrm{Fe}$ oxidation state, but more experiments are necessary before the ratio may be employed for this distinction. 


\subsection{Mechanism of TBP Desorption from Surfaces}

\subsection{Introduction}

Secondary ion mass spectrometry (SIMS) has been used to characterize contaminants adsorbed to surfaces, but is generally considered insensitive to the orientation or adsorption of surface species, because it is a high energy technique. This view is consistent with experiments which employ energetic (kilovolt), atomic, primary ion guns that are operated at microamps of current: excellent elemental analyses and elemental depth profiling are achieved, but little molecular information from the top monolayer is generated. Molecular species can be observed in SIMS by using an atomic primary at lower beam current (i.e. by employing static SIMS conditions), but little is known about the relationship between the secondary ions observed and the nature of the adsorbed surface molecules. In the present paper we show that SIMS using a molecular primary ion, operated at picoamps of current, is sensitive not only to the presence of surface molecules, but also sensitive to their mode of adsorption. This indicates that at least in some cases, static SIMS is useful for understanding contaminant-surface interactions in the environment. These interactions are important because they control transport, degradation, and remediation chemistries. The system presently under study is tri-n-butyl phosphate (TBP) on basalt and quartz.

The detection of TBP on mineral surfaces is being investigated because TBP has been used extensively for the extraction of uranium and plutonium as nitrate salts from nitric acid solutions'. TBP evolved as the most attractive chemical for these processes, because the phosphoryl moiety coordinates with metals having oxidation states of III or higher to form adducts or solvates (an example of such a species is $\mathrm{UO}_{2}\left(\mathrm{NO}_{3}\right)_{2} \cdot 2 \mathrm{TBP}$ ). These species are partitioned from concentrated $\mathrm{HNO}_{3}$ solutions into organic phases, and this phenomenon is exploited in separation processes. ${ }^{1}$ Poor disposal practices for process wastes have resulted in TBP and radionuclides being buried together in uncontained landfills; as a result, TBP is a significant environmental contaminant at some DOE sites. ${ }^{2}$

SIMS investigations of TBP have been focused on basalt, because it is the predominant mineral found on the Department of Energy (DOE) Hanford site $^{3}$, and at the DOE's Idaho National Engineering Laboratory (INEL). Significant nuclear fuel reprocessing, and waste disposal activities have occurred at both sites, and at Hanford improper disposal has resulted in the release of TBP, radionuclides, and other contaminants into the environment. ${ }^{2}$ Thus basalt is an environmental medium that will have to be reckoned with during the course of characterization and remediation activities. At the present time, there are no rapid means for the analysis of TBP on basalt, and little is known about the interaction of TBP with basalt surfaces. This is partly due to the fact that basalt is an inhomogeneous mineral, consisting of many phases, ${ }^{4}$ and can have a 
highly variable surface morphology. The inhomogeneity and morphology makes contaminant-surface interactions difficult to sort out.

In the present study, SIMS was used for the analysis of TBP on basalt, because the technique is sensitive for surface contaminants, and can be performed with little or no sample preparation. ${ }^{5}{ }^{8}$ As a result, many samples could be rapidly analyzed for TBP, which allowed the SIMS spectra of TBP to be correlated with the mineral phase.

\subsection{Experimental}

3.2.1. SIMS Instrumentation. The instrument used for the majority of the studies has been described in detail previously: ${ }^{7}$ a brief description will be provided here. The instrument uses $\mathrm{ReO}_{4}$ as the primary bombarding particle, which is produced by heating a $\mathrm{Ba}\left(\mathrm{ReO}_{4}\right)_{2}$ ceramic in vacuum. "The ceramic was synthesized in our laboratories, and processed in a form that could be used as an ion source. $\mathrm{ReO}_{4}$ ions that are emitted upon heating are accelerated to 10 $\mathrm{keV}$. The ion gun was typically operated at 80 picoamps (the ion current from the gun could be continuously adjusted by adjusting the current passing through the heating element that supported the ceramic). The focusing of the primary ion gun was adjusted so that the sample was just silhouetted on an image intensifier located behind the sample. Thus, most of the primary ion beam is directed onto the target. A typical acquisition required 120 seconds, and a typical sample had an area of about $0.03 \mathrm{~cm}^{2}$; thus a normal primary ion dose was $2.0 \times 10^{12}$ ions $/ \mathrm{cm}^{2}$, which is less than the commonly accepted static SIMS limit. $^{9}$

The secondary anions and cations were extracted from the sample target region using pulsed secondary ion extraction. ${ }^{7}$ This technique alternately extracts anions and cations from the sample surface by alternating the polarity of the secondary ion extraction lens. This technique mitigates charge buildup on the surface of the sample, and thus permits facile analysis of electrically insulating samples like basalt and quartz. The ratio of [time extracting cations] / [time extracting anions] is adjustable in this instrument, and in the case of the basalt and quartz samples, a value of 3 worked well. The total period for the pulsed extraction sequence was 120 milliseconds, divided as follows: cation extraction, 84 milliseconds; electronic settle time, 4 milliseconds; anion extraction, 28 milliseconds; electronic settle time, 4 milliseconds. This sequence was repeated for each $0.2 \mathrm{u}$ step of the scan of the quadrupole secondary mass spectrometer, which was scanned from 10 to $310 \mathrm{u}$. The quadrupole was a $\mathrm{m} / \mathrm{z}$ 2 - 2000 u instrument, manufactured by Extrel, and modified in our laboratory. The quadrupole was tuned for unit mass resolution and optimum sensitivity for $\mathrm{m} / \mathrm{z} 81^{-}$and $198^{+}$in the SIMS spectrum of tetrahexyl ammonium bromide. ${ }^{10}$

Several measurements were made to verify fragmentation pathways using an ion trap SIMS instrument recently constructed in the authors' laboratory." A 
rigorous description of this instrument is beyond the scope of this paper at this date, because the instrument is still undergoing substantial refinement. Briefly, an $\mathrm{ReO}_{4}$ ion gun and an offset electron multiplier are located coaxially behind one end cap of a modified Finnigan ion trap mass spectrometer (Finnigan-MAT Corporation, San Jose, CA 95134-1991 USA). The sample, attached to a probe, is located $3 \mathrm{~mm}$ from the opposite end cap and the $\mathrm{ReO}$; beam at $3.5 \mathrm{keV}$ is focused on the sample through the ion trap. A diagram of the instrument is found in reference 11 . lons in the mass range of interest were collected using filtered noise fields applied with a Teledyne system (Teledyne Electronics Technology, Mountain View, CA 94043), and collisionally induced dissociation was performed using a supplementary RF field on the end caps.

3.2.2. Precision of SIMS data. Since the interpretations in this paper are based on measurement of relative abundances, a discussion of the precision of relative abundance measurements is appropriate. Replicate analyses of the TBP- or tributyl phosphite-exposed samples were not performed, because the adsorbed organic compounds tend to slowly desorb while in the vacuum system (pressure is $5 \times 10^{-7}$ to $5 \times 10^{-8}$ torr), thereby introducing a systematic variance to the measurements. Further, comparison of multiple samples is confounded by irregular surface morphology, and varying surface composition, which has an important effect on the secondary ion mass spectrum. Precision was addressed by analyzing an "unexposed" basalt sample on four consecutive days, normalizing the data to the base peak, and then calculating relative standard deviations for the relative abundances for each mass. Relative abundances and relative standard deviation (rsd) values are presented for selected ions in Table 19 for four replicate analyses of a single INEL basalt chip which had not been exposed to TBP. Values for rsd range from $4 \%$ to over $90 \%$. Generally, the larger rsd values are calculated for those ions having small relative abundances. Large rsd values are also calculated for some abundant ions susceptible to changing surface chemistry as the analyses proceeded. An example of an ion of this type is $m / z 23^{+}\left(\mathrm{Na}^{+}\right)$: this ion likely holds constant across the four analyses, but appears to be variable because the abundance of the base peak $\left(\mathrm{m} / \mathrm{z} 41^{+}\right)$ and many other organic ions slowly decreases as the sample is repetitively analyzed. These considerations illustrate that SIMS of organic surface contaminants is a qualitative technique at this point in time. Nevertheless, the above discussion leads us to conclude that the rsd for relative abundance measurements are within $100 \%$ for low abundance ions, and can be expected to be in the $4 \%-30 \%$ range for other more abundant ions.

Many spectra of TBP-and tributyl phosphite-exposed minerals were collected during the course of this study. For reasons documented in the preceding paragraph, it was not appropriate to average spectra of exposed minerals. The relative abundance values presented in Table 20 were instead derived from single spectra, which were chosen because they were representative of multiple experiments: the values reported were close the midrange of relative 
abundances observed in all analyses of a given compound for a given sampletype.

3.2.3. $\mathrm{Cl}$ and $\mathrm{El} \mathrm{MS}$. Chemical ionization $\left(\mathrm{CH}_{4}\right) \mathrm{GC} / \mathrm{MS}$ analyses were performed using a Hewlett Packard 5989A MS Engine interfaced to a Hewlett Packard 5890 Series II gas chromatograph. For the $\mathrm{Cl}$ experiments, the reagent gas pressure in the ion source was adjusted such that the abundance of $\mathrm{m} / \mathrm{z}^{4} 1^{+}$ was optimized, and this corresponded to an ion gauge reading of $2 \times 10^{-4}$ torr on the ion gauge located on the source manifold; the source pressure was estimated to be 3 orders of magnitude higher. Electron ionization mass spectra were acquired using a Varian Saturn ITMS (ion trap); electron energy was 70 $\mathrm{eV}$.

3.2.4. SEM/EDS. The mineral compositions of the basalt samples were investigated using scanning electron microscopy (SEM) and energy dispersive $x$ ray spectroscopy (EDS). No attempt was made to cut or polish the basalt chips prior to SEM and EDS (or SIMS) analysis. This decision was made in order to ensure that the sample surfaces would be undisturbed, and would hence correlate well with the types of basalt chips which would be encountered in the field. A consequence of this decision is that the error in the EDS data may be augmented because the surface is not flat. However, the samples were mounted to provide relatively flat areas for analysis and minimize this error. SEM images were obtained using an Amray Model 1830 instrument, which was operated with a $20 \mathrm{keV}$ electron beam. EDS analyses were performed using a Fisons-Kevex Delta 5 instrument. As in the case of the SEM analyses, $20 \mathrm{keV}$ incident electrons were used. The spatial resolution for this analysis is approximately 1-2 microns, which corresponds to the diameter of the approximate volume excited by the incident electron beam. The EDS analyses were standardless, and ZAF ( $Z$ \#, absorption, fluorescence) corrections were accomplished by using either the Magic $V$ or extended PHIRHOZ (XPP, Quantex+ version 6 software, Fisons Instrument Manufacturers, Inc., 24911 Stanford Avenue, Valencia, CA 91355) quantification routines. Magic $\mathrm{V}^{12}$ was used when oxygen was not present in the spectrum, and XPP, which is considered more accurate for light elements, was used when oxygen was present. For elements which are $>5$ atom \%, the accuracy of this method is on the order of $4-8 \%$ (relative) when analyzing flat, polished specimens.

3.2.5. Sample origin and handling and preparation. Basalt samples were collected from the Central Facilities Area of the INEL, the Blackfoot River area of southeast Idaho, and the Elephant Mountain area, near the Hanford reservation (Washington). The INEL basalt was chosen because it is typical of the INEL site: it has a very rough surface morphology which is typical of young basalt (in this case approximately 7000 years old). The Blackfoot River basalt was collected from off the INEL site, and had a smoother surface as a result of extensive weathering. This basalt is older than the INEL basalt, but the exact age is not known. The Elephant Mountain basalt is also smoother and older (it is thought 
to be approximately 10.5 million years old), and is typical of the Hanford site. ${ }^{3}$ One additional sample was analyzed: this was a quartzic rock collected from the Raritan, NJ area. Samples from this area are being studied because it has experienced environmental contamination from chemical warfare agents. The Raritan rocks consisted almost entirely of $\mathrm{SiO}_{2}$ (as determined by EDS).

Typical sample preparation involved wrapping the basalt or quartz sample in a paper towel, and then pounding it with a hammer to make small rock chips (size was variable, but typically $2 \mathrm{~mm}$ in diameter). These chips were then attached to target planchets using double-sided tape, and admitted to the spectrometer using a direct insertion probe.

The basalt and quartz chips, and the ferrous and ferric oxide powders were exposed to TBP in three different ways: 1) known quantities of aqueous TBP solutions were spiked onto the mineral surfaces, and allowed to dry prior to admitting the samples into the instrument; 2) the mineral samples were immersed in aqueous, and $\mathrm{CH}_{2} \mathrm{Cl}_{2}$ solutions of TBP for typically 1 - 2 hours, removed, and allowed to dry; 3 ) samples were exposed to TBP in the atmosphere, by holding a basalt sample over an open bottle of TBP for 15 to 60 seconds. The concentrations of the $\mathrm{TBP} / \mathrm{H}_{2} \mathrm{O}$ and $\mathrm{TBP} / \mathrm{CH}_{2} \mathrm{Cl}_{2}$ solutions were 800 and 1000 ppm, respectively. All TBP exposures were conducted at room temperature. These concentrations resulted in SIMS spectra which had good signal-to-background, whether the samples were spiked or immersed in the TBP solutions.

Basalt and quartz chips, and the ferrous and ferric oxide powders were exposed to tributyl phosphite in two ways: 1) chips were suspended for 1-2 hours in a vial, which contained a few microliters of tributyl phosphite in the bottom; 2) chips were spiked with 2 - 4 ul of tributyl phosphite/ $\mathrm{CH}_{2} \mathrm{Cl}_{2}$ solution (1 ug/ul). Similar spectra (ions and relative abundances) were observed using both techniques. All tributyl phosphite exposures were conducted at room temperature.

3.2.6. Chemicals. Tributyl phosphate was obtained from $M C B$ Manufacturing Chemists, Inc. The purity of TBP was checked using GC/MS; only TBP was observed in the chromatogram. Tributyl phosphite was obtained from Aldrich (technical grade); GC/MS analysis of this compound showed an impurity that was identified as tributyl phosphate. The concentration of tributyl phosphate in the tributyl phosphite was estimated at $3-4 \%$, based on the GC/MS peak areas. Iron (III) oxide was obtained from John Mathey Specialty Products, and was Grade I. Iron (II) oxide was obtained from Cerac.

\subsection{Results}

3.3.1 SIMS Analysis of TBP on basalt, quartz, and iron oxides. The cation SIMS spectra of basalt samples from three different geographical 
locations, and of quartz samples were similar in that they contained peaks which corresponded to even-electron hydrocarbon ions, alkali metal ions, and ions derived from phthalate, and siloxane (Figure 10a). In addition, ions originating from cyclohexylamine were usually observed: this compound is added to the laboratory boiler at INEL to prevent scaling, and gets into the laboratory air because the boiler is also used for humidification. These observations are consistent with the idea that most of the secondary ion signal is originating from surface contaminants. Fortunately, few ions above mass $>100$ were very abundant in the spectra of the unexposed samples, which allowed the chemistry of TBP to be observed without significant isobaric interferences.

lons originating from TBP could be readily observed in the cation and anion SIMS spectra of basalt, quartz, and iron oxide samples that had been exposed to TBP (Figure 10b, 10c, Table 20). These ions could be observed when the samples were exposed to TBP solutions $\left(\mathrm{H}_{2} \mathrm{O}\right.$ or $\left.\mathrm{CH}_{2} \mathrm{Cl}_{2}\right)$, or TBP vapor. On a qualitative basis, the SIMS spectra of TBP were consistent irrespective of the method of exposure for all surfaces, except $\mathrm{FeO}$ (see below). The fact that TBP vapor would readily contaminate a mineral surface created problems in the laboratory, because when neat TBP or highly TBP-contaminated samples were manipulated in the lab, it was subsequently difficult to acquire a SIMS spectrum of basalt which did not have ions derived from TBP. The phenomenon is indicative of both the unusual ability of TBP to adsorb to mineral surfaces, and the high sensitivity of SIMS for the detection of compounds bound in this manner. A positive aspect of the phenomenon is that it provided a means by which mineral samples could be exposed to TBP without using solvent.

The relative abundances of the salient ions observed in the cation SIMS spectra of TBP were observed to vary significantly, depending on the mineral sample (Table 20). Changes in the abundances of ions at $\mathrm{m} / 2249^{+}, 235^{+}$, $217^{+}, 193^{+}, 175^{+}, 137^{+}$, and $119^{+}$permit the samples to be grouped into two categories: abundances of these ions are high in the spectra of Elephant Mountain (Figure 10b) and Blackfoot River basalts, and FeO (exposed to $\mathrm{TBP} / \mathrm{CH}_{2} \mathrm{Cl}_{2}$ solution), and low in the spectra of the INEL basalt (Figure 10c), Raritan quartz, and $\mathrm{Fe}_{2} \mathrm{O}_{3}$. A second distinction may be made based on the abundances of $\mathrm{m} / \mathrm{z} 209^{+}$and $153^{+}$, which are high in the case of the iron oxides, but lower for the other four samples.

The cation SIMS spectrum of TBP on FeO varied depending on the method of exposure: when $\mathrm{FeO}$ was exposed to TBP vapor or $\mathrm{TBP} / \mathrm{CH}_{2} \mathrm{Cl}_{2}$ solutions, the SIMS spectrum appeared very much like the Elephant Mountain and Blackfoot River Basalt samples. When $\mathrm{FeO}$ was exposed to aqueous TBP, on the other hand, the spectrum looked like the spectrum collected from the $\mathrm{Fe}_{2} \mathrm{O}_{3}$ sample; in fact, tiny patches of orange, oxidized FeO could be observed (using an optical microscope) on the sample that had been exposed to the aqueous TBP solution.

The anion SIMS spectra of the unexposed mineral samples were also very similar (Figure 11a): they are dominated by $\mathrm{O}^{\circ}$ and $\mathrm{OH}^{\circ}$, with lower abundance ions corresponding to $\mathrm{C}_{2} \mathrm{H}_{1} \mathrm{SiO}_{2}$, and $\mathrm{SiO}_{3}$. When the mineral samples are exposed to TBP, the only significant ions that can be observed are $\mathrm{m} / \mathrm{z} 63^{\circ}$ and 79; which correspond to $\mathrm{PO}_{2}{ }^{\circ}$ and $\mathrm{PO}_{3}{ }^{\circ}$ (Figure 11b, 11c). The anion spectra 
were not observed to be dependent upon the surface chemistry of the TBP. mineral system.

3.3.2. SEM/EDS Analyses of Basalt The surfaces of the basalt samples were difficult to quantitatively describe because they were very inhomogeneous: scanning electron micrographs together with energy dispersive $X$-ray spectroscopy (EDS) revealed that samples from all three locations contained four significant types of mineral phases, which were plagioclase, pyroxene, olivine, and Ti-bearing spinels. Plagioclase accounts for the largest fraction of the surface area of the basalt samples that were studied, and by definition, its composition ranges from anorthite $\left(\mathrm{CaAl}_{2} \mathrm{Si}_{2} \mathrm{O}_{8}\right)$ to albite $\left(\mathrm{NaAlSi}_{3} \mathrm{O}_{8}\right)$. Generally, plagioclase was identified by significant quantities of Al ( $6-9$ atom \%) in the EDS analyses, and appearance of dark gray to black areas in the back scattered electron images generated by the SEM (indicative of few higher $Z$ number elements). Pyroxene phases were also observed on the sample surfaces; in contrast to the plagioclase, the pyroxenes contained substantial amounts of $\mathrm{Fe}$, and lack substantial $\mathrm{Al}$. By definition, pyroxenes have the stoichiometry $\mathrm{X}_{1-\mathrm{p}} \mathrm{Y}_{1+p} \mathrm{Si}_{2} \mathrm{O}_{6}$, where $\mathrm{X}$ is $\mathrm{Ca}$ or $\mathrm{Na}, \mathrm{Y}$ can be one of several transition metals (including $\mathrm{Fe}^{+2}$ and $\mathrm{Fe}^{+3}$ ), and $0 \leq \mathrm{p} \leq 1$. Olivine phases were also observed in most of the samples, although in general they are not as prevalent as are the plagioclase and pyroxene phases. The olivines have the general formula $\mathrm{Mg}_{x} \mathrm{Fe}_{2-x} \mathrm{SiO}_{4}$, where $0 \leq x \leq 2$. Finally, most of the samples that were examined had smaller areas which corresponded to phases that were high in Ti: examples of these minerals are ilmenite, $\mathrm{FeTiO}_{3}$, and ulvospinel, $\mathrm{Fe}_{2} \mathrm{TiSiO}_{4}$. These $\mathrm{Ti}$-bearing spinels are readily observed as bright areas in the back-scattered electron images generated by the SEM. The important observation relative to the SIMS behavior of TBP on basalt is the fact that substantial amounts of $\mathrm{Fe}^{+2}$ are certainly present in the olivine and Ti-spinel phases, and probably in the pyroxenes.

When the SEM/EDS analyses of basalt samples from different areas were compared, significant qualitative differences were observed. Plagioclase was the most important phase in the samples of INEL basalt, accounting for up to $90 \%$ of the surface area (based upon visual estimation). A minor phase was identified was Fe-bearing pyroxene. Occasionally, samples of INEL basalt contained higher percentages of Fe-bearing phases, which were identified as hematite $\left(\mathrm{Fe}_{2} \mathrm{O}_{3}\right)$. This identification was consistent with the reddish color of these samples. No olivine phases were observed, and Ti-bearing spinels accounted for only a small fraction of the total surface area. Significantly, phases which contain $\mathrm{Fe}$ (II) are much less prevalent in INEL basalts than in the Elephant Mountain or Blackfoot River samples.

Although the Elephant Mountain basalt samples also contained substantial plagioclase phases, they could be readily distinguished from the INEL basalt samples by the presence of Ti-bearing spinels and olivine phases, which accounted for a significant portion of the surface area. These phases all contain substantial amounts of $\mathrm{Fe}(\mathrm{II})$. Specific phases identified included fayalite $\left(\mathrm{Fe}_{2} \mathrm{SiO}_{4}\right.$, an olivine), ilmenite $\left(\mathrm{FeTiO}_{3}\right)$, and ulvospinel $\left(\mathrm{Fe}_{2} \mathrm{TiO}_{4}\right)$. In addition, 
pyroxene phases containing substantial $\mathrm{Fe}$ (7 to 10 atom \%) were more abundant than in the case of the INEL basalt samples.

Fewer phases were observed in the SEM/EDS images of the Blackfoot River basalt. As in the cases of the Elephant Mountain and INEL basalts, plagioclase accounted for substantial fractions of the sample surfaces $(70-80 \%$, based upon visual estimation), but large areas of olivine ( $\left.\mathrm{FeMgSiO}_{4}\right)$ and ulvospinel $\left(\mathrm{Fe}_{2} \mathrm{TiO}_{4}\right.$ ) phases occupied most of the rest of the surface (surface coverage of up to $10 \%$ for each phase). The presence of $\mathrm{Fe}(\mathrm{II})$ in these phases distinguishes them from the INEL basalt samples. A silica phase occupied a small fraction of the surface of the Blackfoot River basalts, and was identified by the presence of $\mathrm{Si}, \mathrm{O}$, and almost nothing else.

A quartzic rock obtained from a Raritan, NJ site was analyzed for comparison with the basalt. SEM/EDS analyses revealed that the sample was overwhelmingly $\mathrm{SiO}_{2}$, with a few very small areas which contained transition metals.

3.3.3. SIMS analysis of tributyl phosphite on basalt, quartz, and iron oxides. When Blackfoot River basalt was exposed to tributyl phosphite vapor, the same set of secondary ions was observed as in the case of TBP (Table 20), together with a $\mathrm{m} / \mathrm{z} 83^{+}$which was more abundant than the background spectra

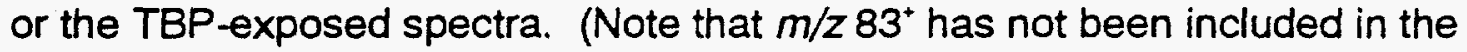
data tables, because it is isobaric with a background $\mathrm{C}_{8} \mathrm{H}_{11}{ }^{+}$, which arises from ubiquitous hydrocarbon background, and the cyclohexyl amine surface contaminant.) The absolute abundances (counts per second) of the secondary ions for tributyl phosphite were usually on the order of 2 to 5 times lower than similar TBP ion abundances, for similar samples exposed in the same fashion. This may indicate that more TBP is adsorbed to the sample surface, or that TBP is more prolific at forming cations than tributyl phosphite. A consequence of the lower abundances is that the tributyl phosphite ions are not greatly more abundant than the normal SIMS background, and hence the higher mass, lower abundance ions reported for tributyl phosphite (Table 20) must be interpreted with this caution. The above caveat notwithstanding the relative abundances of the tributyl phosphite ions observed on Blackfoot River Basalt were in reasonable agreement with those recorded for TBP on Blackfoot River and Elephant Mountain basalts, and FeO (the latter exposed to gas phase TBP).

The analysis of tributyl phosphite on $\mathrm{FeO}$ (deposited as a $\mathrm{CH}_{2} \mathrm{Cl}_{2}$ solution, 1 part-per-thousand) was also difficult to interpret because of lower secondary ion intensity associated with analyses of tributyl phosphite. Nevertheless, $m / z 193^{+}$, $175^{+}, 153^{+}, 137^{+}, 119^{+}, 99^{+}$, and $83^{+}$were clearly discernible above the background. The FeO powder was also exposed to tributyl phosphite vapor; in this experiment, the same ions were observed, but the absolute ion abundances were less than in the $\mathrm{CH}_{2} \mathrm{Cl}_{2}$ experiment. In both the tributyl phosphite on $\mathrm{FeO}$ experiments (vapor and $\mathrm{CH}_{2} \mathrm{Cl}_{2}$ solution exposures), the relative abundances of these ions were similar to tributyl phosphite on Blackfoot River basalt, and to TBP on FeO, Blackfoot River basalt, and Elephant Mountain basalt. For example, $\mathrm{m} / \mathrm{z} 137^{+}$was observed at 50 to $60 \%$ in the tributyl phosphite spectra, 
which suggests that the tributyl phosphite spectra can be grouped with TBP spectra on basalts with $\mathrm{Fe}(\mathrm{II})$ and on $\mathrm{FeO}$.

The SIMS spectrum of tributyl phosphite (gas-phase) on $\mathrm{Fe}_{2} \mathrm{O}_{3}$ is very similar to that obtained for FeO.

3.3.4. Gas-phase behavior of ionized TBP and tributyl phosphite. The chemical ionization $(\mathrm{Cl})$ and electron ionization (EI) mass spectra of the subject compounds were examined in order to determine whether the ions attributed to surface reduction could also be formed from gas-phase processes. The methane $\mathrm{Cl}$ spectrum (Table 21) of TBP contains four separate ion series, that originate with four "parent" ions: these four ions correspond to $\left[\mathrm{M}+\mathrm{C}_{3} \mathrm{H}_{5}\right]^{+}$, [M $\left.+\mathrm{C}_{2} \mathrm{H}_{5}\right]^{+},[\mathrm{M}+\mathrm{H}]^{+}$, and $[\mathrm{M}-\mathrm{H}]^{+}$. They behave similarly in that they proceed to eliminate one and/or two and/or three butene molecules. The series which originates with $[\mathrm{M}+\mathrm{H}]^{+}$accounts for the most abundant ions in the spectrum, at $\mathrm{m} / \mathrm{z} 267^{+}, 211^{+}, 155^{+}$, and $99^{+}$. MS/MS decompositions relating these ions have been observed using a new ion trap SIMS instrument recently constructed in the authors' laboratory: $267^{*}$ produces $211^{+}, 155^{*}$, and $99^{+} ; 211^{+}$produces $155^{+}$and $99^{+} ; 155^{+}$produces $99^{+} ; 137^{*}$ produces $119^{+}$.

The electron ionization (EI) mass spectrum of $\mathrm{TBP}^{13}$ (Table 22) contains a

low abundance $\mathrm{M}^{+\cdot}$ at $\mathrm{m} / \mathrm{z} 266^{+}$, which fragments via the loss of $\mathrm{C}_{4} \mathrm{H}_{7}{ }^{\circ} \mathrm{(m/z}$ $\left.211^{+}\right)$, and then undergoes losses of $\mathrm{C}_{4} \mathrm{H}_{8}$, to produce ions at $155^{+}$, and $99^{+} .{ }^{14}$ The El spectrum also contains other low abundance ions which correspond to

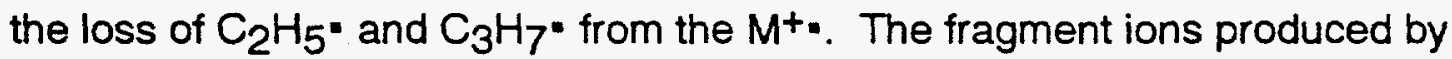
these eliminations subsequently lose one and two $\mathrm{C}_{4} \mathrm{H}_{8}$ molecules to produce other low abundance fragment ions, one of which is $\mathrm{m} / \mathrm{z} 125^{+}$. In addition, a low abundance $\mathrm{m} / \mathrm{z} 137^{+}$ion is observable.

The $\mathrm{Cl}$ and $\mathrm{El}$ mass spectra of tributyl phosphite were examined in order to identify the behavior of gas-phase tributyl phosphite ions, and correlate this behavior with that observed in the SIMS analyses. The methane $\mathrm{Cl}$ mass spectrum of tributyl phosphite (Table 21) was dominated by the sequential losses of three $\mathrm{C}_{4} \mathrm{H}_{8}$ molecules from a very low abundance $[\mathrm{M}+\mathrm{H}]^{+}\left(\mathrm{m} / \mathrm{z} 251^{+}\right)$ to form $\mathrm{m} / 2195^{+}, 139^{+}$, and $83^{+}$(base peak). A lower abundance ion series was observed at $\mathrm{m} / 2249^{+}, 193^{+}$, and $137^{+}$, and as in the case of TBP, the series was interpreted in terms of the elimination of one and two $\mathrm{C}_{4} \mathrm{H}_{8}$ molecules from a $[\mathrm{M}-\mathrm{H}]^{+}$formed via hydride abstraction. The $\mathrm{Cl}$ mass spectrum also contains $\left[\mathrm{M}+\mathrm{C}_{3} \mathrm{H}_{5}\right]^{+}$and $\left[\mathrm{M}+\mathrm{C}_{2} \mathrm{H}_{5}\right]^{+}$, and their $\mathrm{C}_{4} \mathrm{H}_{8}$ elimination products: the [tributyl phosphite $+\mathrm{C}_{2} \mathrm{H}_{5}$ ] were observed at $\mathrm{m} / z 279^{+}, 223^{+}, 167^{+}$, and $111^{+}$; the [tributyl phosphite + $\left.\mathrm{C}_{3} \mathrm{H}_{5}\right]^{+}$ion was not observed, but the $\mathrm{C}_{4} \mathrm{H}_{8}$ losses were observable at $\mathrm{m} / \mathrm{z}$ $235^{+}, 179^{+}$, and $123^{+}$.

The fragmentation reactions of tributyl phosphite under electron ionization (EI) conditions ${ }^{13}$ (Table 22) were very similar to the El fragmentations of TBP: the $\mathrm{M}^{+}$(not observed) eliminates $\mathrm{C}_{4} \mathrm{H}_{7}$ to form $\mathrm{m} / z 195^{+}$, which subsequently undergoes sequential losses of $\mathrm{C}_{4} \mathrm{H}_{8}$, to produce ions at $139^{+}$, and $83^{+} . \mathrm{M} / \mathrm{z}$ $195^{+}$can also eliminate $\mathrm{H}_{2} \mathrm{O}$ to form $\mathrm{m} / z 177^{+}$, which further undergoes losses of two $\mathrm{C}_{4} \mathrm{H}_{8}$ to form $\mathrm{m} / \mathrm{z} 121^{+}$and $65^{+}$. M/z $83^{+}$accounts for the base peak in the 
spectrum, and $m / z 139^{+}$and $195^{+}$also have significant ion abundances. Other than lower mass hydrocarbon peaks $\left(\mathrm{m} / 257^{+}, 41^{+}\right.$, and $\left.29^{+}\right)$, no other significant ions are observed in this spectrum. 


\begin{tabular}{|c|c|c|}
\hline $\mathrm{m} / \mathrm{z}$ & $\begin{array}{r}\text { mean relative abundance } \\
\text { (base peak is } m / z 41^{+} \text {) }\end{array}$ & relative standard deviation \\
\hline 23 & $61 . \%$ & $32 . \%$ \\
\hline 27 & $50 . \%$ & $22 . \%$ \\
\hline 39 & $99 . \%$ & $17 . \%$ \\
\hline 43 & $50 . \%$ & $4.0 \%$ \\
\hline 55 & $60 . \%$ & $4.1 \%$ \\
\hline 67 & $23 . \%$ & $8.7 \%$ \\
\hline 99 & $4.6 \%$ & $31 . \%$ \\
\hline 119 & $2.3 \%$ & $16 . \%$ \\
\hline 125 & $0.87 \%$ & $12 . \%$ \\
\hline 137 & $1.1 \%$ & $37 . \%$ \\
\hline 149 & $0.71 \%$ & $23 . \%$ \\
\hline 153 & $0.72 \%$ & $9.5 \%$ \\
\hline 155 & $0.58 \%$ & $3.3 \%$ \\
\hline 175 & $0.35 \%$ & $38 . \%$ \\
\hline 193 & $0.27 \%$ & $38 . \%$ \\
\hline 211 & $0.14 \%$ & $49 . \%$ \\
\hline 217 & $0.11 \%$ & $53 . \%$ \\
\hline 235 & $0.13 \%$ & $91 . \%$ \\
\hline 249 & $0.17 \%$ & $58 \%$ \\
\hline
\end{tabular}




\begin{tabular}{|c|c|c|c|c|c|c|c|c|c|c|}
\hline mass & \begin{tabular}{|l|} 
TBP \\
(aqueous) \\
on quartzic \\
rock
\end{tabular} & $\left.\mid \begin{array}{l}\text { TBP on } \\
\text { INEL } \\
\text { basalt } \\
\text { (aqueous) }\end{array}\right]$ & $\left|\begin{array}{l}\mathrm{TBP} \\
\left(\mathrm{CH}_{2} \mathrm{Cl}_{2}\right) \\
\text { on } \mathrm{Fe}_{2} \mathrm{O}_{3}\end{array}\right|$ & $\begin{array}{l}\text { TBP } \\
\text { (aqueous) } \\
\text { on } \mathrm{FeO}\end{array}$ & $\left|\begin{array}{l}\mathrm{TBP} \\
\left(\mathrm{CH}_{2} \mathrm{Cl}_{2}\right) \\
\text { on } \mathrm{FeO}\end{array}\right|$ & \begin{tabular}{|l|} 
TBP \\
(aqueous) \\
on \\
Blackfoot \\
River \\
basalt \\
\end{tabular} & \begin{tabular}{|l|} 
TBP \\
(aqueous) \\
on \\
Elephant \\
Mountain \\
basalt \\
\end{tabular} & \begin{tabular}{|l|} 
tributyl \\
phosphite \\
(vapor) on \\
Blackfoot \\
River \\
basalt \\
\end{tabular} & $\begin{array}{l}\text { tributyl } \\
\text { phosphite } \\
\left(\mathrm{CH}_{2} \mathrm{Cl}_{2}\right) \\
\text { on } \mathrm{FeO}\end{array}$ & \begin{tabular}{|l|} 
tributyl \\
phosphite \\
(vapor) on \\
$\mathrm{Fe}_{2} \mathrm{O}_{3}$
\end{tabular} \\
\hline 99 & 100.0 & 100.0 & 100.0 & 100.0 & 100.0 & 100.0 & 100.0 & 100.0 & 100.0 & 100.0 \\
\hline 119 & 3.5 & 11.4 & 2.7 & 9.3 & 52.8 & 40.7 & 27.9 & 32.6 & 50.0 & 35.7 \\
\hline 125 & 7.6 & 9.3 & 6.6 & 7.5 & 9.8 & 13.8 & 11.0 & 24.6 & 13.0 & 12.5 \\
\hline 137 & 5.5 & 10.6 & 6.6 & 6.2 & 47.2 & 44.8 & 50.0 & 51.4 & 63.0 & 62.1 \\
\hline 153 & 2.5 & 5.4 & 49.3 & 21.2 & 37.0 & 5.5 & 6.5 & 10.1 & 30.4 & 33.7 \\
\hline 155 & 6.4 & 5.2 & 12.6 & 4.3 & 14.2 & 6.6 & 6.9 & 13.0 & 17.4 & 23.0 \\
\hline 175 & 0.7 & 2.2 & 1.9 & 1.8 & 15.5 & 8.4 & 6.4 & 7.2 & 21.4 & 5.2 \\
\hline 193 & 0.8 & 2.2 & 1.9 & 8.1 & 12.7 & 7.6 & 6.1 & 10.1 & 23.7 & 6.3 \\
\hline 209 & 0.4 & 1.1 & 7.2 & 1.3 & 4.1 & 0.9 & 1.2 & 3.6 & 15.2 & 13.6 \\
\hline 211 & 0.9 & 1.2 & 2.7 & 1.8 & 7.0 & 1.3 & 1.3 & 6.5 & 1.8 & 3.1 \\
\hline 217 & 0.7 & 2.1 & 4.0 & 1.3 & 9.8 & 5.5 & 5.4 & 9.4 & 15.2 & 8.3 \\
\hline 235 & 0.6 & 1.0 & 0.6 & 0.6 & 4.1 & 3.7 & 3.7 & 7.2 & 8.5 & 5.2 \\
\hline 249 & 0.4 & 1.3 & 0.6 & 0.0 & 8.5 & 4.6 & 2.7 & 7.9 & 8.5 & 0.9 \\
\hline
\end{tabular}




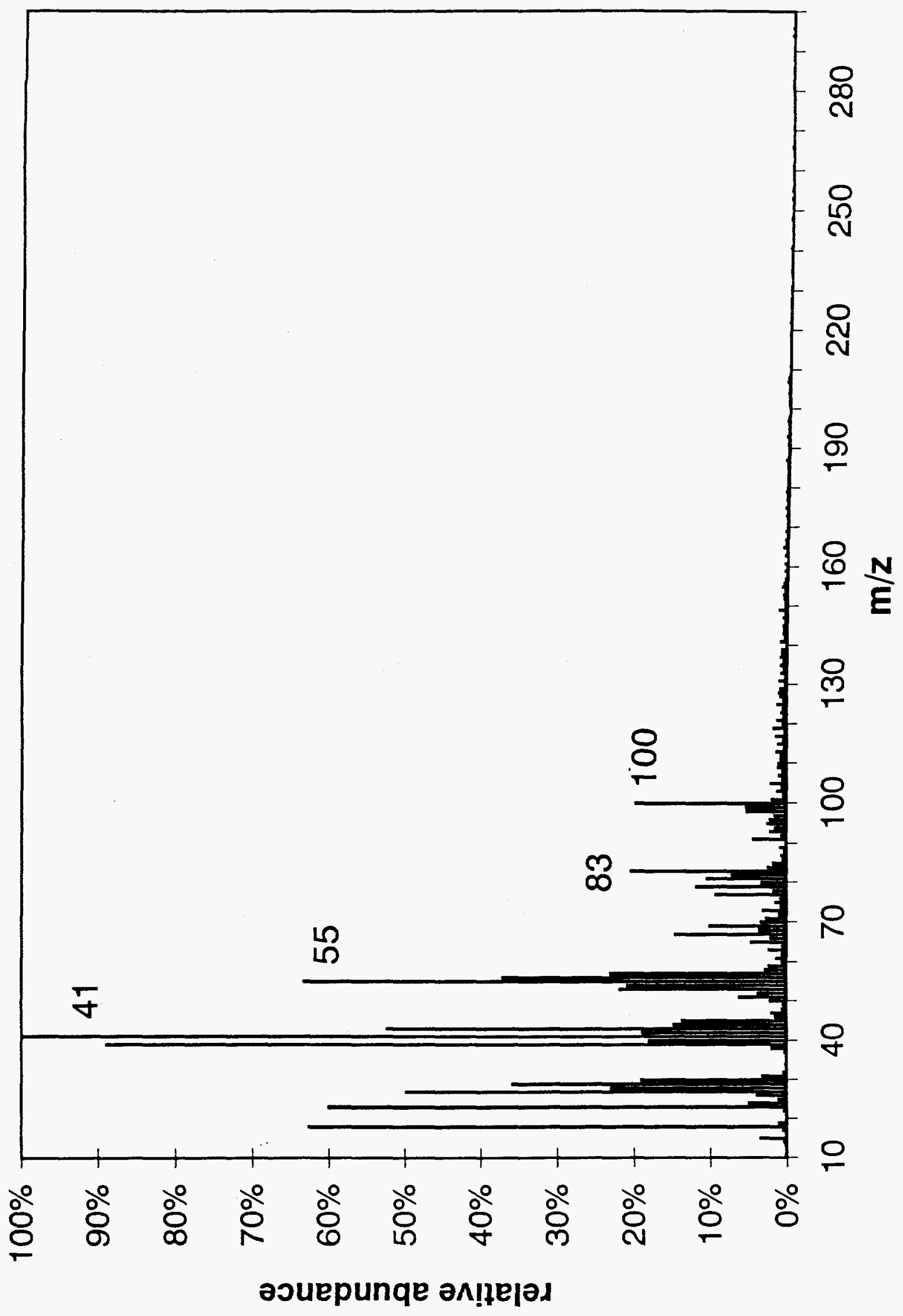




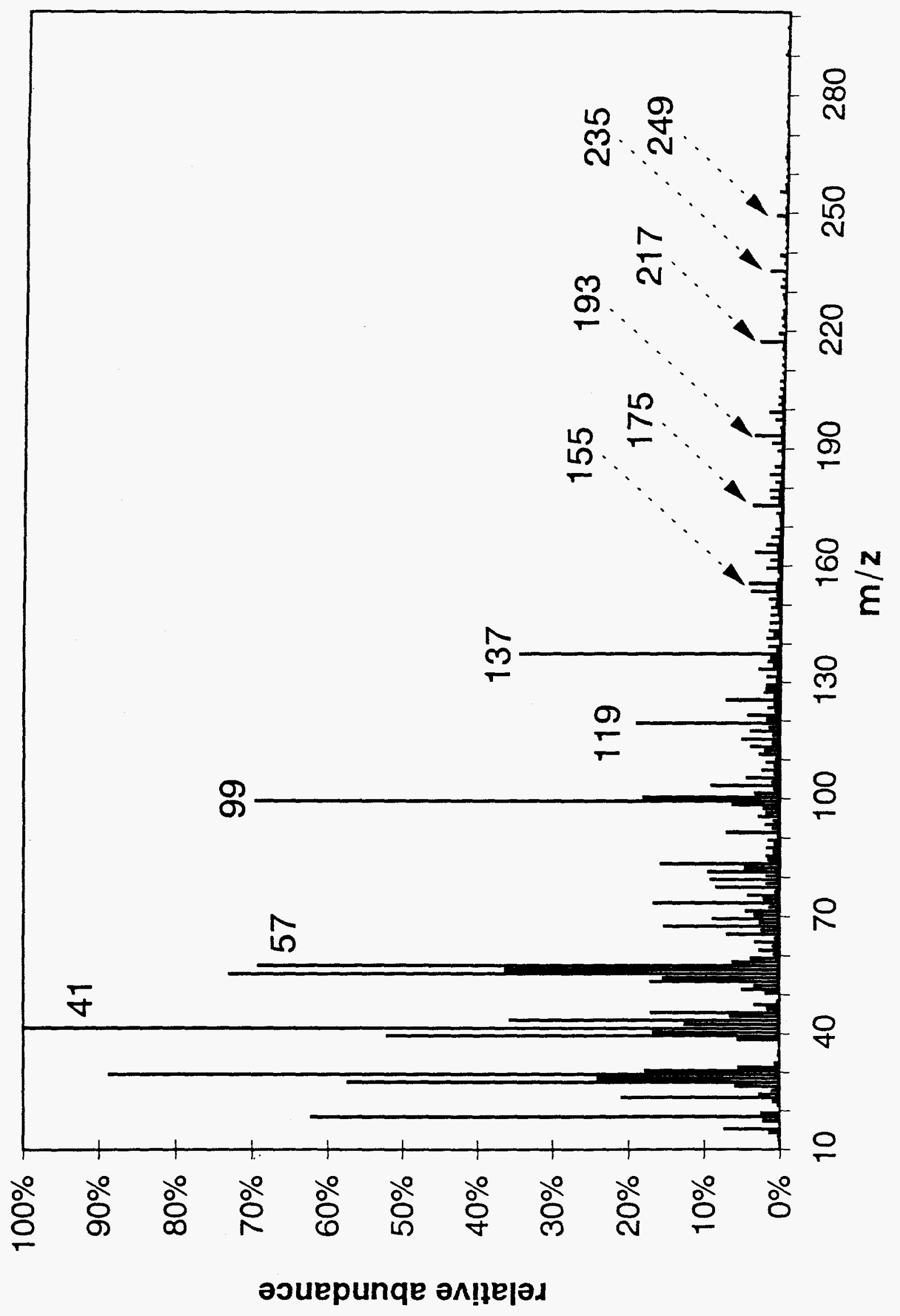




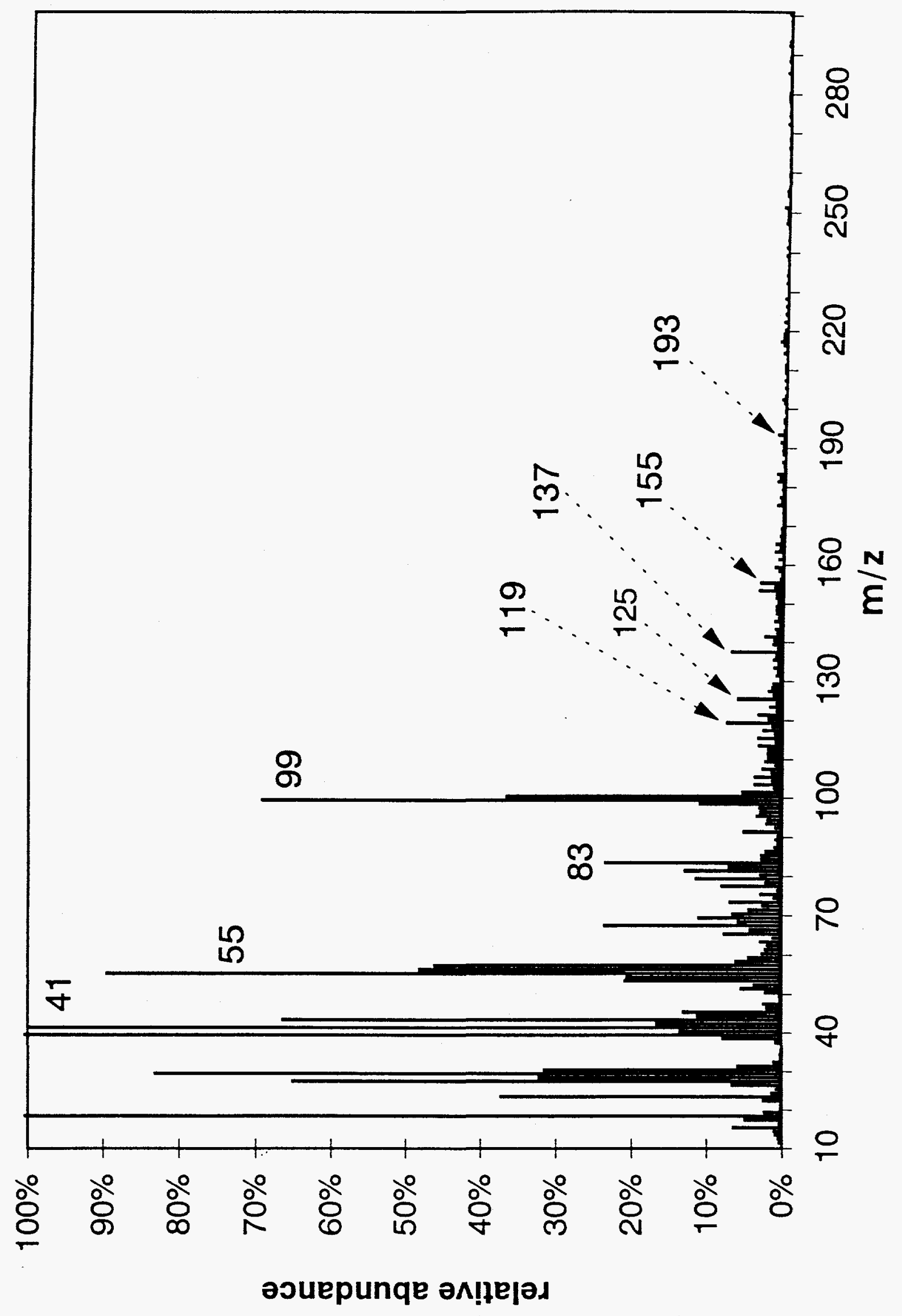




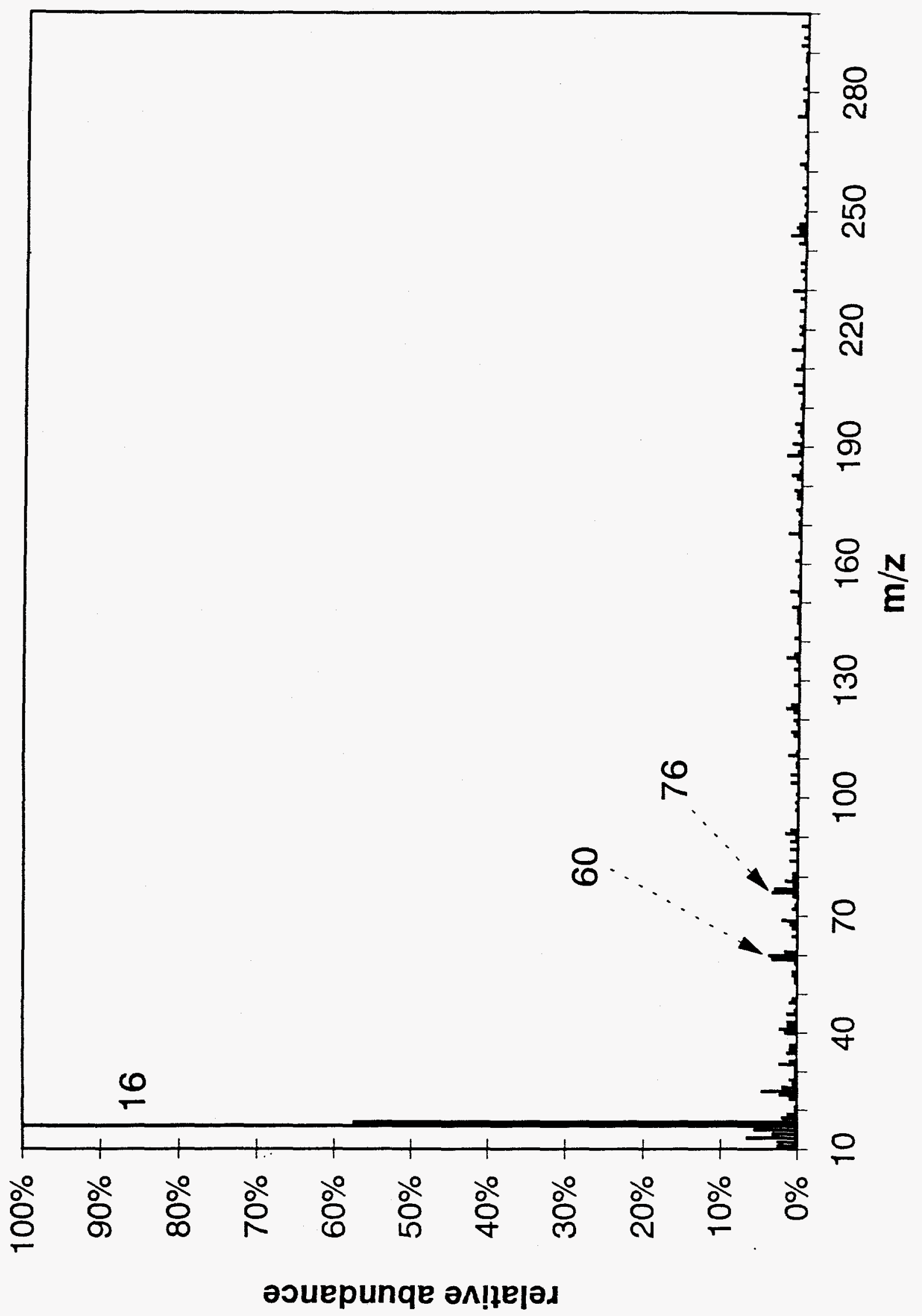




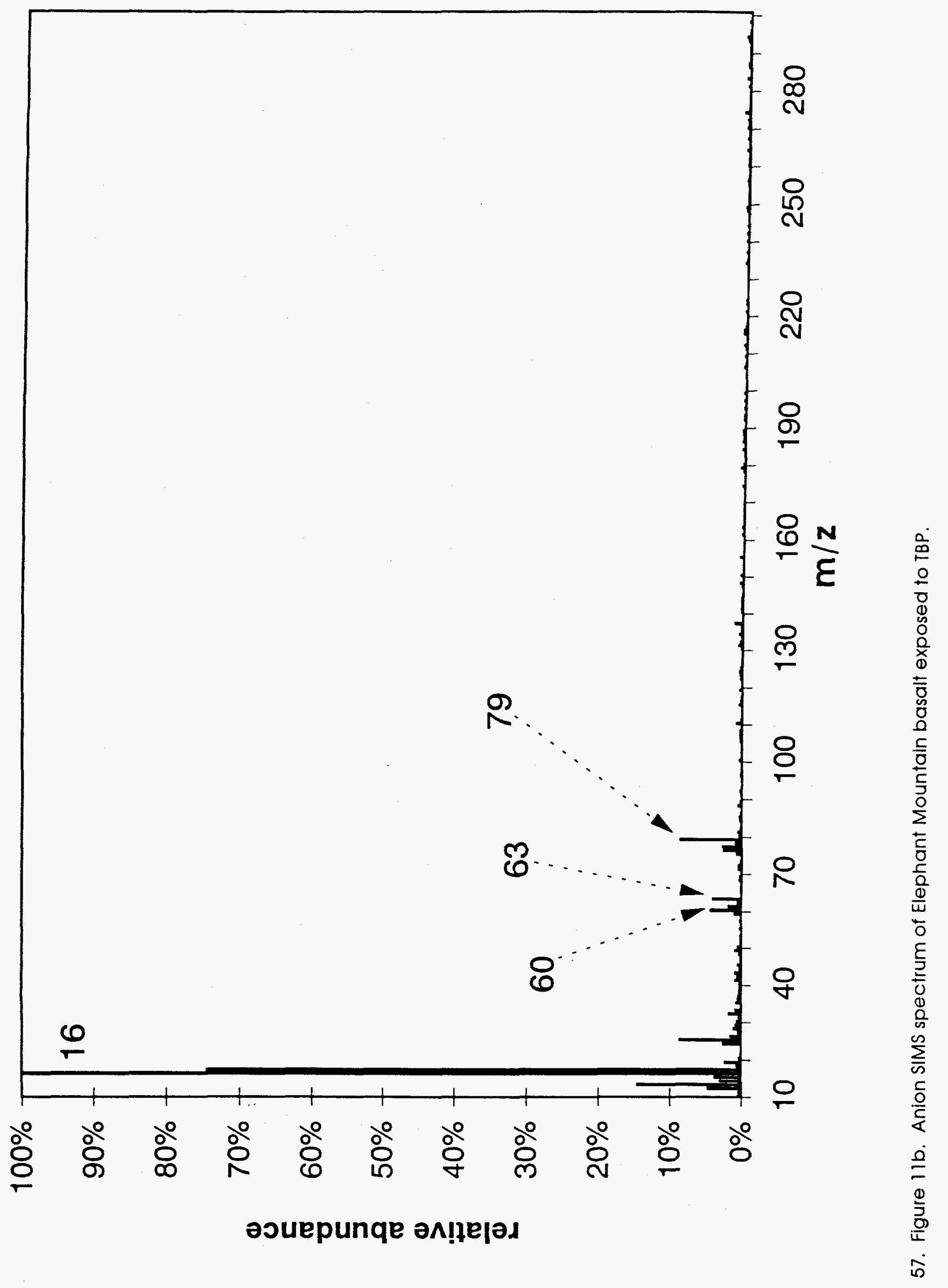




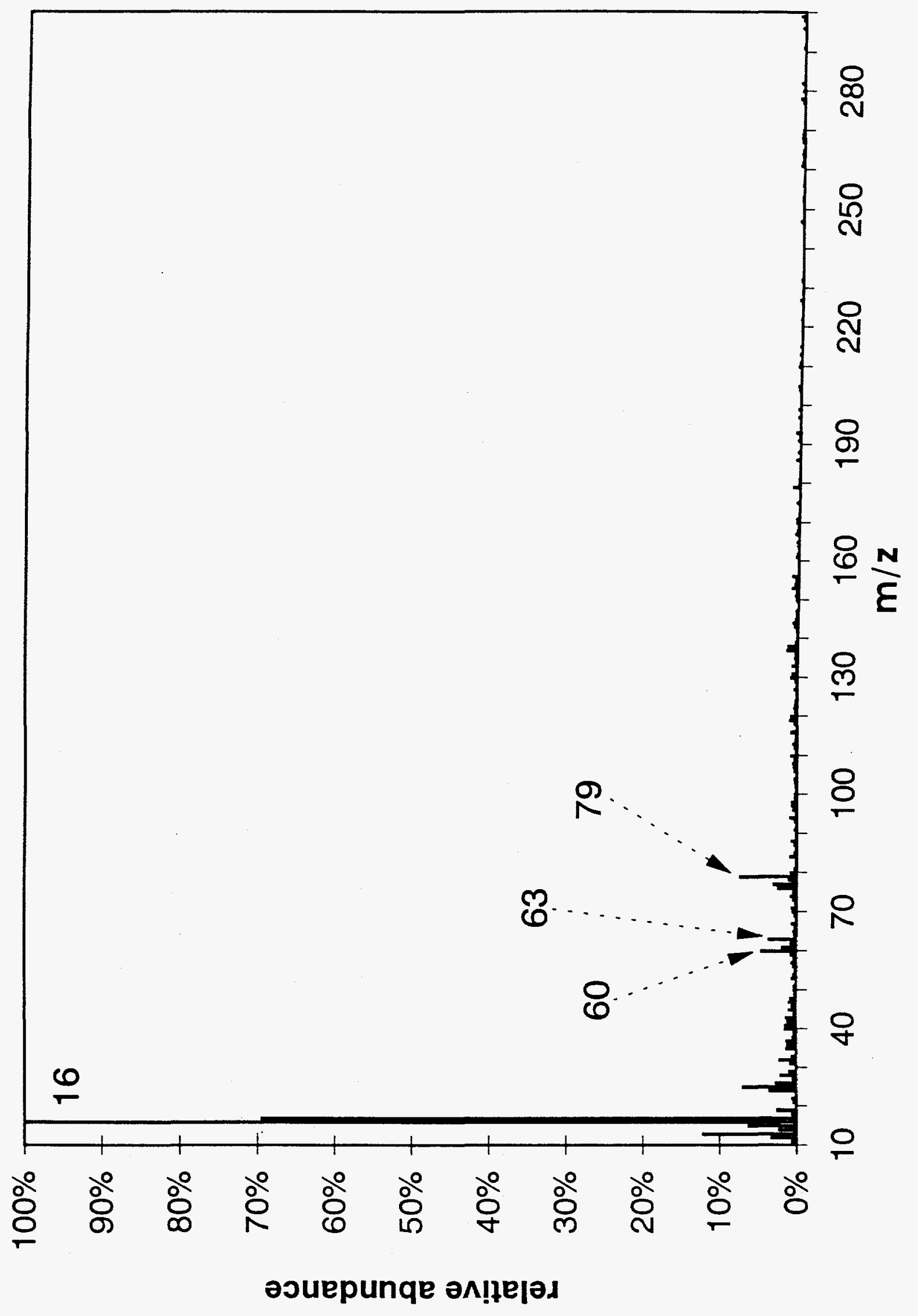




\begin{tabular}{|c|c|c|c|c|}
\hline \multirow[b]{2}{*}{ assignment } & \multicolumn{2}{|c|}{ TBP } & \multicolumn{2}{|c|}{$\begin{array}{c}\text { tributyl } \\
\text { phosphite }\end{array}$} \\
\hline & $m / z$ & r.a." & $m / z$ & r.a." \\
\hline $\mathrm{C}_{4} \mathrm{H}_{7}^{+}$ & 57 & 26. & 57 & 74. \\
\hline $\mathrm{M}+\mathrm{H}^{+}-3 \mathrm{C}_{4} \mathrm{H}_{8}$ & 99 & 17. & 83 & 100 \\
\hline unknown & & & 97 & 2.2 \\
\hline possibly $\mathrm{M}+\mathrm{H}^{+}-\mathrm{C}_{2} \mathrm{H}_{6}-2 \mathrm{C}_{4} \mathrm{H}_{8}$ & 125 & 1.2 & & \\
\hline $\mathrm{M}+\mathrm{C}_{2} \mathrm{H}_{5}^{+}-3 \mathrm{C}_{4} \mathrm{H}_{8}$ & 127 & 1.2 & 111 & 17. \\
\hline $\mathrm{M}+\mathrm{C}_{3} \mathrm{H}_{5}^{+}-3 \mathrm{C}_{4} \mathrm{H}_{8}$ & 139 & 1.2 & 123 & 4.7 \\
\hline $\mathrm{M}-\mathrm{H}^{+}-2 \mathrm{C}_{4} \mathrm{H}_{8}$ & 153 & 1.0 & 137 & 4.0 \\
\hline $\mathrm{M}+\mathrm{H}^{+}-2 \mathrm{C}_{4} \mathrm{H}_{8}$ & 155 & 19. & 139 & 59. \\
\hline $\mathrm{M}+\mathrm{C}_{2} \mathrm{H}_{5}^{+}-2 \mathrm{C}_{4} \mathrm{H}_{8}$ & 183 & 2.1 & 167 & 14. \\
\hline $\mathrm{M}+\mathrm{C}_{3} \mathrm{H}_{5}^{+}-2 \mathrm{C}_{4} \mathrm{H}_{8}$ & 195 & 2.1 & 179 & 1.9 \\
\hline $\mathrm{M}-\mathrm{H}^{+}-\mathrm{C}_{4} \mathrm{H}_{8}$ & 209 & 1.8 & 193 & 1.6 \\
\hline $\mathrm{M}+\mathrm{H}^{+}-\mathrm{C}_{4} \mathrm{H}_{8}$ & 211 & 54. & 195 & 59. \\
\hline possibly $\mathrm{M}+\mathrm{H}^{+}-\mathrm{C}_{3} \mathrm{H}_{8}$ & 223 & 3.1 & & \\
\hline $\mathrm{M}+\mathrm{C}_{2} \mathrm{H}_{5}^{+}-\mathrm{C}_{4} \mathrm{H}_{8}$ & 239 & 9.3 & 223 & 4.6 \\
\hline $\mathrm{M}+\mathrm{C}_{3} \mathrm{H}_{5}^{+}-\mathrm{C}_{4} \mathrm{H}_{8}$ & 251 & 3.9 & 235 & 5.1 \\
\hline $\mathrm{M}-\mathrm{H}^{+}$ & 265 & 9.9 & 249 & 0.1 \\
\hline $\mathrm{M}+\mathrm{H}^{+}$ & 267 & 100. & 251 & 0.0 \\
\hline $\mathrm{M}+\mathrm{C}_{2} \mathrm{H}_{5}^{+}$ & 295 & 17. & 279 & 0.0 \\
\hline $\mathrm{M}+\mathrm{C}_{3} \mathrm{H}_{5}^{+}$ & 307 & 7.1 & 291 & 0.0 \\
\hline
\end{tabular}




\begin{tabular}{|c|c|c|c|c|}
\hline \multirow[b]{2}{*}{ assignment } & \multicolumn{2}{|c|}{ TBP } & \multicolumn{2}{|c|}{ tributyl phosphite } \\
\hline & $m / z$ & r.a.* & $m / z$ & r.a.* \\
\hline $\mathrm{C}_{4} \mathrm{H}_{7}^{+}$ & 57 & 15 & 57 & 29 \\
\hline $\mathrm{M}-\mathrm{C}_{4} \mathrm{H}_{7}-2 \mathrm{C}_{4} \mathrm{H}_{8}{ }^{+}$ & 99 & 100 & 83 & 100 \\
\hline $\mathrm{M}-\mathrm{C}_{3} \mathrm{H}_{7}-2 \mathrm{C}_{4} \mathrm{H}_{8}^{+}$ & 111 & 4.5 & & \\
\hline $\mathrm{M}-\mathrm{C}_{2} \mathrm{H}_{5}-2 \mathrm{C}_{4} \mathrm{H}_{8}{ }^{+}$ & 125 & 8.6 & & \\
\hline $\mathrm{M}-\mathrm{C}_{4} \mathrm{H}_{7}-\mathrm{C}_{4} \mathrm{H}_{8}-\mathrm{H}_{2} \mathrm{O}^{+}$ & 137 & 7.8 & 121 & 2.7 \\
\hline $\mathrm{M}-\mathrm{C}_{4} \mathrm{H}_{7}-\mathrm{C}_{4} \mathrm{H}_{8}{ }^{+}$ & 155 & 32 & 139 & 17 \\
\hline $\mathrm{M}-\mathrm{C}_{3} \mathrm{H}_{7}-\mathrm{C}_{4} \mathrm{H}_{8}{ }^{+}$ & 167 & 4.5 & & \\
\hline $\mathrm{M}-\mathrm{C}_{4} \mathrm{H}_{7}-\mathrm{H}_{2} \mathrm{O}^{+}$ & & & 177 & 2.6 \\
\hline $\mathrm{M}-\mathrm{C}_{2} \mathrm{H}_{5}-\mathrm{C}_{4} \mathrm{H}_{8}^{+}$ & 181 & 2.8 & & \\
\hline $\mathrm{M}-\mathrm{C}_{4} \mathrm{H}_{7}^{+}$ & 211 & 30 & 195 & 4.8 \\
\hline $\mathrm{M}-\mathrm{C}_{3} \mathrm{H}_{7}^{+}$ & 223 & 2.8 & & \\
\hline $\mathrm{M}-\mathrm{C}_{2} \mathrm{H}_{5}{ }^{+}$ & 237 & 2.4 & & \\
\hline $\mathrm{M}^{+}$ & 266 & 2.4 & 250 & 0.2 \\
\hline & & non & & \\
\hline
\end{tabular}




\subsection{Discussion}

3.4.1. Production of $m / z 137^{+}$and related ions. The observation of abundant ions at $m / z 137^{+}$and $119^{+}$(as well as less abundant ions at $m / z 249^{+}$, $193^{+}$, and $175^{+}$) in the SIMS spectra of TBP on $\mathrm{FeO}$ but not $\mathrm{Fe}_{2} \mathrm{O}_{3}$ or quartz indicates that $\mathrm{Fe}(11)$ on the surface is necessary for their observation. This conclusion is consistent with the data obtained for the basalt samples: abundant "Fe(II)" ions were observed in the spectra of the TBP-exposed Elephant Mountain and Blackfoot River basalt samples, but not the INEL basalt or quartz. The spectral difference observed when comparing the basalt samples is attributed to the presence of substantial $\mathrm{Fe}$ (II)-bearing phases in the Elephant Mountain and Blackfoot River samples, but not in the other two. These ions are interpreted in terms of concomitant reduction and hydride abstraction occurring upon ion bombardment (Figure 12).

Gas-phase production of $m / 2137^{+}$, etc., from ionized TBP is not likely. The methane $\mathrm{Cl}$ mass spectrum shows that gas-phase TBP undergoes protonation and hydride abstraction (as it does on surfaces), and that these processes are followed by one, two, and or three $\mathrm{C}_{4} \mathrm{H}_{8}$ eliminations. However, TBP has no propensity for the formation of $\mathrm{m} / z 137^{+}$(or the other " $\mathrm{Fe}(\mathrm{II})$ " ions mentioned) under $\mathrm{Cl}$ conditions, which further supports the contention that these ions are the result of surface chemistry.

Because much of the discussion is based upon the $m / z 137^{+}$, it must be noted that a low abundance $\mathrm{m} / \mathrm{z} 137^{+}$ion (ca. $8 \%$ ) is observable in the El mass spectrum of TBP (Table 22). Hence one explanation for the observation of this ion in the SIMS spectra would be a one electron oxidation of TBP followed by elimination reactions to form $\mathrm{m} / \mathrm{z} 137^{+}$. Reasonable elimination reactions would be loss of $\mathrm{C}_{4} \mathrm{H}_{7}$ radical followed by the loss of $\mathrm{C}_{4} \mathrm{H}_{9} \mathrm{OH}$ or $\left(\mathrm{C}_{4} \mathrm{H}_{8}+\mathrm{H}_{2} \mathrm{O}\right)$. This explanation is not favored for three reasons: 1) under SIMS conditions, radical ions (in this case TBP radical cation) tend to be substantially less important than even electron ions; 2) this process should be observable irrespective of the mineral matrix; 3) the abundance of the $m / 2137^{+}$in the El spectrum (8\%) is not consistent with the abundances observed in the SIMS spectra collected on reducing surfaces $(40-60 \%)$. Thus we believe that one-electron oxidation leading to $\mathrm{m} / \mathrm{z} 137^{+}$is at most a minor contributor to the abundance of this ion as observed in the SIMS spectra.

3.4.2. Production of $m / z 153^{+}$. The $m / z 153^{+}$ion observed in the spectra of TBP on the iron oxide surfaces is interpreted in terms of hydride abstraction followed by the elimination of two $\mathrm{C}_{4} \mathrm{H}_{\mathrm{a}}$ molecules. These reactions are also observed as a low abundance ion series in the methane $\mathrm{Cl}$ spectrum of TBP. The elimination of a third $\mathrm{C}_{4} \mathrm{H}_{8}$ molecule to form $\mathrm{m} / \mathrm{z} 97^{+}$could only occur with difficulty, because of the formation of a $\mathrm{C}=\mathrm{O}$ bond upon hydride abstraction; in fact, only very low abundance $\mathrm{m} / \mathrm{z} 97^{*}$ ions are observed. The mechanism proposed (Figure 13) would require the presence of a Fe(III) species in order to 
accept the hydride, which is consistent with the observation of abundant $\mathrm{m} / \mathrm{z}$ $153^{+}$on $\mathrm{Fe}_{2} \mathrm{O}_{3} . \mathrm{M} / \mathrm{z} 153^{+}$is also observed in the spectrum of TBP on $\mathrm{FeO}$; we believe that this may be due to a partial layer of more highly oxidized iron oxide species on the surface of the $\mathrm{FeO}$ particles.

3.4.3. Production of $m / z 99^{+}$and $155^{+}$. These ions are formed by the protonation of TBP followed by the elimination of two and three $\mathrm{C}_{4} \mathrm{H}_{8}$ molecules (Figure 14). They are observed in all SIMS spectra of TBP presented here, and are the dominant ions in the $\mathrm{Cl}$ mass spectra of TBP. Significantly, they are much more abundant than $\mathrm{m} / \mathrm{z} 137^{+}$and $153^{+}$in the SIMS spectrum of TBP on quartz (no $\mathrm{Fe}$ ), which indicates that $\mathrm{SiO}_{2}$ surfaces are efficient at protonating, and reinforces the necessity for $\mathrm{Fe}$ for reduction and hydride abstraction.

SIMS ionization is substantially more energetic than methane $\mathrm{Cl}$ : the base peak in the $\mathrm{Cl}$ spectrum of TBP corresponds to $[\mathrm{M}+\mathrm{H}]^{*}$, which indicates that the ionization is sufficiently soft that a substantial fraction of the TBP ions formed remain intact. In contrast, $\left[\mathrm{M}+\mathrm{H}^{+}\right.$is only occasionally observed at very low abundance in the SIMS spectra of TBP; in this case, the largest fraction of the ion current has been shifted to $\mathrm{m} / \mathrm{z} 99^{+}$, which means that the initially formed [M $+\mathrm{H}^{+}$possessed sufficient internal energy for the occurrence of three $\mathrm{C}_{4} \mathrm{H}_{8}$ eliminations.

3.4.4. Tributyl phosphite model for TBP reduction. If TBP is reduced during the production of $\mathrm{m} / \mathrm{z} 137^{+}$, then an intermediate or transition state resembling tributyl phosphite would presumably be involved. Accordingly, tributyl phosphite was examined on basalt and on the iron oxide powders to see if it exhibited behavior similar to that of TBP. The resulting SIMS spectra were remarkably similar to TBP on reducing surfaces: an abundant $\mathrm{m} / \mathrm{z} 137^{+}$is interpreted in terms of tributyl phosphite undergoing $\mathrm{H}^{-}$abstraction, followed by the elimination of two $\mathrm{C}_{4} \mathrm{H}_{\mathrm{a}}$. These observations support the contention that TBP is undergoing a similar process subsequent to reduction. It is noteworthy that a low abundance ion series corresponding to $\mathrm{H}^{-}$abstraction, and subsequent loss of one and two $\mathrm{C}_{4} \mathrm{H}_{8}$ molecules is also observed in the methane $\mathrm{Cl}$ spectrum of tributyl phosphite. One salient difference was observed when comparing the SIMS spectra of TBP with that of tributyl phosphite: the latter has an abundant $\mathrm{m} / \mathrm{z} 83^{*}$, which corresponds to the protonation of tributyl phosphite, followed by the elimination of three $\mathrm{C}_{4} \mathrm{H}_{8}$ molecules. These ions constitute the major ion series in the $\mathrm{Cl}$ mass spectrum of tributyl phosphite, but are not present in abundance in the SIMS spectra of TBP.

The observation of $m / z 99^{*}\left(\mathrm{H}_{4} \mathrm{PO}_{4}{ }^{*}\right)$ in the SIMS spectra of tributyl phosphite indicates that some of the tributyl phosphite has undergone oxidation on the surface of $\mathrm{FeO}, \mathrm{Fe}_{2} \mathrm{O}_{3}$, and the basalt samples. This finding is surprising in the case of FeO, which would be difficult to reduce; however it is possible that the oxidation of tributyl phosphite is the result of more oxidized Fe species present on the FeO surface. It is of interest that $m / z 153^{+}$is also observed in the SIMS spectra of tributyl phosphite on $\mathrm{FeO}$ and $\mathrm{Fe}_{2} \mathrm{O}_{3}$ i this is also interpreted in terms 
of tributyl phosphite undergoing oxidation (followed by hydride abstraction) on the iron oxide surfaces.

\subsubsection{Structure of $m / 2125^{+}, 217^{+}, 235^{+}$observed in the SIMS spectra of} TBP. M/z $125^{+}, 217^{+}$and $235^{+}$were reproducibly observed in the SIMS spectra of basalt, $\mathrm{FeO}$, and $\mathrm{Fe}_{2} \mathrm{O}_{3}$ that had been exposed to TBP. These ions are not considered to be important to arguments relating to the reduction, hydride abstraction, or oxidation of TBP; nevertheless, they do constitute part of the signature for TBP on environmental samples, and hypotheses have been suggested regarding their origin.

$M / 2125^{+}$is observed at low abundance in the $\mathrm{El}$ and $\mathrm{Cl}$ mass spectra of TBP; its abundance is normally modest in the SIMS spectrum also, but it can be as high as $15 \%$ (relative to $\mathrm{m} / \mathrm{z}^{99^{+}}$). The ion was assigned the structure of protonated vinyl phosphoric acid based on the results of a MS/MS study, which showed that collisionally activated $m / z 125^{+}$will eliminate $\mathrm{C}_{2} \mathrm{H}_{2}$ to form $m / z 99^{*}$. The MS/MS study did not identify any parent ions for $\mathrm{m} / z 125^{+}$, however. One possibility is that $m / 2125^{+}$may arise via the loss of $\mathrm{C}_{2} \mathrm{H}_{6}$ from $[\mathrm{M}+\mathrm{H}]^{+}$to form $\mathrm{m} / 2237^{+}$, which then undergoes the sequential elimination of two $\mathrm{C}_{4} \mathrm{H}_{8}$ molecules to form $181^{+}$and finally $125^{+}$. All of these ions are observed at low abundance, but above the background in the methane $\mathrm{Cl}$ spectrum, and this explanation would support the protonated vinyl phosphoric acid structure proposed earlier. An alternative explanation would be the elimination of $\mathrm{C}_{2} \mathrm{H}_{4}$ from the $[\mathrm{M}-\mathrm{H}]+$ to form $\mathrm{m} / \mathrm{z} 237^{+}$which then eliminates two $\mathrm{C}_{4} \mathrm{H}_{8}$; this is in some ways a more plausible explanation because $\mathrm{C}_{2} \mathrm{H}_{4}$ could be eliminated via a six-membered transition state. We do not favor the latter explanation, however, because an abundant $m / 2153^{+}$(signature for $[M-H]^{+}$) is not observed with abundant $\mathrm{m} / \mathrm{z}^{125^{+}}$in the SIMS experiments.

The elimination of two carbons from TBP molecular ion species leading to $\mathrm{m} / \mathrm{z} 125^{+}$draws additional support from the El mass spectrum. The TBP molecular ion undergoes elimination of $\mathrm{C}_{2} \mathrm{H}_{5}$ radical to form $\mathrm{m} / 2237^{+}$, which then sequentially eliminates two $\mathrm{C}_{4} \mathrm{H}_{8}$ to form $\mathrm{m} / \mathrm{z} 181^{+}$and finally $125^{+}$. All of these ions are all observed at low abundance in the $\mathrm{El}$ spectrum.

The $m / z 235^{+}$ion is observed in the SIMS spectra of TBP which contain evidence for reduction, and is also observable in the $\mathrm{Cl}$ mass spectrum of tributyl phosphite. The explanation for $\mathrm{m} / \mathrm{z} 235^{+}$in the $\mathrm{Cl}$ experiment is attachment of $\mathrm{C}_{3} \mathrm{H}_{5}{ }^{+}$to tributyl phosphite to form $\mathrm{m} / 2291^{+}$(not observed), which then undergoes the sequential elimination of three $\mathrm{C}_{4} \mathrm{H}_{8}$ to form $\mathrm{m} / 2235^{+}, 179^{+}$, and $123^{+}$(all ions observed at low abundance in the $\mathrm{Cl}$ spectrum). An analogous process could be occurring in the SIMS analyses: abundant hydrocarbons are present on the mineral surfaces, and $\mathrm{m} / \mathrm{z} 41^{+}$is the base peak in many of the SIMS spectra collected in our laboratory. Thus, formation of $\mathrm{m} / \mathrm{z}^{235^{+}}$would require reduction of TBP and proximity to a source of $\mathrm{C}_{3} \mathrm{H}_{5}{ }^{+}$. One problem with this explanation is that ions at $m / 2179^{+}$and $123^{+}$are not observed in the SIMS 
spectrum of tributyl phosphite: these ions were observable in the $\mathrm{Cl}$ spectrum, and correspond the sequential losses of two additional $\mathrm{C}_{4} \mathrm{H}_{8}$ molecules.

$M / z 217^{+}$is also frequently observed in the SIMS spectra of TBP. The best hypothesis for this ion is that it is formed by attachment of $\mathrm{Na}^{+}$to tributyl phosphite to form $\mathrm{m} / \mathrm{z} 273^{+}$(not observed), which then eliminates $\mathrm{C}_{4} \mathrm{H}_{8}$ to produce $217^{+}$. However the anticipated eliminations of a second and third $\mathrm{C}_{4} \mathrm{H}_{8}$ molecule (forming $\mathrm{m} / \mathrm{z} 161^{\circ}$ and $105^{\circ}$ ) are not observed, and hence this explanation is not entirely satisfactory. 


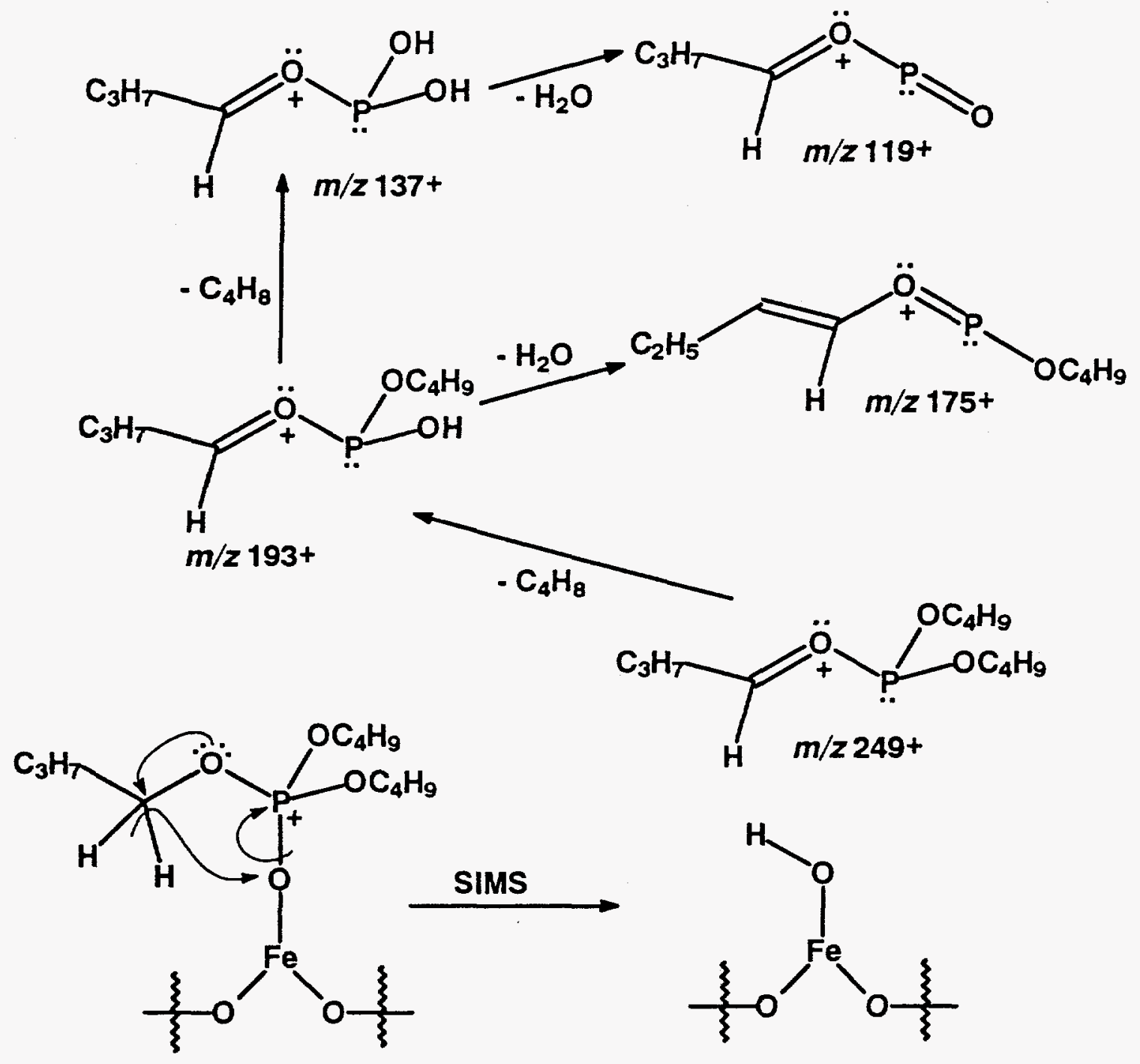

Figure 12. Mechanism proposed for the formation of $m / z 137^{+}$in the SIM spectrum of TBP adsorbed to $\mathrm{Fe}(I I)$-bearing surfaces. 


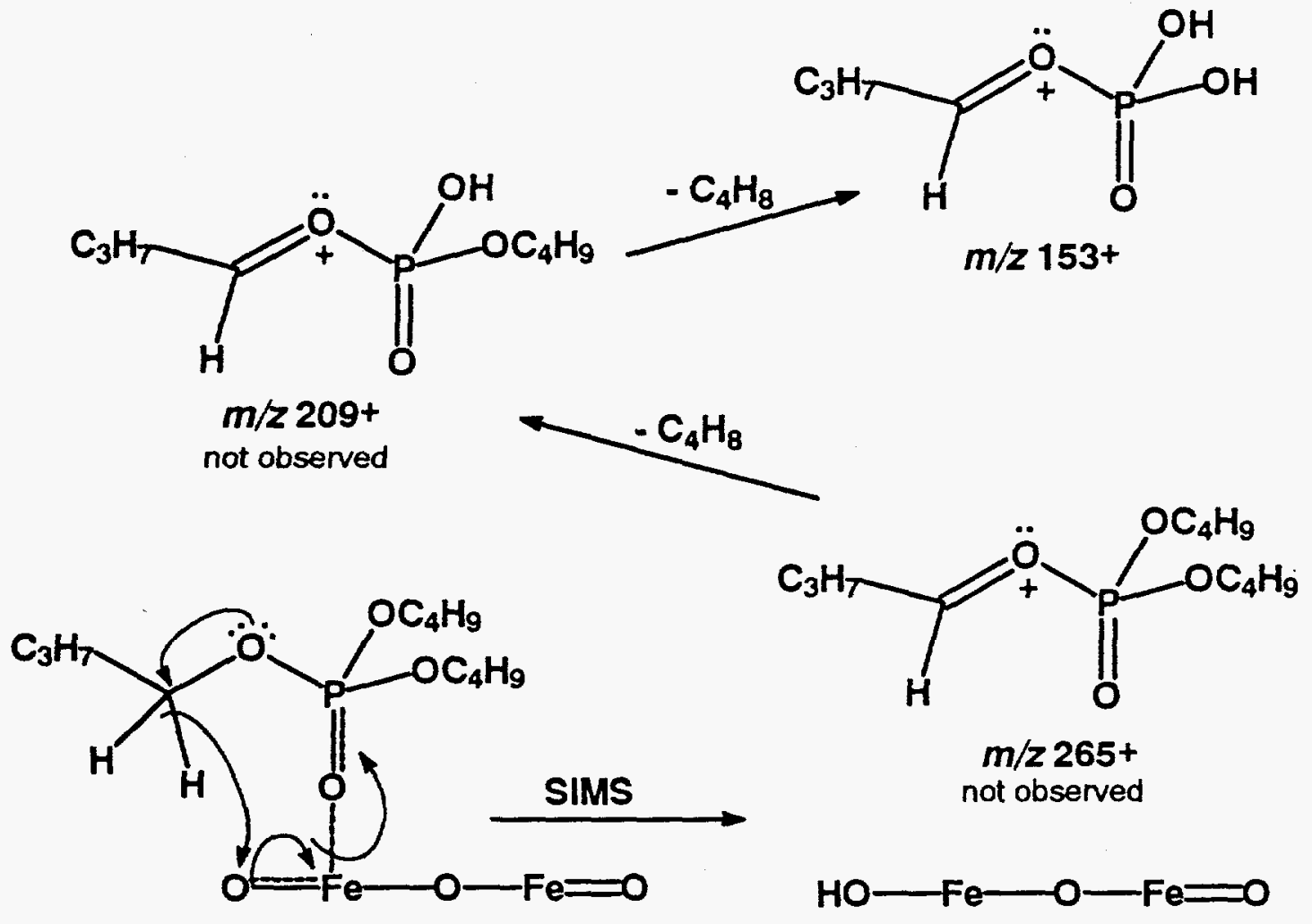

Figure 13. Proposed mechanism for surface hydride abstraction and subsequent elimination of two $\mathrm{C}_{4} \mathrm{H}_{8}$ molecules, forming $\mathrm{m} / \mathrm{z} 153^{+}$. 

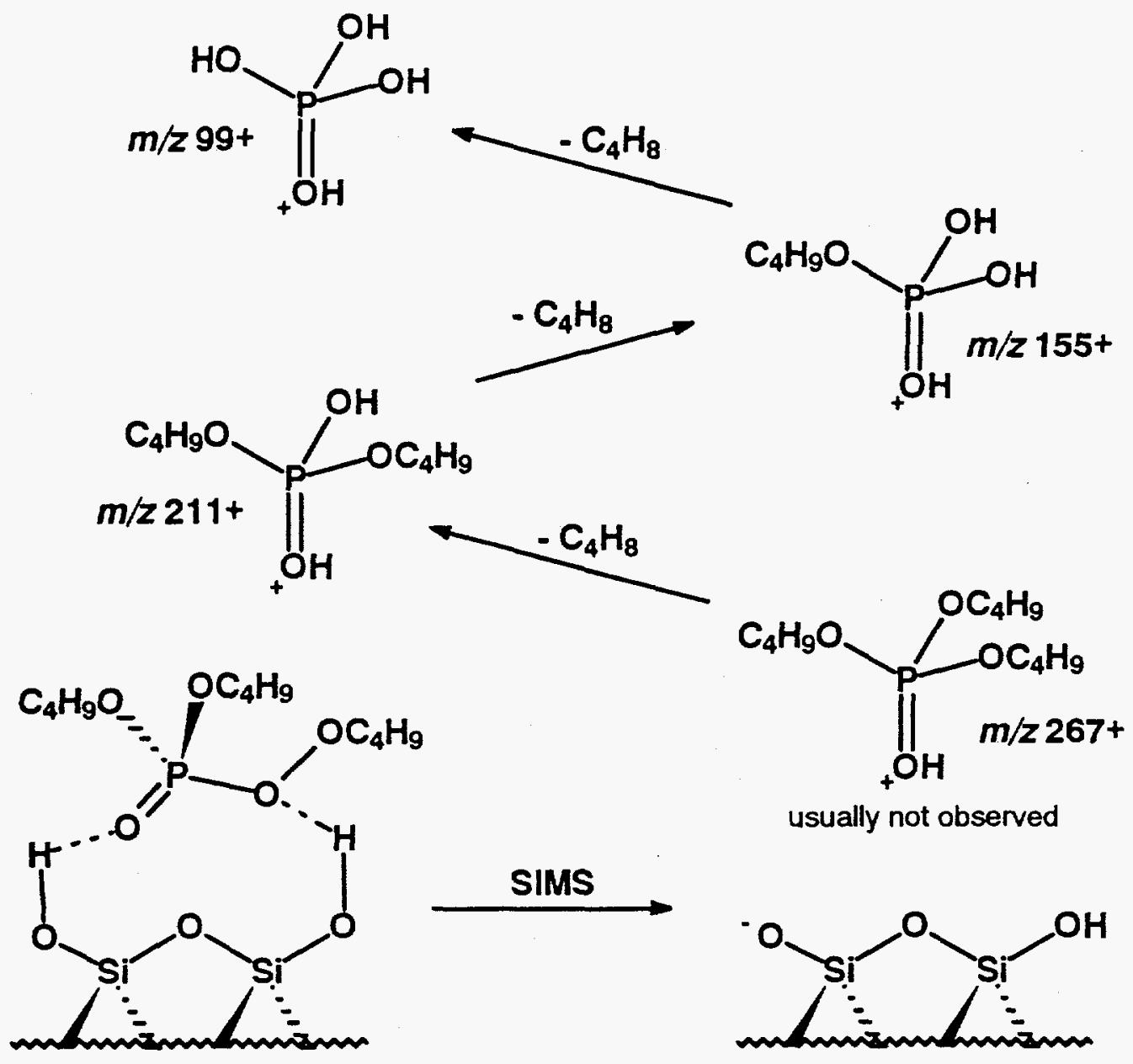

usually not observed

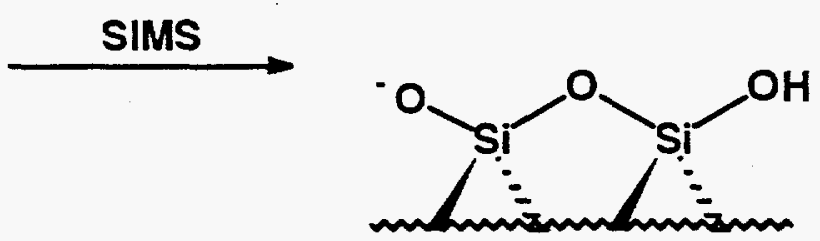

Figure 14. Proposed mechanism for the surface protonation of TBP, and subsequent elimination of three $\mathrm{C}_{4} \mathrm{H}_{8}$ molecules. 


\subsection{Conclusions: TBP Mechanism}

The SIMS spectrum of TBP on mineral samples, acquired using a molecular primary ion under low beam current conditions, is indicative of whether the TBP is in contact with reducing surface sites, protonating sites, or sites which promote hydride abstraction (presumably Fe(III)). Similarly, the SIMS spectrum of tributyl phosphite is influenced by sites where tributyl phosphite can be oxidized. This indicates that static SIMS of TBP and tributyl phosphite have potential for characterizing the chemical nature of mineral surfaces, and the mode of contaminant-surface interaction. This information is important because the oxidizing/reducing nature of the surfaces of mineral samples has important bearing on the binding of contaminants in the environment. This work raises the possibility that SIMS analysis of organophosphates other than TBP could be used to characterize surfaces which would be less reducing than the basalt samples described herein.

\subsection{References}

'Schulz, W. W., Navratil, J. D., ed's., Science and Technology of Tributyl Phosphate, Volume I. Synthesis, Properties, Reactions and Analysis, CRC Press, Inc., Boca Raton, Florida, 1984.

${ }^{2}$ Hanford Site Sampling and Analysis Data Document, Department of Energy Report EGG-ES-7953, August, 1988: Volume I, pages 4-114, 4-215; Volume IA pages 4-474, 4-586, 4-588; Addendum (November, 1988), pages 4-88, 4-209.

${ }^{3}$ Reidel, S. P., Lindsey, K. A., Fecht, K. R., Field Trip Guide to the Hanford Site, DOE Report WHC-MR--0391, Nov., 1992.

"Brown, G. M., "Mineralogy of Basaltic Rocks", in The Poldervaart Treatise on Rocks of Basaltic Composition, Volume I, Hess, H. H., and Poldervaart, A., eds., Interscience Publishers, New York, p. 103, 1962.

5Unger, S. E., Vincze, A., Cooks, R. G., Chrisman, R., Rothman, L. D., Anal. Chem., 1981, 53, 976-981.

${ }^{6}$ Day, R. J., Unger, S. E., Cooks, R. G., Anal. Chem., 1980, 52, 557A-572A. 'Appelhans, A. D., Dahl, D. A., Delmore, J. E., Anal. Chem., 1990, 62, 16791686.

BDelmore, J. E., Appelhans, A. D., Peterson, E. S., Int. J. Mass Spectrometry and Ion Processes, 1991, 108, 179-187.

9Briggs, D., Hearn, M. J., Vacuum, 1986, 36, 1005 - 1010. 
'QWinger, B. E., Hand, O. W., Cooks, R. G., Int. J. Mass Spectrom. Ion Processes, 1988, 84, $89-100$.

"Appelhans, A. D.; Dahl, D. A.; Delmore, J. E.; Groenewold, G. S.; Ingram, J. C.; Book of Abstracts, presented at PITTCON '94, February 27 - March 3, 1994, Chicago, IL, Abstract 1229.

'2a. Hanke, W.; Wernisch, J.; Poehn, Ch.; X-Ray Spectrom., 1985, 14, $43-7$. b. Poehn, Ch.; Wernisch, J.; Hanke, W.; X-Ray Spectrom., 1985, 14, 120 - 4.

${ }^{13}$ NIST Standard Reference Database 1A, NIST/EPANIH Mass Spectral Database, PC Version 4.0, May, 1992, U. S. Department of Commerce, National Institute of Standards and Technology, Standard Reference Data Program, Gaithersburg, MD 20899.

${ }^{14}$ D'Agostino, P. A., Provost, L. R., Tandem Mass Spectrometric Analysis of Phosphate Esters, Suffield Report No. 581, Defense Research Establishment Suffield: Ralston: Alberta, Canada, March, 1993. 


\subsection{Minimum Detectable Limit of TBP on Environmental Surfaces}

\subsection{Introduction}

The objective of these studies was to develop a method to determine quantitatively a minimum detection limit (MDL) for analyses of contaminants on surfaces using static secondary ion mass spectrometry (SIMS). Although static SIMS is currently a qualitative technique, MDL information is critical to its application for screening environmental samples for contamination. Difficulties associated with determining MDL's for static SIMS are similar to most other surface analysis methods which include unavailability of standards for quantitation for most "real world" samples, ill-defined surface areas, matrix effects on secondary ion formation, and inhomogeneous chemical composition of the sample. The focus of this study was to determine the MDL for the detection of tributyl phosphate (TBP) on soils. Two different types of soils were investigated in order to compare the effect of soil type on the MDL for TBP. In surface analysis, the MDL is expressed in terms of the mass of the analyte divided by the surface area of the sample.

\subsection{Experimental}

The experimental approach taken in these studies was the following: a) determine the surface area of the soils by sieving the soils to divide different grain sizes and using nitrogen adsorption analysis to measure the surface areas, b) determine the SIMS minimum detectability of TBP adsorbed on soil by exposing the sieved soil to solutions of various TBP concentrations, acquiring SIM spectra for five similar samples, and evaluating the signal-to-noise of the TBP fragment peaks, c) determine the amount of TBP adsorbed to the soil exposed to the lowest TBP concentration determined in step b by methylene chloride extraction of the soil followed by gas chromatography (GC) analysis of the extracts, and d) calculation of the MDL based on the GC and surface area results.

Instrumentation used in these studies were the following: a) surface area measurements were performed on a Micromeritics Flowsorb || 2300 instrument using an adsorption gas mixture of 30 mole $\%$ nitrogen and 70 mole $\%$ helium, b) SIMS analysis were performed using the $\mathrm{ReO}_{4}$ quadrupole SIMS instrument designed and built at the INEL (see section 3.2.1, this report), and c) gas chromatography analyses were performed with a Hewlett Packard GC 5890 Series II equipped with a XTI- 5 column ( $30 \mathrm{~m} \times 0.25 \mathrm{~mm} \mathrm{ID} \times 0.25 \mu \mathrm{m}$ df) using a split flow of $20: 1$ and a flame ionization detector. 


\subsection{Results and Discussion}

The SIMS spectra of TBP on soil were very similar to those reported for TBP on CFA basalt (see section 3.3, this report). Determination of the SIMS minimum detectability (as described in step $b$ above) was based on detection of the TBP fragment ions at $m / z 99^{+}, 119^{+}, 125^{+}$, and $137^{+}$. Soil samples of specific grain sizes were exposed to TBP solutions (solvent: 1-to-1 water/methanol) at concentrations ranging from $2500 \mathrm{ppm}$ to $50 \mathrm{ppm}$. TBP was deemed detectable if the fragment ions were observed at a signal-to-noise ratios $>5$, and their relative intensities were similar to those described for the CFA basalt in section 3.3. These analyses were performed on 5 separate soil samples of each grain size. The results were averaged from the SIMS data of these 5 samples and wre tested against the criteria described above.

The MDL's of two soil samples were investigated. One of the samples was from the Hanford DOE site in eastern Washington (Upper Hanford soil). This sample was separated according to grain size, and two of the grain sizes were selected for deteailed study. The second sample was a very fine sand used for calibration purposes by Utah State University (USU soil), and had been characterized as having a narrow grain size distribution.

\begin{tabular}{|c|c|c|c|c|}
\hline $\begin{array}{c}\text { Soil Type } \\
\text { [grain size (in)] }\end{array}$ & $\begin{array}{c}\text { Surface Area } \\
\left(\mathrm{m}^{2} / \mathrm{g}\right)\end{array}$ & $\begin{array}{c}\text { Mass of TBP } \\
\text { Adsorbed to Soil } \\
(\mu \mathrm{g})^{\psi}\end{array}$ & $\begin{array}{c}\mathrm{MDL} \\
\left(\mathrm{pg} / \mathrm{mm}^{2}\right)\end{array}$ & $\begin{array}{l}\text { MDL } \\
\text { (mono- } \\
\text { layers)* }\end{array}$ \\
\hline $\begin{array}{l}\text { Upper Hanford } \\
{[0.0049]}\end{array}$ & 3.0 & 168 & 56 & 0.1 \\
\hline $\begin{array}{l}\text { Upper Hanford } \\
{[0.0165]}\end{array}$ & 2.0 & 196 & 100 & 0.2 \\
\hline $\begin{array}{c}\text { Utah St. Univ. (USU) } \\
{[0.0049]}\end{array}$ & 20.0 & 690 & 34 & 0.07 \\
\hline
\end{tabular}

The MDL's for TBP on the two soil types are in reasonably good agreement (Table 23). In terms of the minimum detectable quantity expressed in terms of mass TBP adsorbed to $1 \mathrm{~g}$ of soil, both upper Hanford fractions yield a more sensitive response than did the USU soil. This result is expected, because the USU soil has a significantly higher surface area, which serves to dilute the TBP in mass per unit area terms. Indeed, when the MDL was expressed in terms of mass per unit area, or monolayers, the samples were comparable, and if anything, the TBP was detected most sensitively on the USU soil. We 
hypothesize that the improved MDL observed on the higher surface area soil is attributable to an increased adsorption sites.

\subsection{Conclusion}

The MDL values are encouraging from the perspective of using SIMS as a screening tool: The above results were achieved without sample preparation or waste generation, and required 5 minutes per sample for analysis. Similar analyses performed using $G C$ require solvent extractions and a minimum of 1 hour per sample. Additionally, the GC analysis requires approximately $1 \mathrm{gram}$ of sample to achieve MDL's that are similar to those achieved with a mg sample of soil using the SIMS analysis reported here. This latter consideration is significant when dealing with radioactive samples, where minimizing occupational radiation exposure is a goal. 


\subsection{Ion Trap SIMS Development}

At the end of FY-93, a decision was made to interface INEL SIMS technology to an ion trap mass spectrometer. The motivation for the pursuit of the SIMS technology has been detailed in the preceding sections of this report; consequently this section will briefly discuss the motivation behind the selection of the ion trap.

There is a substantial motivation toward the development of instrumentation which is portable, or at least transportable. This motivation stems from the fact that traditional characterization activities have involved sample collection, followed by transport of the samples to a remote laboratory, where they are analyzed; finally the results are transmitted back to the management of the characterization or remediation project. The delays inherent in this system exacerbate the risk to personnel and costs associated with these projects.

In order for a mass spectrometer system to achieve transportability, it must be rugged, small, and operationally simple. The advent of ion trap mass spectrometers offer promise that these desires can be achieved; indeed the direct sampling ion trap mass spectrometer (DSITMS) developed at Oak Ridge and the most recent Bruker products supports this premise. In addition, the ion trap offers improved sensitivity as a result selected ion storage capability, and improved selectivity as a result of its MS/MS capability. For these reasons, it was decided that the ion trap was the best mass spectrometer choice for the development of a transportable SIMS system.

The drawbacks to the ion trap systems at the present time are that the data systems are immature, particularly for selected ion storage and MS/MS functions. Development in these areas has languished, for some time, but the recent entry of new vendors into the ion trap mass spectrometry market has offered hope of improvement in these areas.

In FY-1994, an order was placed with the Teledyne Corporation for an ion trap mass spectrometer. The controlling computer and data system have been received, and it is anticipated that the ion trap unit will be received by midNovember, 1994. When the instrument is received, a major activity in the SIMS development program will be interfacing a $\mathrm{ReO}_{4}{ }_{4}$ ion gun to the ion trap. The resulting instrument will then be tested for efficacy in performing contaminant identification and speciation determinations. 


\subsection{Technology Transfer}

Three separate technology transfer efforts have been initiated. These have focused on transfer of INEL SIMS components, as opposed to complete systems. The reason for the component emphasis is that it is extremely expensive for a mass spectrometer manufacturer to offer a brand new instrument product. On the other hand, a manufacturer can offer accessories to existing products for a fraction of the cost. Because INEL SIMS components are generally small, it would be conceptually possible to accessorize existing, commercial mass spectrometer instruments with the $\mathrm{ReO}_{4}{ }_{4}$ ion gun, pulsed extraction, instrument control, data acquisition, and other components.

\subsection{Teledyne.}

At present, Teledyne is very interested in INEL detector technology which would permit SIMS analysis on the ion trap. Specifically, Teledyne is interested in a novel scheme for the direct detection of anions. Teledyne is committed to keeping their ion trap design open, in order to accommodate SIMS (and other) accessories. Teledyne currently has an ion trap system on the market, is about the size of a bread maker and will easily accommodate INEL SIMS technology. A non-disclosure agreement between Teledyne and INEL was generated and signed.

\subsection{Charles Evans \& Associates, Inc.}

Technology transfer of $\mathrm{ReO}_{4}$ and possibly other technology was initiated with Charles Evans \& Associates, Inc. on 7/28. At the present time, there is concern regarding the "brightness" of the $\mathrm{ReO}_{4}$ " primary ion source in a time-of-flight SIMS application. INEL will continue to research this issue. A non-disclosure agreement was generated and signed between Evans and INEL.

\subsection{Extrel.}

Extrel and INEL completed a license agreement for data acquisition and control software, which was developed to support SIMS. A non-disclosure agreement was also signed between Extrel and INEL. 


\subsection{University Collaborations}

Several collaborations with research groups at universities were initiated in order to broaden participation in the SIMS program and also to support the educational mission of OTD.

\subsection{Idaho State University}

A collaboration was initiated between INEL and the engineering department of Idaho State University. A masters engineering student (Mr. John Olsen) worked on modifying instrument control and data acquisition software, and this led to the completed technology transfer of the INEL software to Extrel. The student was funded using OTD resources.

A second collaboration with Idaho State University was initiated late in FY-94 was with the chemistry department (Dr. Rene Rodriguez), for the purpose of using SIMS to characterize mercury species on $\mathrm{TiO}_{2}$ catalysts. This collaboration will continue in FY-95.

\subsection{Utah State University}

A collaboration was initiated in late $\mathrm{FY}-94$ with the engineering department (Mr. Andy Cramer) for the purpose of using SIMS to characterize pentachlorophenol and its degradation products on $\mathrm{MnO}_{2}$ surfaces. This effort will continue in FY-95.

\subsection{University of Illinois-Chicago}

A collaboration was initiated in late FY-94 with the chemistry department (Dr. Luke Hanley), for the purpose of evaluating laser desorption ion trap mass spectrometry for the characterization of chelates (e.g., EDTA), which tend to be too strongly bound to surfaces to be amenable to SIMS analysis. This effort will be continued in FY-95, and will be supported using OTD funding.

\subsection{University of Idaho}

A collaboration was initiated in FY-94 with the college of Mines (Dr. Batric Pesic) for the purpose of using SIMS to characterized heavy metal cyanide complexes. This effort will be considered for modest support using OTD SIMS funding in FY-95. 


\subsection{Future Directions}

The SIMS program was redirected in late FY-94 to focus on heavy metal identification and speciation. The redirection was required to be 'end-user', or 'customer' directed. Accordingly, the chemical focus of the program will be on metal speciation, specifically mercury $(\mathrm{Hg})$. $\mathrm{Hg}$ is problematic at two INEL sites: the 'acid pit' at the subsurface disposal area (SDA) of the Radioactive Waste Management Complex (RWMC), and the Central Facilities Area (CFA) 674 waste pond.

In addition, the previously identified tasks of assembling and testing the ion trap SIMS instrument, and technology transfer of SIMS components will continue as planned. 